\title{
Conformational Solvatomorphism in a [2]Catenane
}

Shobhana Krishnaswamy, ${ }^{\dagger a}$ Soumyakanta Prusty, ${ }^{\dagger a}$ Daniel Chartrand, ${ }^{\mathrm{b}}$ Garry S. Hanan ${ }^{\mathrm{b}}$ and Dillip K. Chand*a

${ }^{a}$ Department of Chemistry, Indian Institute of Technology Madras, Chennai 600 036, India.

Email: dillip@iitm.ac.in

${ }^{\mathrm{b}}$ Department of Chemistry, University of Montreal, Montreal QC H3T-IJ4 (Canada)

${ }^{\dagger}$ These authors contributed equally to this work. 


\section{Electronic Supporting Information}

\section{Captions of Figures, Tables and Scheme:}

Figure $\mathbf{S 1 .} 500 \mathrm{MHz}{ }^{1} \mathrm{H}$ NMR spectrum of ligand $\mathbf{L 1}$ in DMSO-d $d_{6}$.

Figure S2. $500 \mathrm{MHz}{ }^{1} \mathrm{H}$ NMR spectrum of $\mathbf{1 a}$ in DMSO-d . $_{\text {. }}$

Figure S3. H-H COSY of 1a in DMSO- $d_{6}$.

Figure S4. H-H NOESY of 1a in DMSO- $d_{6}$.

Figure S5. ${ }^{13} \mathrm{C}$ NMR spectrum of 1a in DMSO- $d_{6}$.

Figure S6. HSQC of 1a in DMSO- $d_{6}$.

Figure S7. $500 \mathrm{MHz}{ }^{1} \mathrm{H}$ NMR spectrum of $\mathbf{1 b}$ in DMSO- $d_{6}$.

Figure S8. H-H COSY of $\mathbf{1 b}$ in DMSO- $d_{6}$.

Figure S9. H-H NOESY of $\mathbf{1 b}$ in DMSO- $d_{6}$.

Figure S10. ${ }^{13} \mathrm{C}$ NMR spectrum of $\mathbf{1 b}$ in DMSO- $d_{6}$.

Figure S11. HSQC of $\mathbf{1 b}$ in DMSO- $d_{6}$.

Figure S12. $500 \mathrm{MHz}{ }^{1} \mathrm{H}$ NMR spectrum of $\mathbf{1 c}$ in DMSO- $d_{6}$.

Figure S13. $500 \mathrm{MHz}{ }^{1} \mathrm{H}$ NMR spectrum (partial) of $1 \mathrm{c}$ in DMSO-d $d_{6}$.

Figure S14. H-H COSY of 1c in DMSO- $d_{6}$.

Figure S15. H-H NOESY of 1c in DMSO-d $d_{6}$.

Figure S16. ${ }^{13} \mathrm{C}$ NMR spectrum of $1 \mathrm{c}$ in DMSO- $d_{6}$.

Figure S17. HSQC of $1 \mathrm{c}$ in DMSO- $d_{6}$.

Figure S18. $500 \mathrm{MHz}{ }^{1} \mathrm{H}$ NMR spectrum of $\mathbf{1 d}$ in DMSO- $d_{6}$.

Figure S19. $500 \mathrm{MHz}{ }^{1} \mathrm{H}$ NMR spectrum (partial) of $\mathbf{1 d}$ in DMSO-d $d_{6}$.

Figure S20. H-H COSY of $\mathbf{1 d}$ in DMSO- $d_{6}$.

Figure S21. H-H NOESY of 1d in DMSO- $d_{6}$.

Figure S22. ${ }^{13} \mathrm{C}$ NMR spectrum of $\mathbf{1 d}$ in DMSO- $d_{6}$.

Figure S23. HSQC of $\mathbf{1 d}$ in DMSO- $d_{6}$. 
Figure S24. $500 \mathrm{MHz}{ }^{1} \mathrm{H}$ NMR spectrum of $\mathbf{1 a} / \mathbf{2 a}$ in $\mathrm{D}_{2} \mathrm{O}$ at $10 \mathrm{mM}$.

Figure S25. H-H COSY of 1a/2a in $\mathrm{D}_{2} \mathrm{O}$ at $10 \mathrm{mM}$.

Figure S26. H-H NOESY of 1a/2a in $\mathrm{D}_{2} \mathrm{O}$ at $10 \mathrm{mM}$.

Figure S27. $500 \mathrm{MHz}{ }^{1} \mathrm{H}$ NMR spectrum of $\mathbf{1 a} / \mathbf{2 a}$ in $\mathrm{D}_{2} \mathrm{O}$ at $50 \mathrm{mM}$.

Figure S28. $\mathrm{H}-\mathrm{H}$ COSY of $1 \mathbf{a} / \mathbf{2 a}$ in $\mathrm{D}_{2} \mathrm{O}$ at $50 \mathrm{mM}$.

Figure S29. H-H NOESY of 1a/2a in $\mathrm{D}_{2} \mathrm{O}$ at $50 \mathrm{mM}$.

Figure S30. ${ }^{13} \mathrm{C}$ NMR spectrum of $\mathbf{1 a} / \mathbf{2} \mathbf{a}$ in $\mathrm{D}_{2} \mathrm{O}$ at $50 \mathrm{mM}$.

Figure S31. HSQC of 1a/2a in $\mathrm{D}_{2} \mathrm{O}$ at $50 \mathrm{mM}$.

Figure S32. $500 \mathrm{MHz}{ }^{1} \mathrm{H}$ NMR spectrum of $\mathbf{1 b} / \mathbf{2} \mathbf{b}$ in $\mathrm{D}_{2} \mathrm{O}$ at $10 \mathrm{mM}$.

Figure S33. $\mathrm{H}-\mathrm{H}$ COSY of $\mathbf{1 b} / \mathbf{2} \mathbf{b}$ in $\mathrm{D}_{2} \mathrm{O}$ at $10 \mathrm{mM}$.

Figure S34. H-H NOESY of $\mathbf{1 b} / \mathbf{2 b}$ in $\mathrm{D}_{2} \mathrm{O}$ at $10 \mathrm{mM}$.

Figure S35. $500 \mathrm{MHz}{ }^{1} \mathrm{H}$ NMR spectrum of $\mathbf{1 b} / \mathbf{2} \mathbf{b}$ in $\mathrm{D}_{2} \mathrm{O}$ at $50 \mathrm{mM}$.

Figure S36. $\mathrm{H}-\mathrm{H}$ COSY of $\mathbf{1 b} / \mathbf{2} \mathbf{b}$ in $\mathrm{D}_{2} \mathrm{O}$ at $50 \mathrm{mM}$.

Figure S37. H-H NOESY of $\mathbf{1 b} / \mathbf{2 b}$ in $\mathrm{D}_{2} \mathrm{O}$ at $50 \mathrm{mM}$.

Figure S38. ${ }^{13} \mathrm{C}$ NMR spectrum of $\mathbf{1 b} / \mathbf{2} \mathbf{b}$ in $\mathrm{D}_{2} \mathrm{O}$ at $50 \mathrm{mM}$.

Figure S39. HSQC of $\mathbf{1 b} / \mathbf{2 b}$ in $\mathrm{D}_{2} \mathrm{O}$ at $50 \mathrm{mM}$

Figure S40. $400 \mathrm{MHz}{ }^{1} \mathrm{H}$ NMR spectrum of $\mathbf{1 c} / 2 \mathrm{c}$ in $\mathrm{D}_{2} \mathrm{O}$ at $16 \mathrm{mM}$.

Figure S41. ${ }^{1} \mathrm{H}$ NMR spectrum (partial) of $1 \mathrm{c} / 2 \mathrm{c}$ in $\mathrm{D}_{2} \mathrm{O}$ at $16 \mathrm{mM}$.

Figure S42. $\mathrm{H}-\mathrm{H}$ COSY of $\mathbf{1 c} / \mathbf{2 c}$ in $\mathrm{D}_{2} \mathrm{O}$ at $16 \mathrm{mM}$.

Figure S43. H-H NOESY of $\mathbf{1 c} / \mathbf{2 c}$ in $\mathrm{D}_{2} \mathrm{O}$ at $16 \mathrm{mM}$.

Figure S44. ${ }^{13} \mathrm{C}$ NMR spectrum of $1 \mathrm{c} / 2 \mathrm{c}$ in $\mathrm{D}_{2} \mathrm{O}$ at $16 \mathrm{mM}$.

Figure S45. HSQC of $1 \mathrm{c} / 2 \mathrm{c}$ in $\mathrm{D}_{2} \mathrm{O}$ at $10 \mathrm{mM}$.

Figure S46. $400 \mathrm{MHz}{ }^{1} \mathrm{H}$ NMR spectrum of $\mathbf{1 d} / \mathbf{2 d}$ in $\mathrm{D}_{2} \mathrm{O}$ at $10 \mathrm{mM}$.

Figure S47. ${ }^{1} \mathrm{H}$ NMR spectrum (partial) of $\mathbf{1 d} / \mathbf{2 d}$ in $\mathrm{D}_{2} \mathrm{O}$ at $10 \mathrm{mM}$.

Figure S48. H-H COSY of $\mathbf{1 d} / \mathbf{2 d}$ in $\mathrm{D}_{2} \mathrm{O}$ at $10 \mathrm{mM}$. 
Figure S49. $\mathrm{H}-\mathrm{H}$ NOESY of $\mathbf{1 d} / \mathbf{2 d}$ in $\mathrm{D}_{2} \mathrm{O}$ at $10 \mathrm{mM}$.

Figure S50. ${ }^{13} \mathrm{C}$ NMR spectrum of $\mathbf{1 d} / \mathbf{2 d}$ in $\mathrm{D}_{2} \mathrm{O}$ at $10 \mathrm{mM}$.

Figure S51. HSQC spectrum of $\mathbf{1 d} / \mathbf{2 d}$ in $\mathrm{D}_{2} \mathrm{O}$ at $10 \mathrm{mM}$.

Table S1. ${ }^{1} \mathrm{H}$ NMR chemical shifts (ppm) for phenylene and methylene protons of the macrocycles 1a-d and [2]catenanes 2a-d in $\mathrm{D}_{2} \mathrm{O}$.

Figure S52. ${ }^{1} \mathrm{H}$ DOSY NMR spectrum of $\mathbf{1 a} / \mathbf{2 a}$ in $\mathrm{D}_{2} \mathrm{O}(8 \mathrm{mM}$ with respect to $\mathrm{Pd}(\mathrm{II})$ ).

Figure S53. ${ }^{1} \mathrm{H}$ DOSY NMR spectrum of $\mathbf{1 b} / \mathbf{2} \mathbf{b}$ in $\mathrm{D}_{2} \mathrm{O}$ (8 $\mathrm{mM}$ with respect to $\mathrm{Pd}(\mathrm{II})$ ).

Figure S54. ${ }^{1} \mathrm{H}$ DOSY NMR spectrum of $1 \mathbf{c} / \mathbf{2 c}$ in $\mathrm{D}_{2} \mathrm{O}(10 \mathrm{mM}$ with respect to $\mathrm{Pd}(\mathrm{II}))$.

Figure S55. ${ }^{1} \mathrm{H}$ DOSY NMR spectrum of $\mathbf{1 d} / \mathbf{2 d}$ in $\mathrm{D}_{2} \mathrm{O}(5 \mathrm{mM}$ with respect to $\mathrm{Pd}(\mathrm{II})$ ).

Figure S56. Concentration variation ${ }^{1} \mathrm{H}$ NMR study of $\mathbf{1 a} / \mathbf{2 a}$ in $\mathrm{D}_{2} \mathrm{O}$ at (i) $50 \mathrm{mM}$, (ii) $15 \mathrm{mM}$ (iii) $8 \mathrm{mM}$ (iv) $4 \mathrm{mM}$ (v) $2 \mathrm{mM}$ (vi) $0.5 \mathrm{mM}$.

Figure S57. Concentration variation ${ }^{1} \mathrm{H}$ NMR study of $\mathbf{1 b} / \mathbf{2} \mathbf{b}$ in $\mathrm{D}_{2} \mathrm{O}$ at (i) $50 \mathrm{mM}$, (ii) $15 \mathrm{mM}$ (iii) 8 mM (iv) 4 mM (v) 2 mM (vi) 0.5 mM.

Figure S58. Concentration variation ${ }^{1} \mathrm{H}$ NMR study of $1 \mathrm{c} / 2 \mathrm{c}$ in $\mathrm{D}_{2} \mathrm{O}$ at (i) $10 \mathrm{mM}$, (ii) $7 \mathrm{mM}$ (iii) $5 \mathrm{mM}$ (iv) $2.5 \mathrm{mM}$ (v) $1 \mathrm{mM}$.

Figure S59. Concentration variation ${ }^{1} \mathrm{H}$ NMR study of $\mathbf{1 d} / \mathbf{2 d}$ in $\mathrm{D}_{2} \mathrm{O}$ at (i) $10 \mathrm{mM}$, (ii) $5 \mathrm{mM}$ (iii) $2.5 \mathrm{mM}$ (iv) $1.25 \mathrm{mM}$ (v) $0.5 \mathrm{mM}$ (vi) $0.1 \mathrm{mM}$.

Figure S60. Plot of the percentage of rings in the [2]catenane (2a-d) and the macrocycle (1ad) under aqueous conditions as a function of the concentration.

Table S2. Equilibrium constants calculated at different concentrations of $\mathbf{1 a} / \mathbf{2 a}, \mathbf{1 b} / \mathbf{2} \mathbf{b}, \mathbf{1 c} / \mathbf{2 c}$ and $\mathbf{1 d} / 2 \mathbf{d}$ in $\mathrm{D}_{2} \mathrm{O}$.

Figure S61. CSI-MS spectrum for 1a recorded in DMSO.

Figure S62. Isotopic pattern of $\left[1 \mathbf{a}-2 \mathrm{NO}_{3}\right]^{2+}$ recorded in DMSO and simulated pattern.

Figure S63. CSI-MS spectrum for $\mathbf{1 b}$ recorded in DMSO.

Figure S64. Isotopic pattern of $\left[\mathbf{1 b}-2 \mathrm{NO}_{3}\right]^{2+}$ recorded in DMSO and simulated pattern. 
Figure S65. CSI-MS spectrum for 1c recorded in DMSO.

Figure S66. Isotopic pattern of $\left[\mathbf{1 c}-3 \mathrm{NO}_{3}\right]^{3+}$ recorded in DMSO and simulated pattern.

Figure S67. CSI-MS spectrum for 1d recorded in DMSO.

Figure S68. Isotopic pattern of $\left[\mathbf{1 d}-3 \mathrm{NO}_{3}\right]^{3+}$ recorded in DMSO and simulated pattern.

Figure S69. CSI-MS spectrum for $\mathbf{1 b}^{\prime} / \mathbf{2} \mathbf{b}^{\prime}$ recorded in $\mathrm{H}_{2} \mathrm{O}$.

Figure S70. Isotopic pattern of $\left[\mathbf{1 b}^{\prime}-3 \mathrm{BF}_{4}\right]^{3+}$ recorded in $\mathrm{H}_{2} \mathrm{O}$ and simulated pattern.

Figure S71. Isotopic pattern of $\left[2 \mathbf{b}^{\prime}-2 \mathrm{BF}_{4}\right]^{2+}$ recorded in $\mathrm{H}_{2} \mathrm{O}$ and simulated pattern.

Figure S72. CSI-MS spectrum for $\mathbf{1} \mathbf{c}^{\prime}$ and $\mathbf{2} \mathbf{c}^{\prime}$ recorded in $\mathrm{H}_{2} \mathrm{O}$.

Figure S73. Isotopic pattern of $\left[\mathbf{1}^{\prime}-3 \mathrm{BF}_{4}\right]^{3+}$ recorded in $\mathrm{H}_{2} \mathrm{O}$ and simulated pattern.

Figure S74. Isotopic pattern of $\left[2 \mathbf{c}^{\prime}-2 \mathrm{BF}_{4}\right]^{2+}$ recorded in $\mathrm{H}_{2} \mathrm{O}$ and simulated pattern.

Figure S75. CSI-MS spectrum for $\mathbf{1} \mathbf{d}^{\prime}$ and $\mathbf{2} \mathbf{d}^{\prime}$ recorded in $\mathrm{H}_{2} \mathrm{O}$.

Figure S76. Isotopic pattern of $\left[\mathbf{1 d}^{\prime}-3 \mathrm{BF}_{4}\right]^{3+}$ recorded in $\mathrm{H}_{2} \mathrm{O}$ and simulated pattern.

Figure S77. Isotopic pattern of $\left[2 \mathbf{d}^{\prime}-\mathrm{BF}_{4}\right]^{+}$recorded in $\mathrm{H}_{2} \mathrm{O}$ and simulated pattern.

Table S3. Summary of crystallographic data for crystals of $\mathbf{2 c}$ and $\mathbf{2 d}$.

\section{Details of crystal structure solution}

Figure S78. ORTEP of the molecule(s) in the crystals of 2cI.

Figure S79. ORTEP of the molecule(s) in the crystals of $\mathbf{2 d I}$.

Figure S80. ORTEP of the molecules in the crystals of 2dII.

Figure S81. Views of the molecular packing in crystals of $\mathbf{2 d I}$.

Scheme S1. Chemical structure of the [2]catenane 3.

Figure S82. Hydrogen bonding interactions of the nitrate anions and water molecules with each other and with the [2]catenanes

Table S4. Intermolecular interactions in the crystals of 2, 2c, 2dI and $\mathbf{2 d I I}$. 


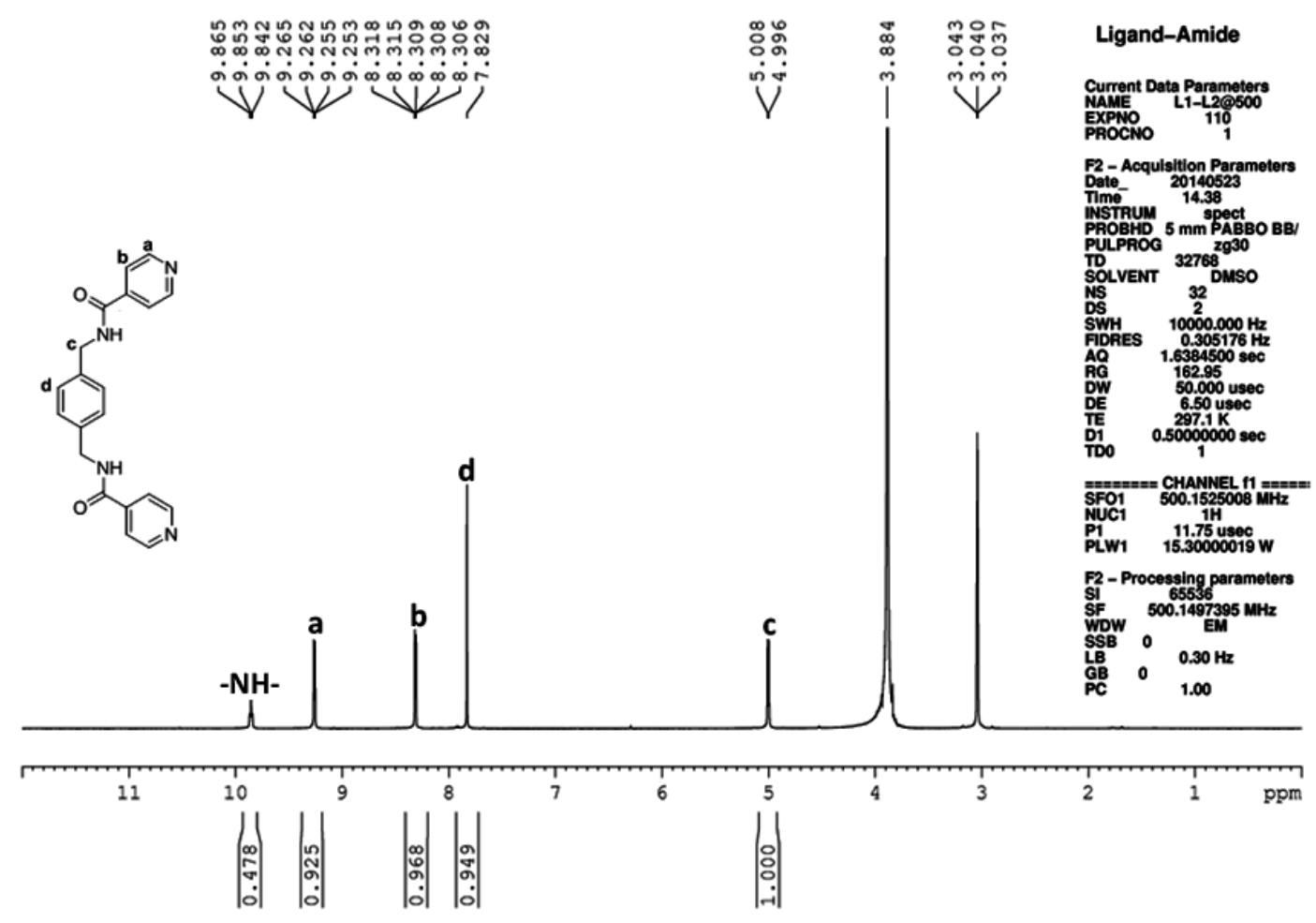

Figure S1. $500 \mathrm{MHz}{ }^{1} \mathrm{H}$ NMR spectrum of ligand $\mathbf{L 1}$ in DMSO- $d_{6}$. 


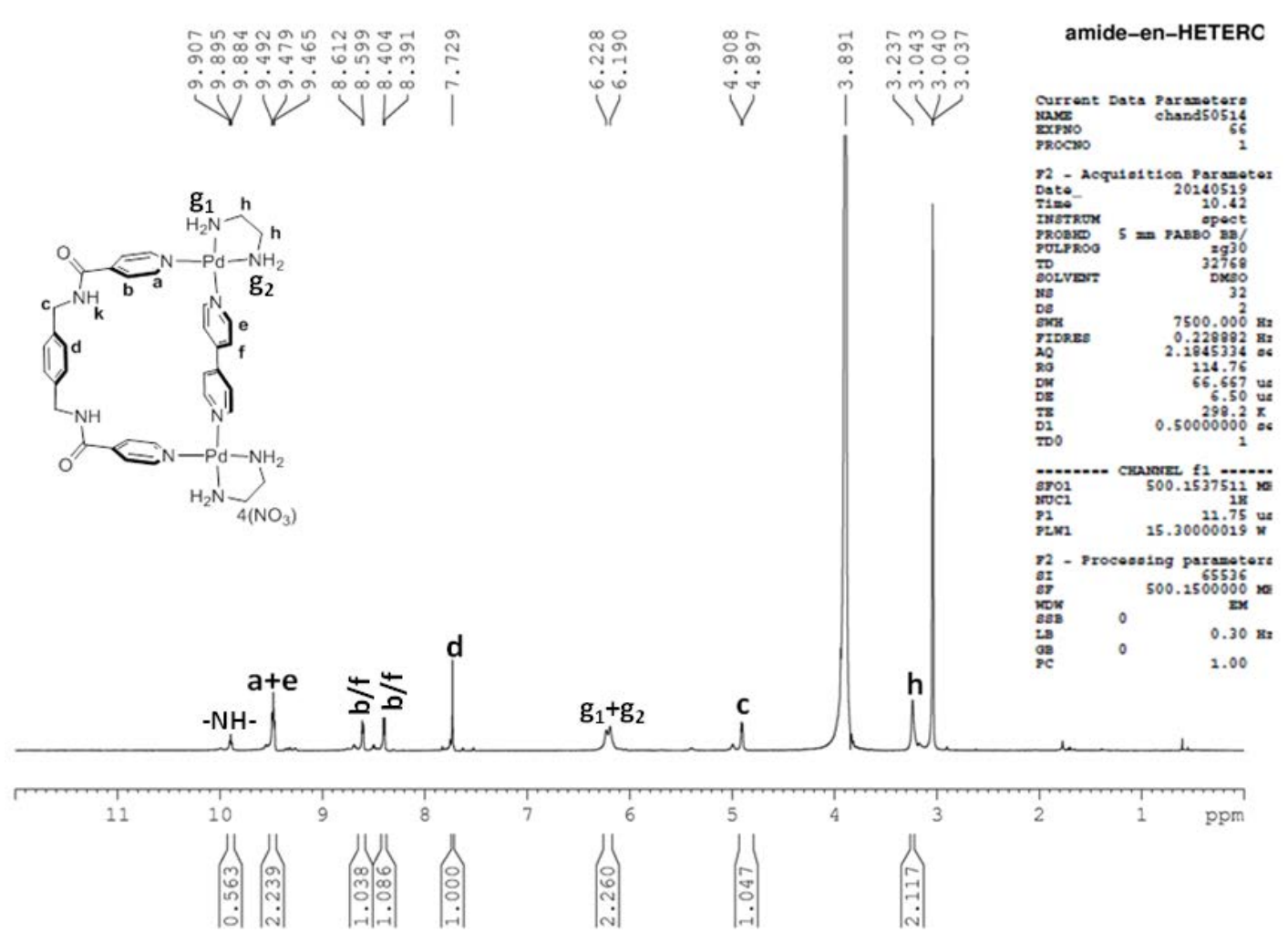

Figure S2. $500 \mathrm{MHz}{ }^{1} \mathrm{H}$ NMR spectrum of complex 1a in DMSO- $d_{6}$.
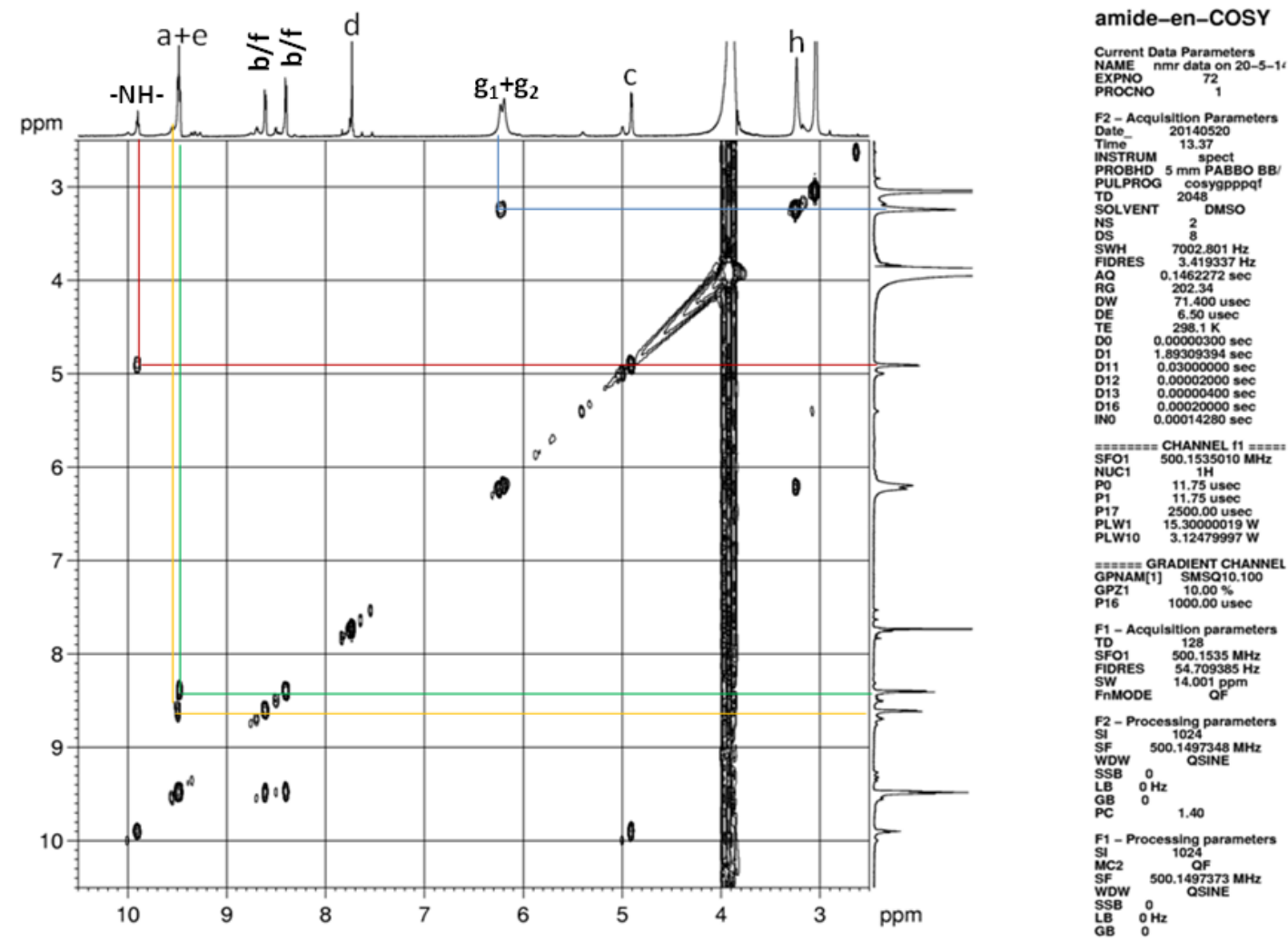

Figure S3. H-H COSY of 1a in DMSO- $d_{6}$. 


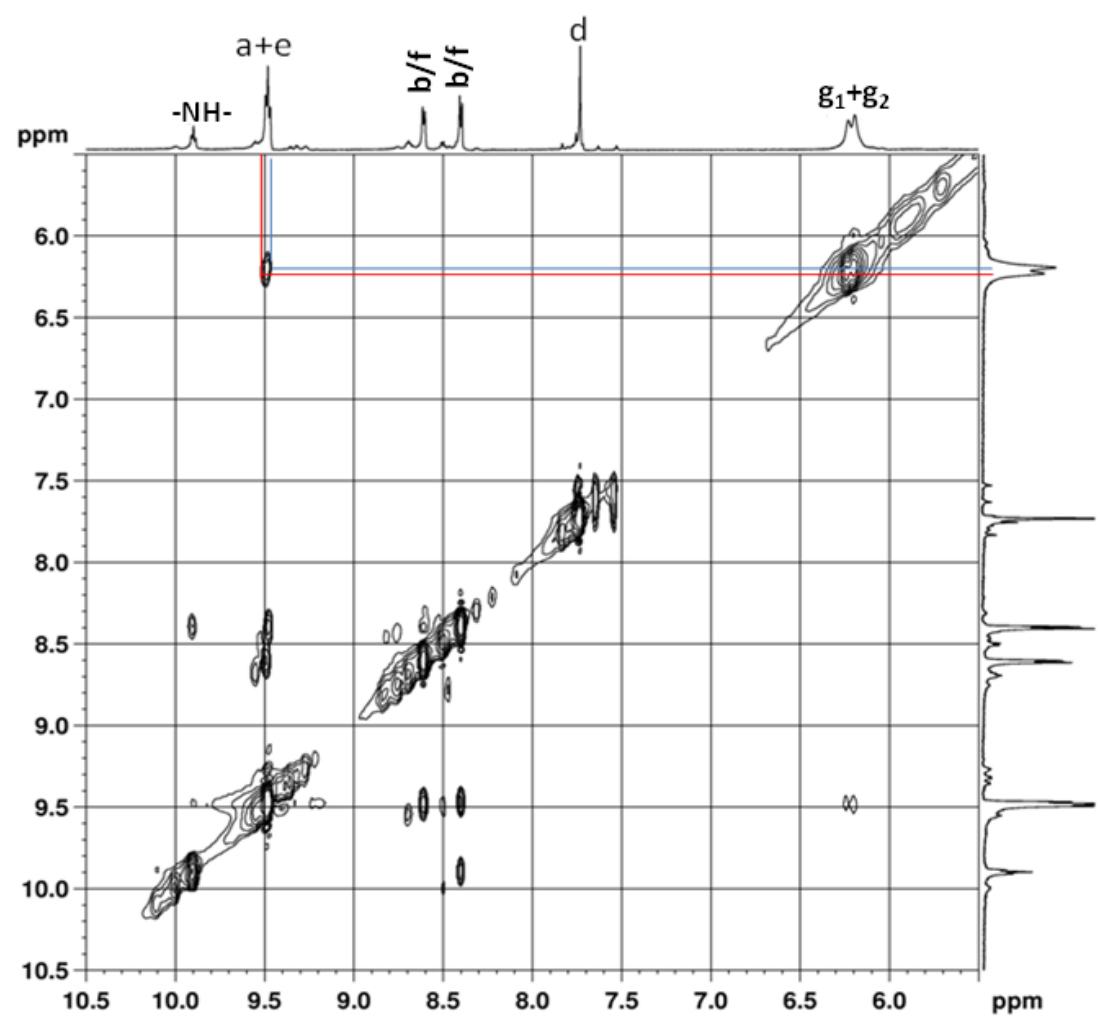

amide-en-NOESY-expn

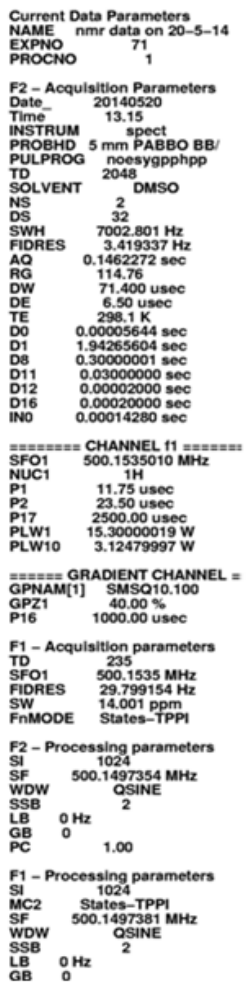

Figure S4. H-H NOESY of 1a in DMSO- $d_{6}$.

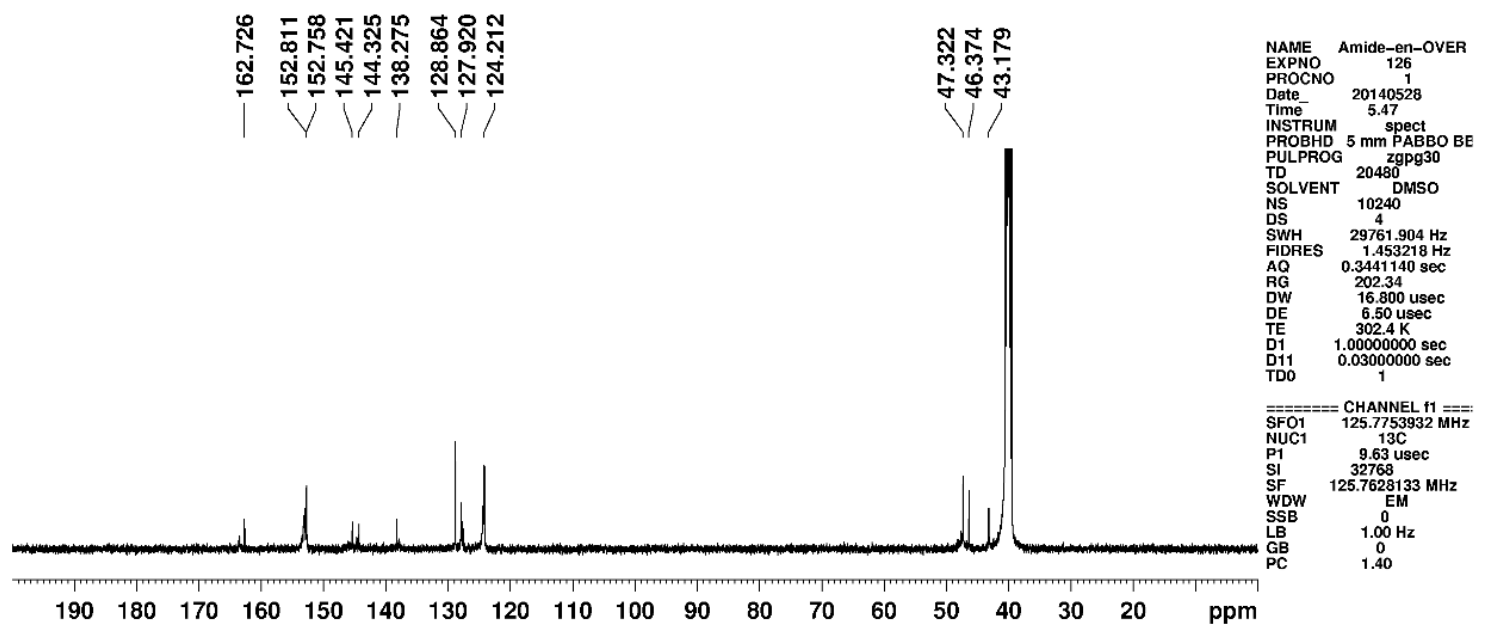

Figure S5. ${ }^{13} \mathrm{C}$ NMR spectrum of $\mathbf{1 a}$ in DMSO- $d_{6}$. 

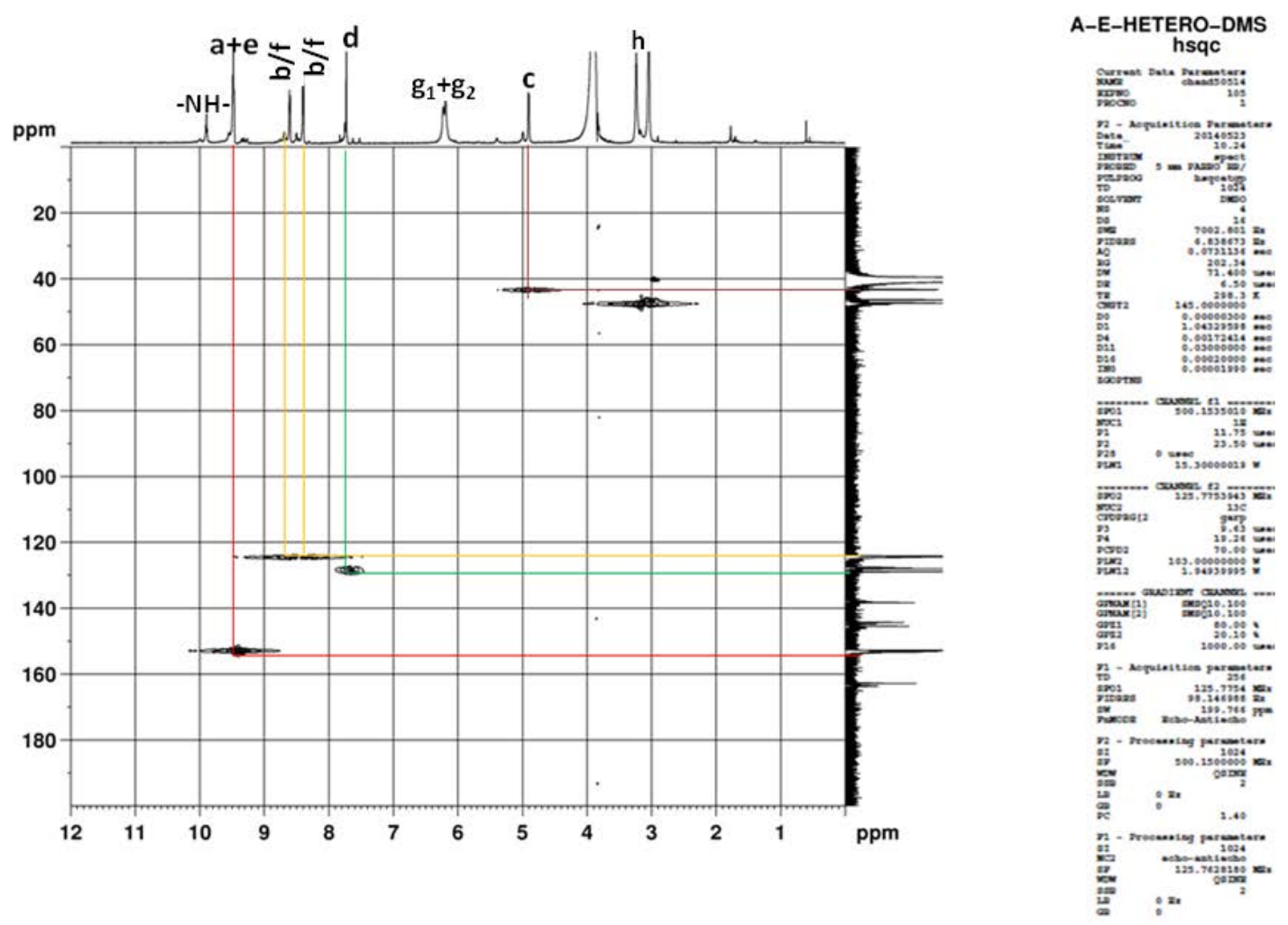

Figure S6. HSQC of 1a in DMSO- $d_{6}$.

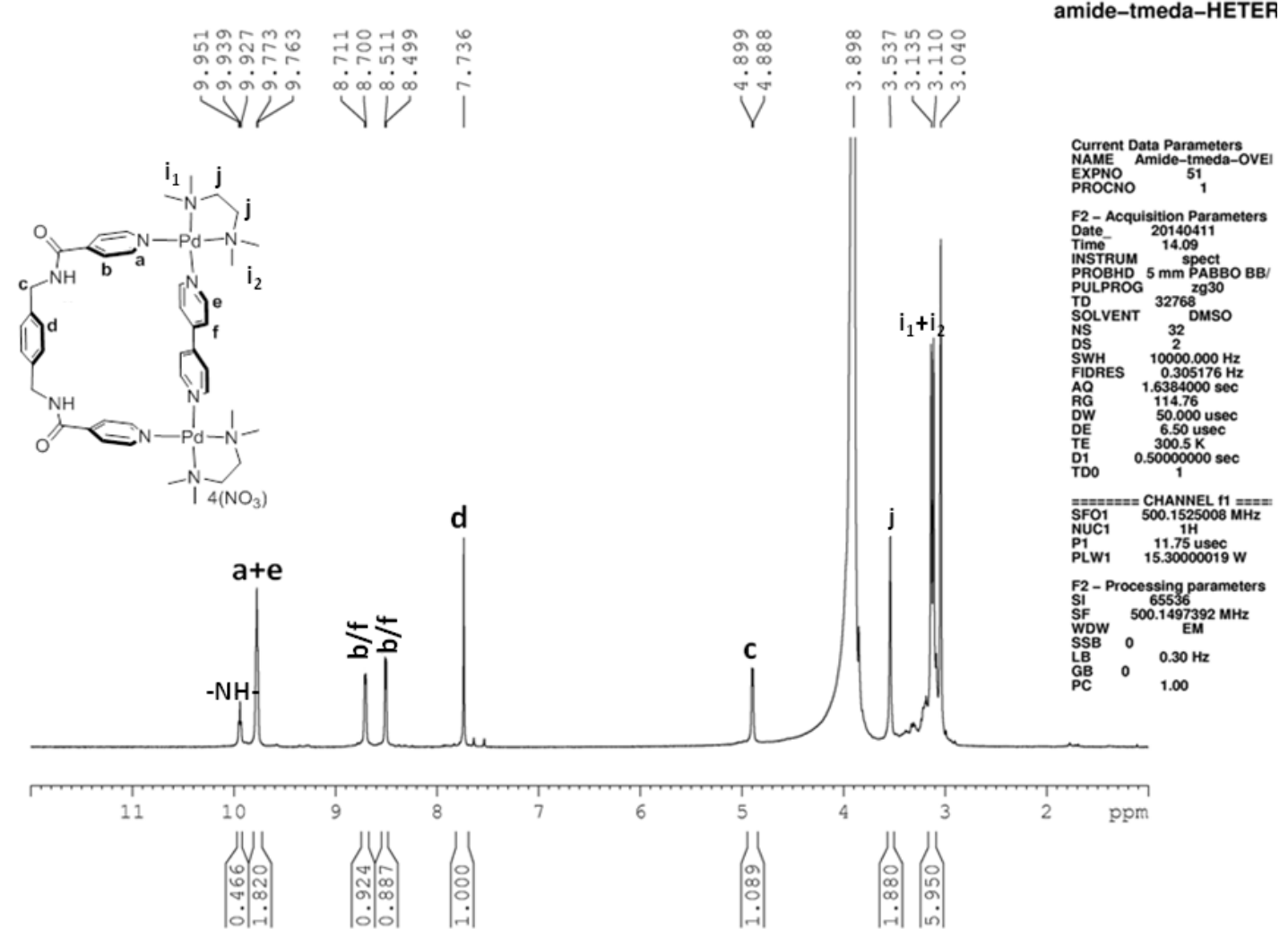

Figure S7. $500 \mathrm{MHz}{ }^{1} \mathrm{H}$ NMR spectrum of complex $\mathbf{1 b}$ in DMSO-d $d_{6}$ 

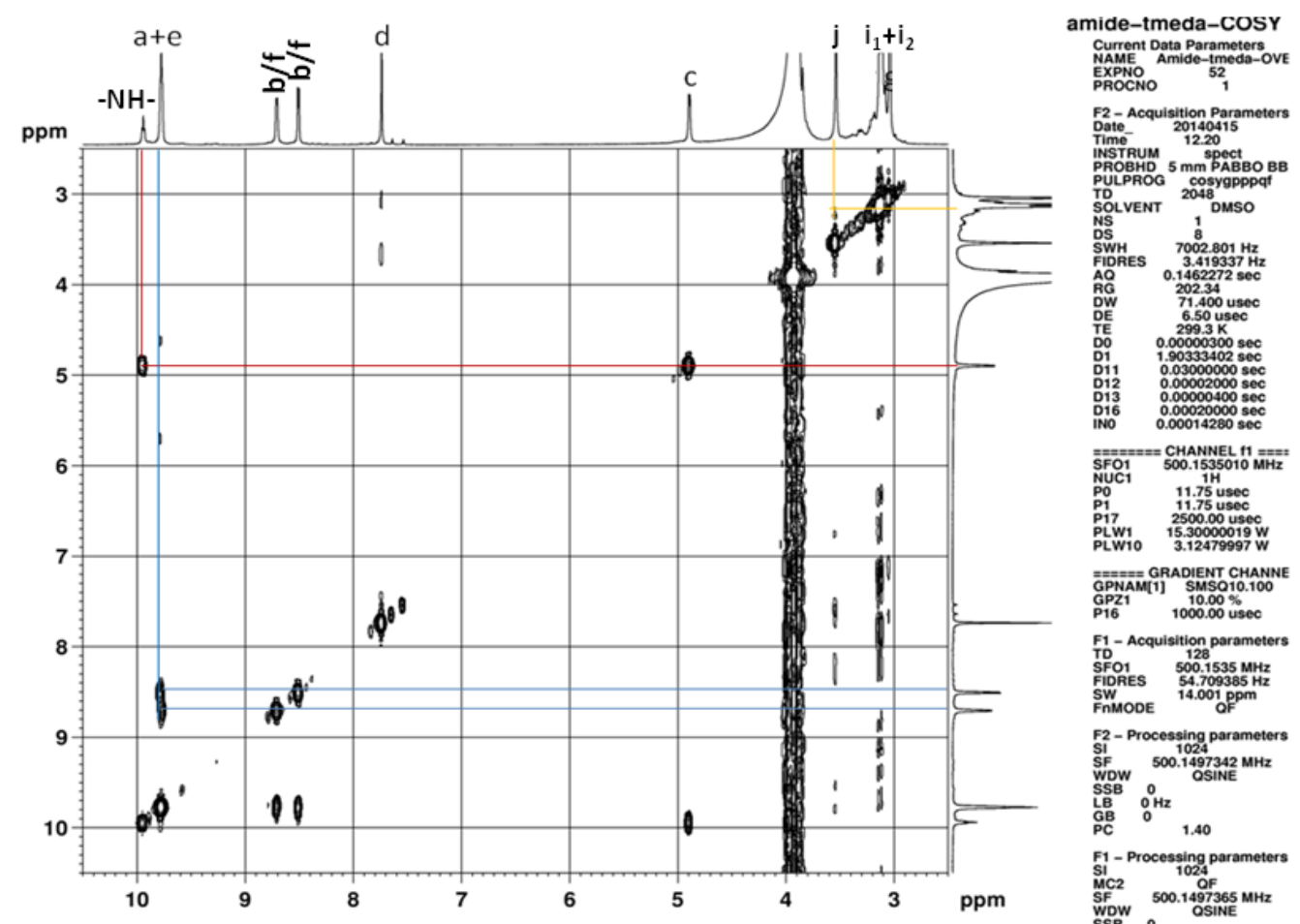

Figure S8. H-H COSY of $\mathbf{1 b}$ in DMSO- $d_{6}$.

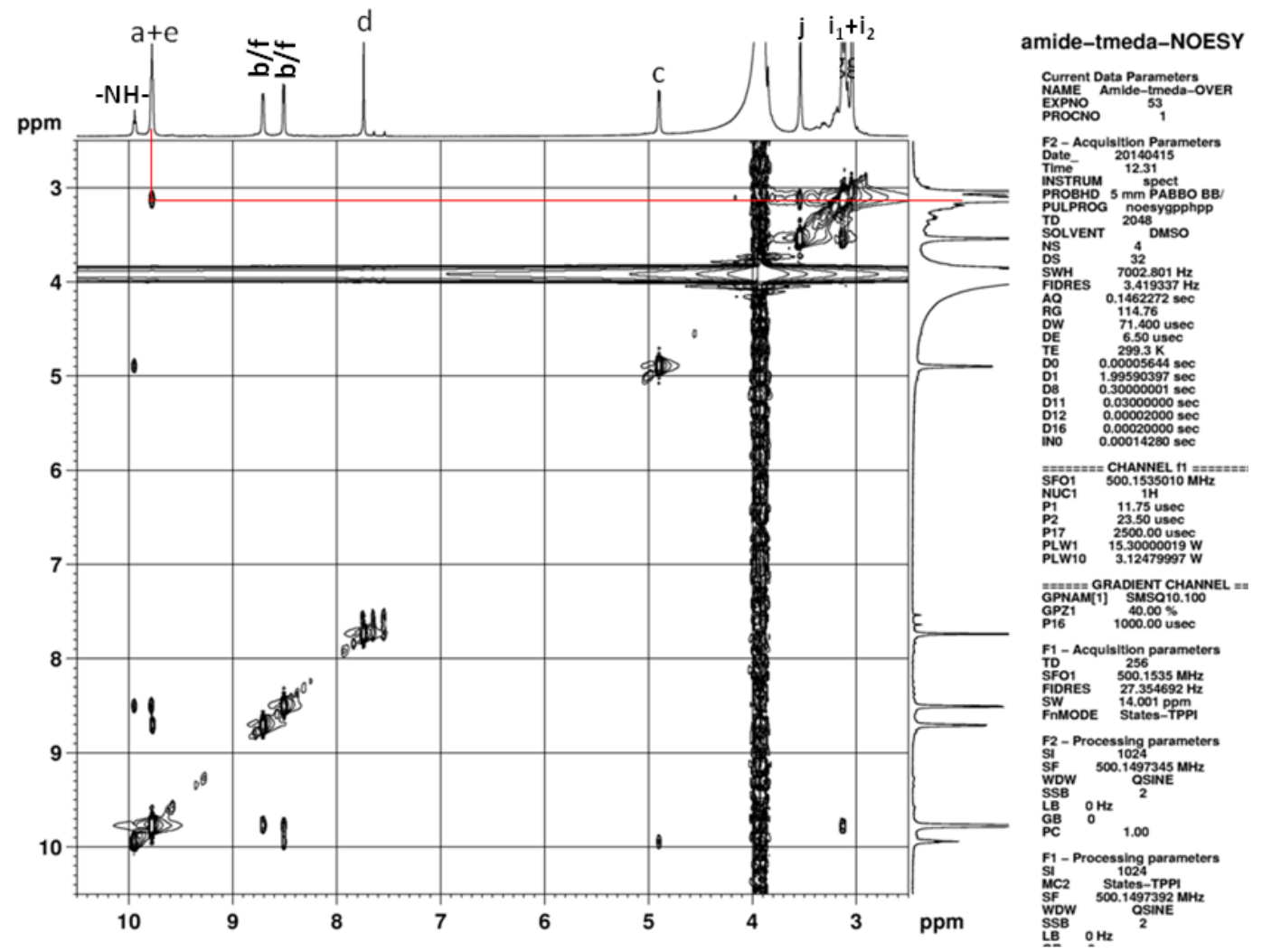

Figure S9. H-H NOESY of $\mathbf{1 b}$ in DMSO- $d_{6}$. 


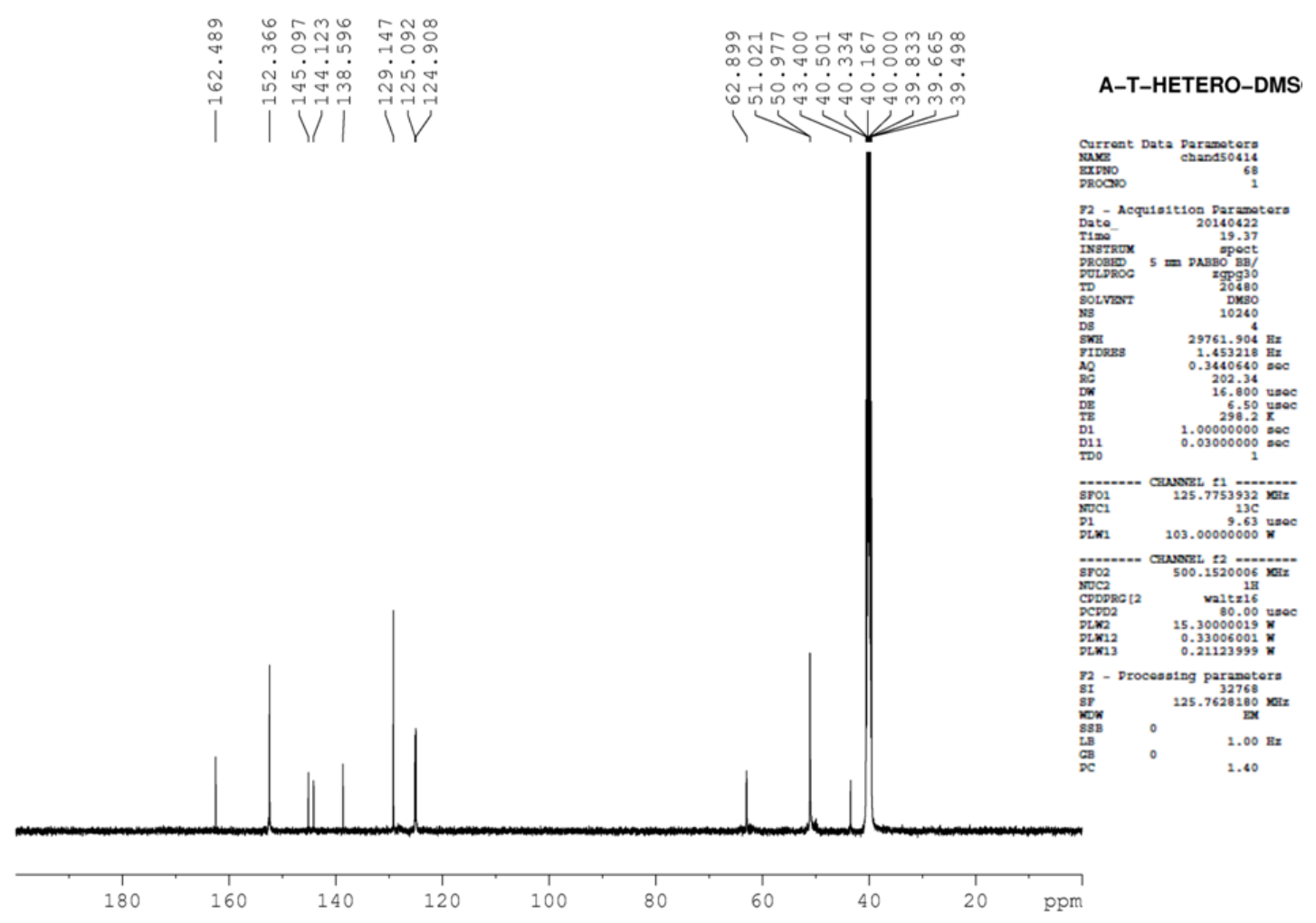

Figure S10. ${ }^{13} \mathrm{C}$ NMR spectrum of complex $\mathbf{1 b}$ in DMSO- $d_{6}$.

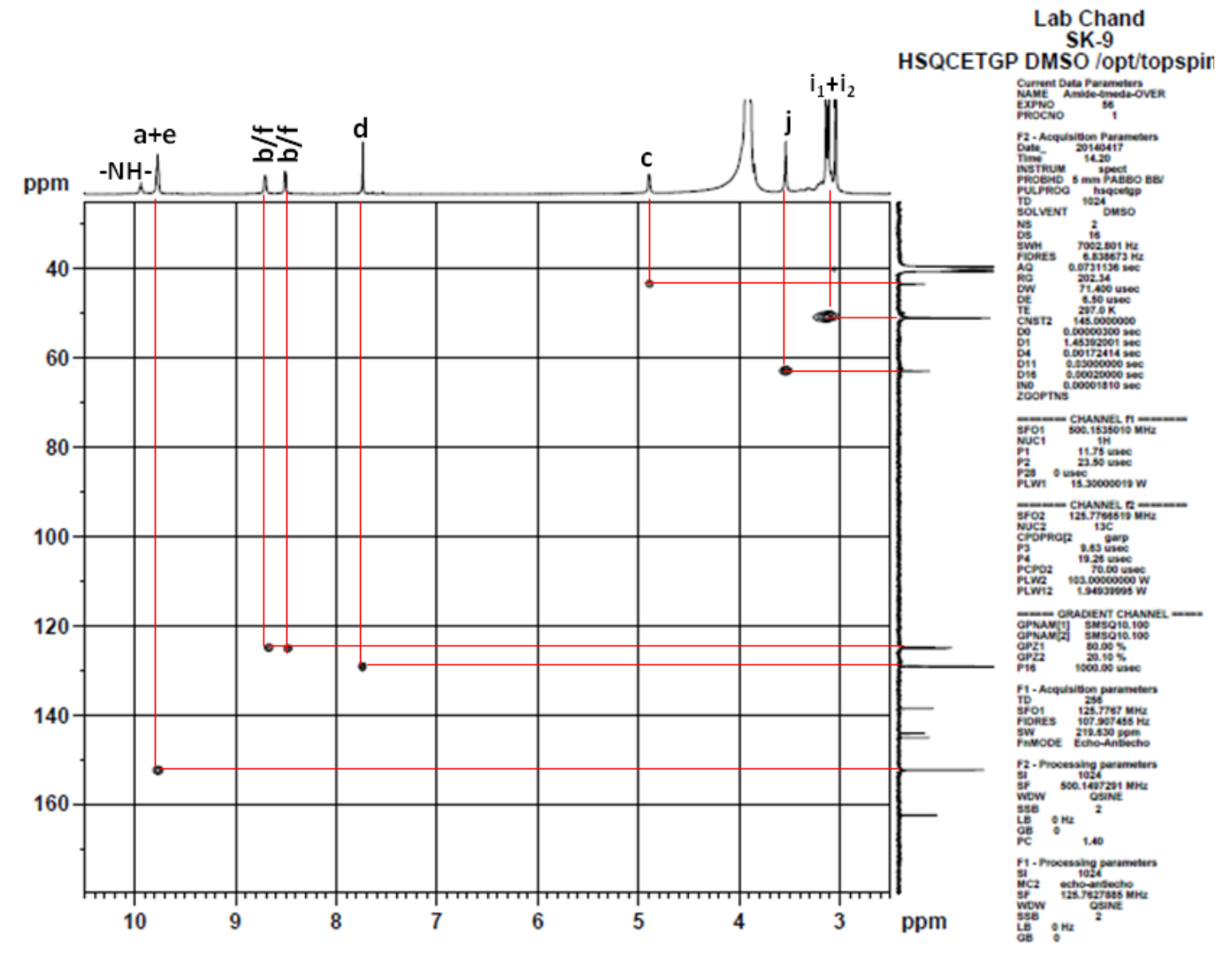

Figure S11. HSQC of $\mathbf{1 b}$ in DMSO- $d_{6}$. 


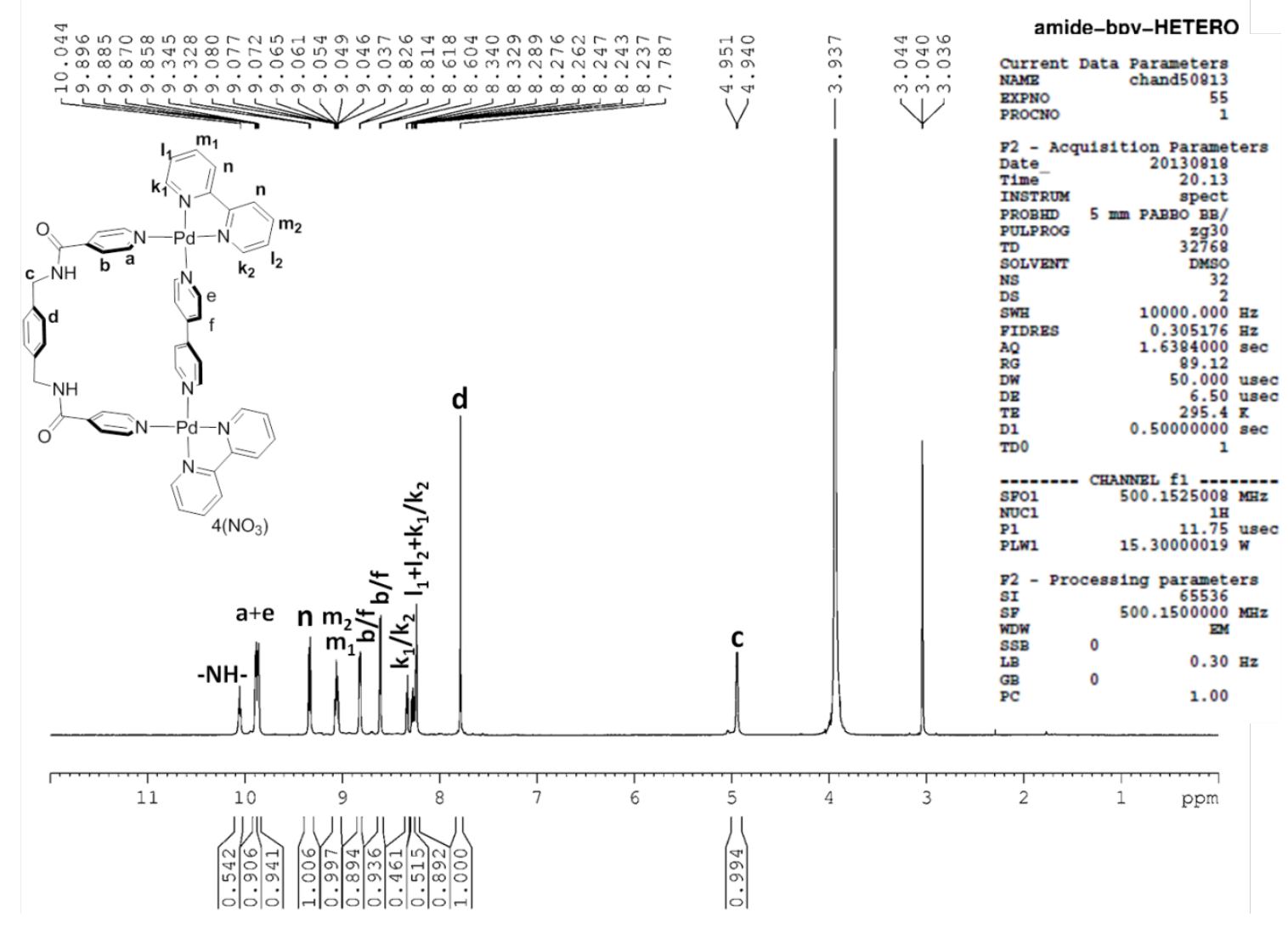

Figure S12. $500 \mathrm{MHz}{ }^{1} \mathrm{H}$ NMR spectrum of $1 \mathrm{c}$ in DMSO-d $d_{6}$.

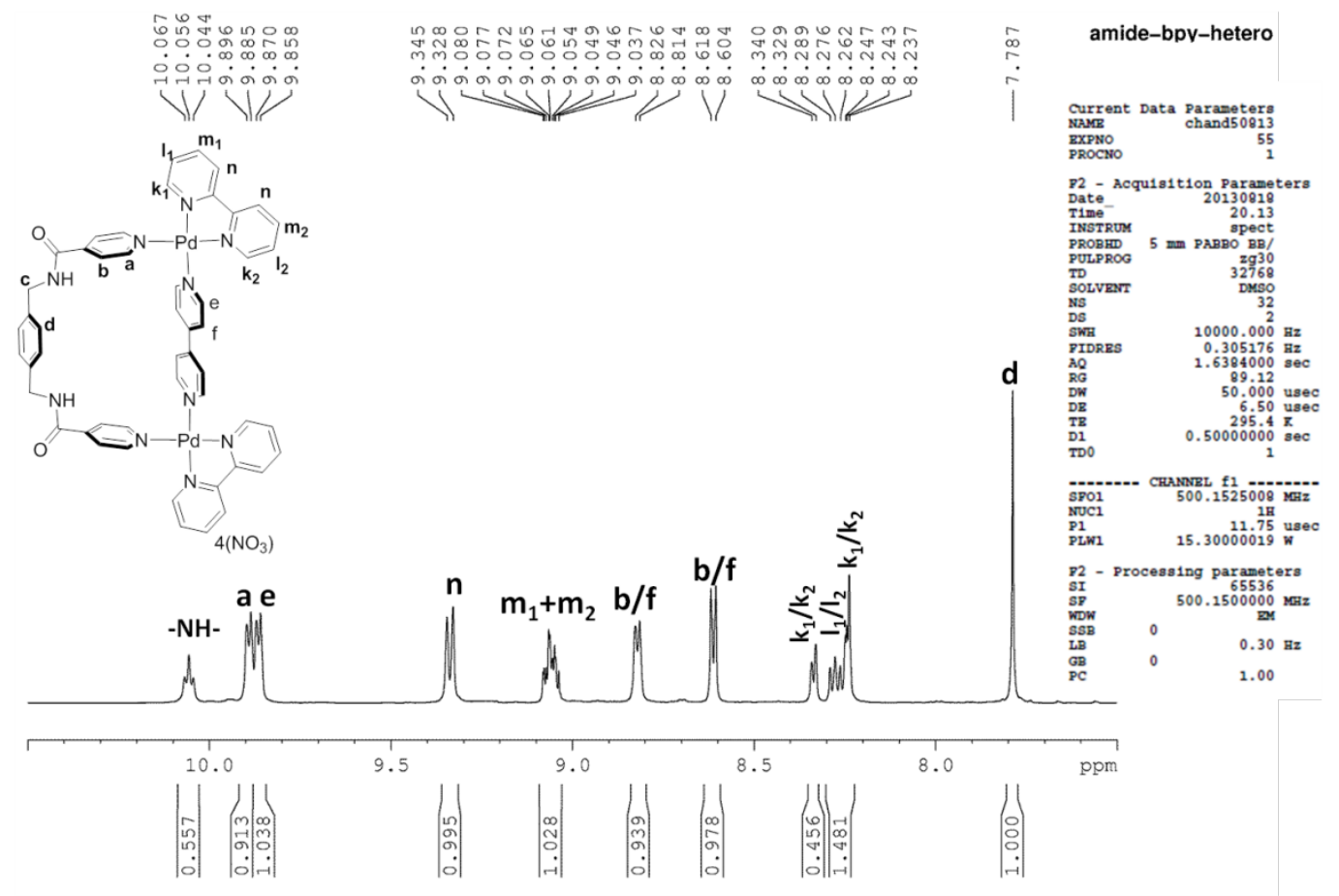

Figure S13. $500 \mathrm{MHz}{ }^{1} \mathrm{H}$ NMR spectrum (partial) of 1c in DMSO- $d_{6}$. 


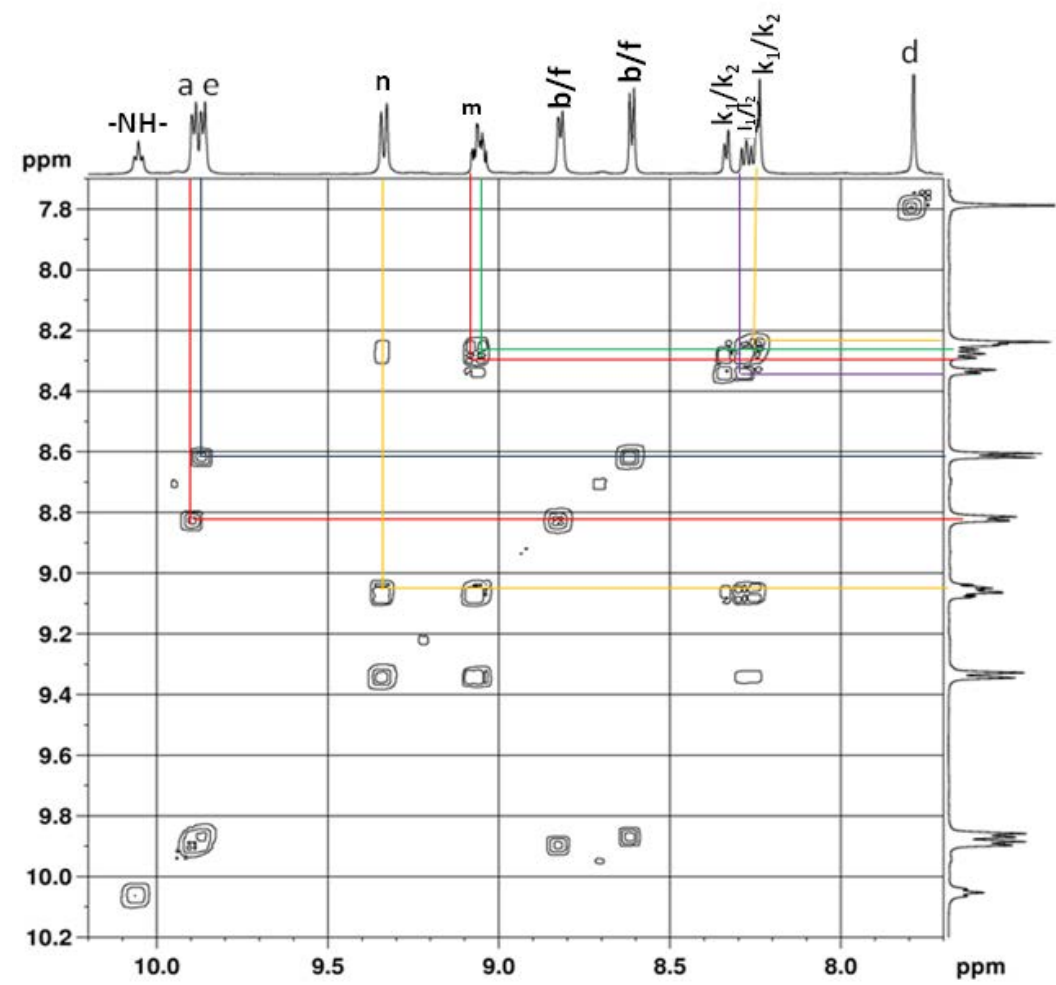

amide-bpy-COSY-expn

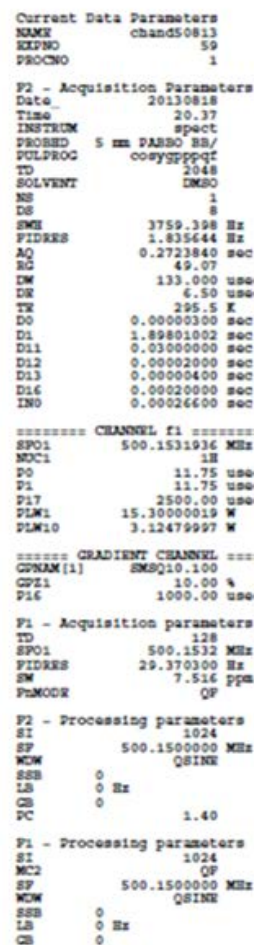

Figure S14. H-H COSY of 1c in DMSO- $d_{6}$.

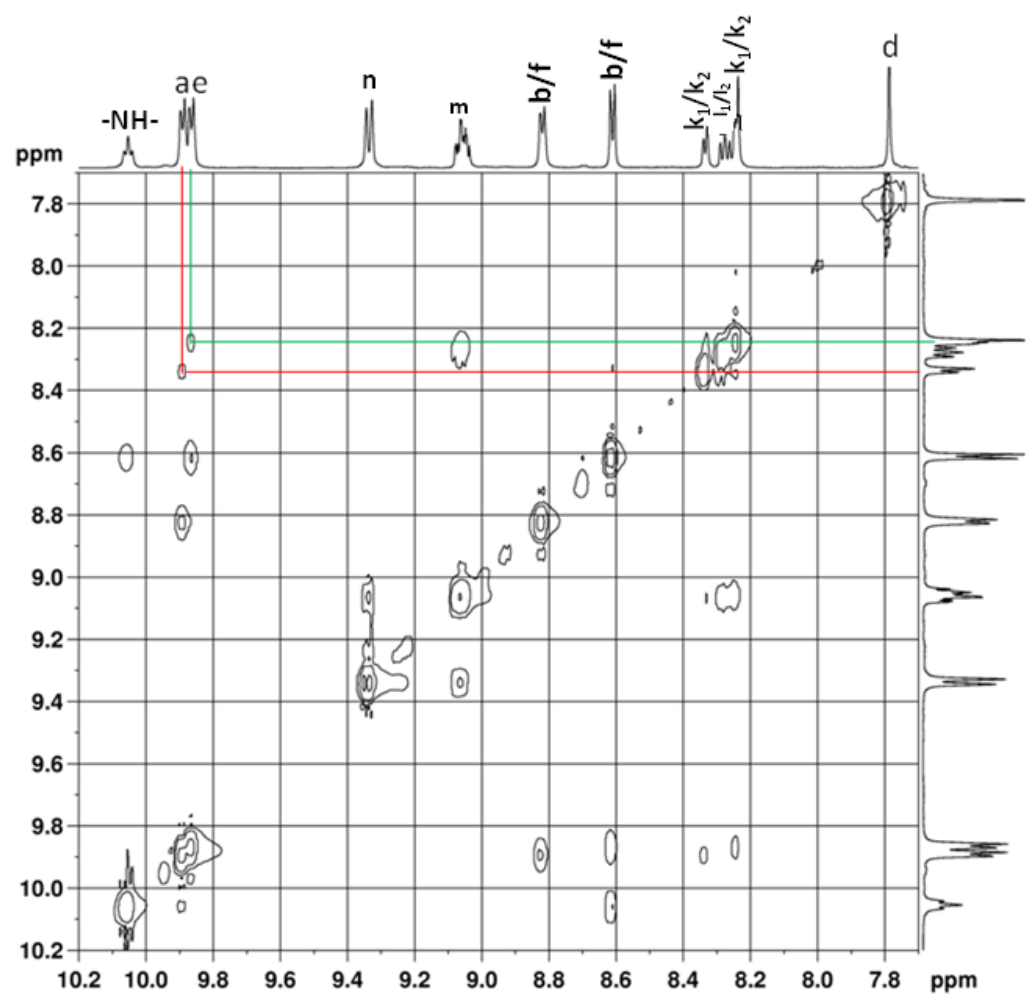

amide-bpy-NOESY-expn

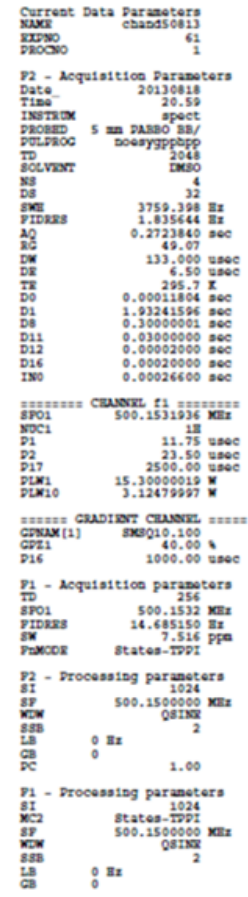

Figure S15. H-H NOESY of 1c in DMSO- $d_{6}$. 


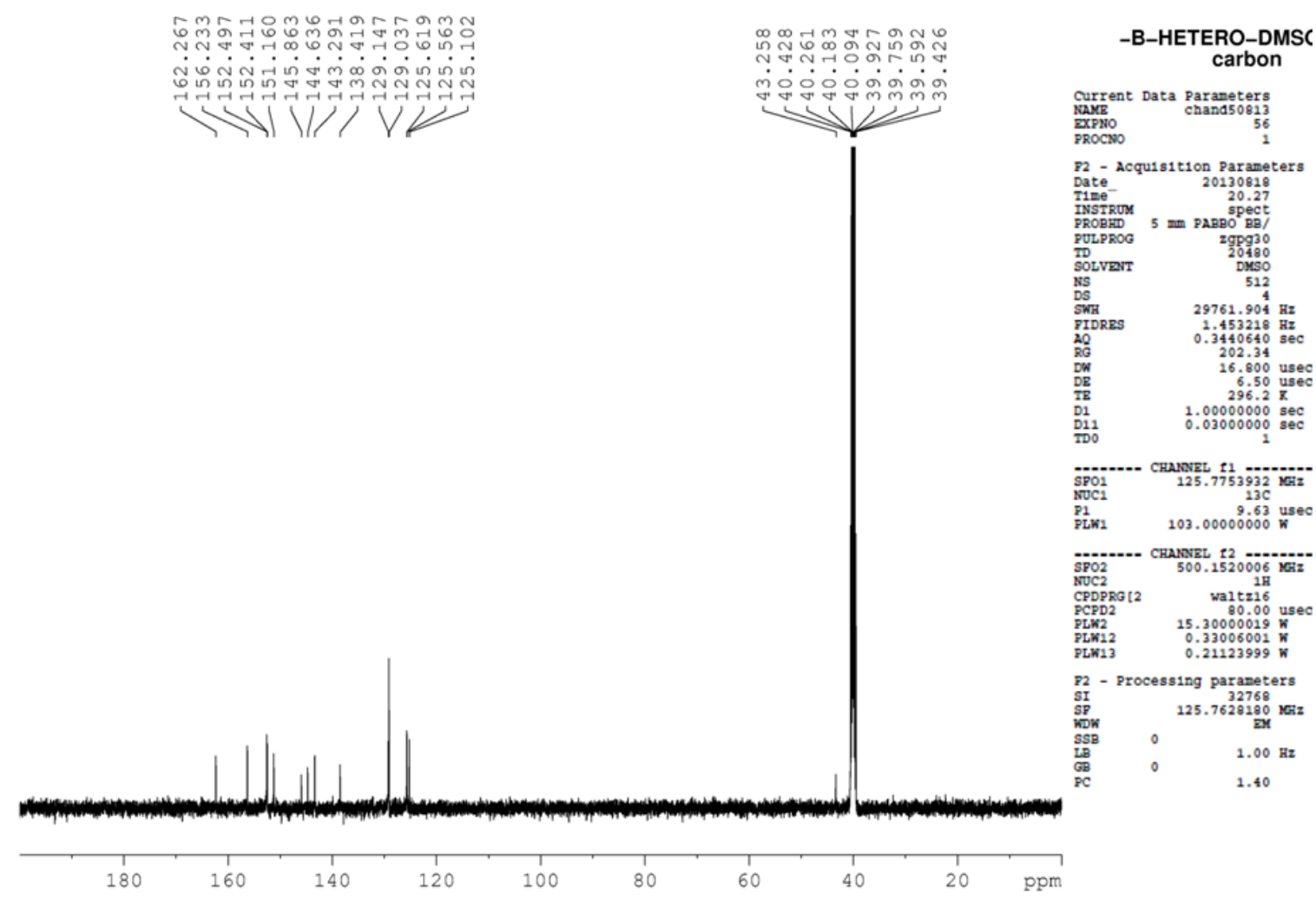

Figure S16. ${ }^{13} \mathrm{C}$ NMR spectrum of complex 1c in DMSO- $d_{6}$.
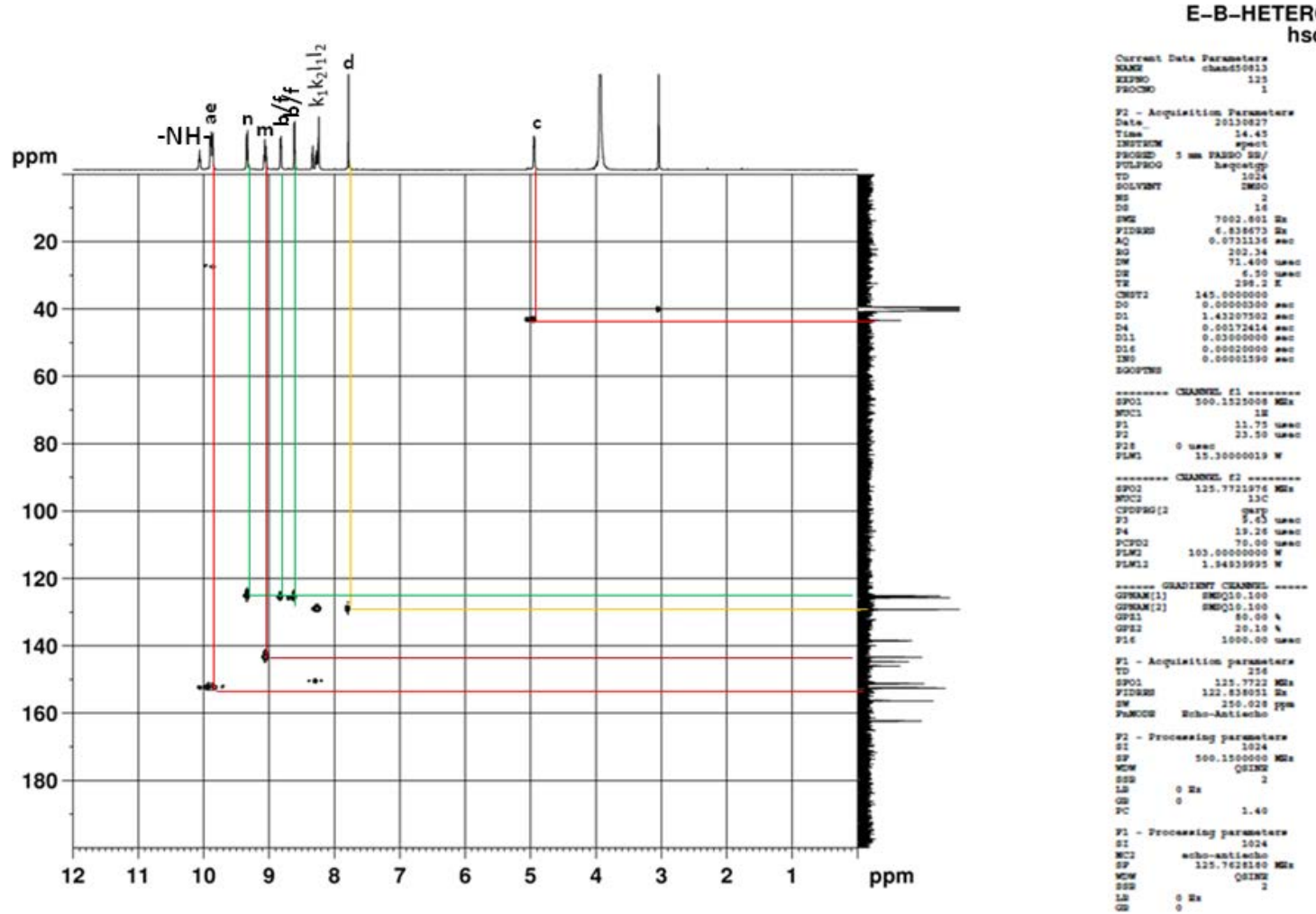

Figure S17. HSQC of 1c in DMSO- $d_{6}$ 


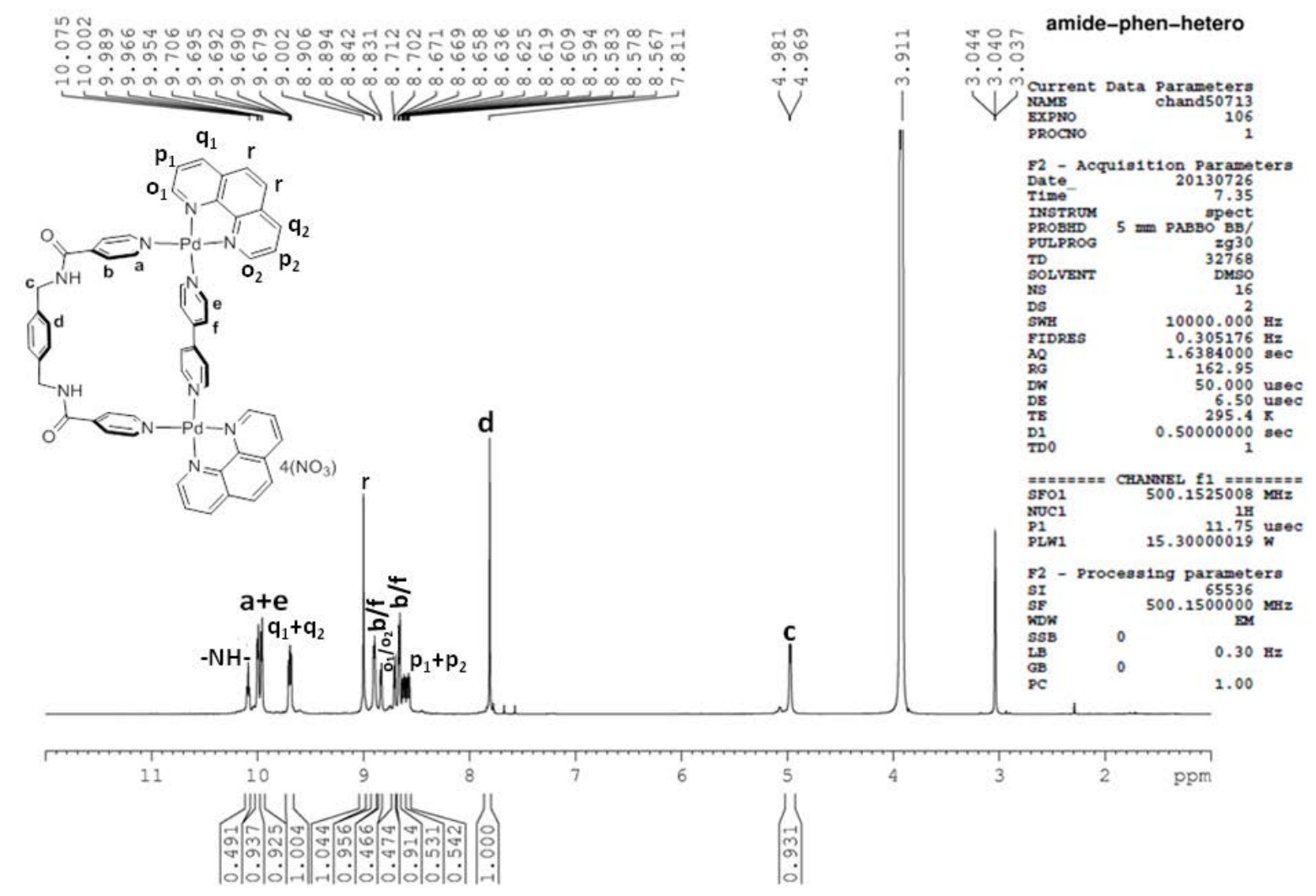

Figure S18. $500 \mathrm{MHz}{ }^{1} \mathrm{H}$ NMR spectrum of 1d in DMSO- $d_{6}$.

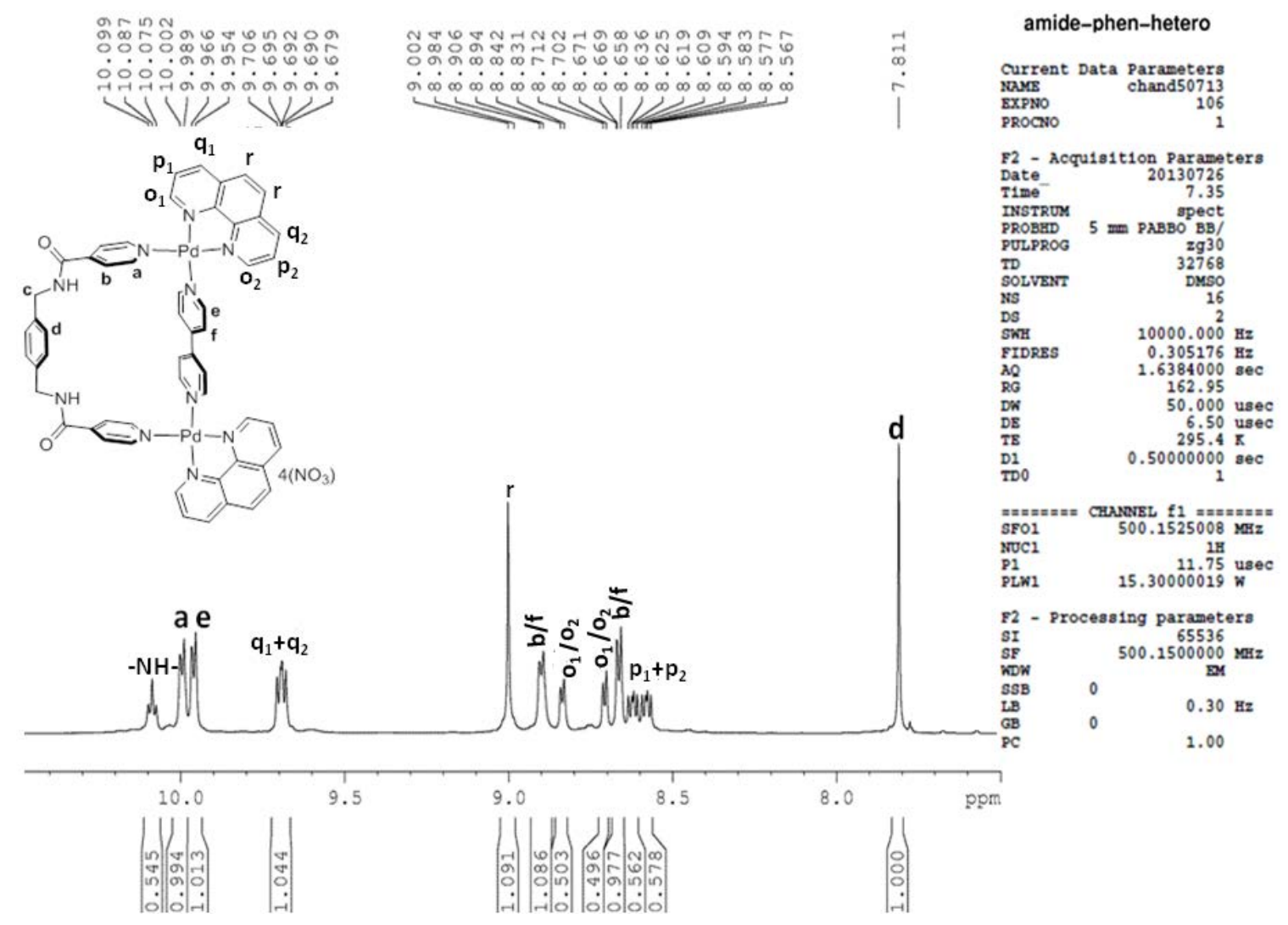

Figure S19. $500 \mathrm{MHz}{ }^{1} \mathrm{H}$ NMR spectrum (partial) of 1d in DMSO-d $d_{6}$. 


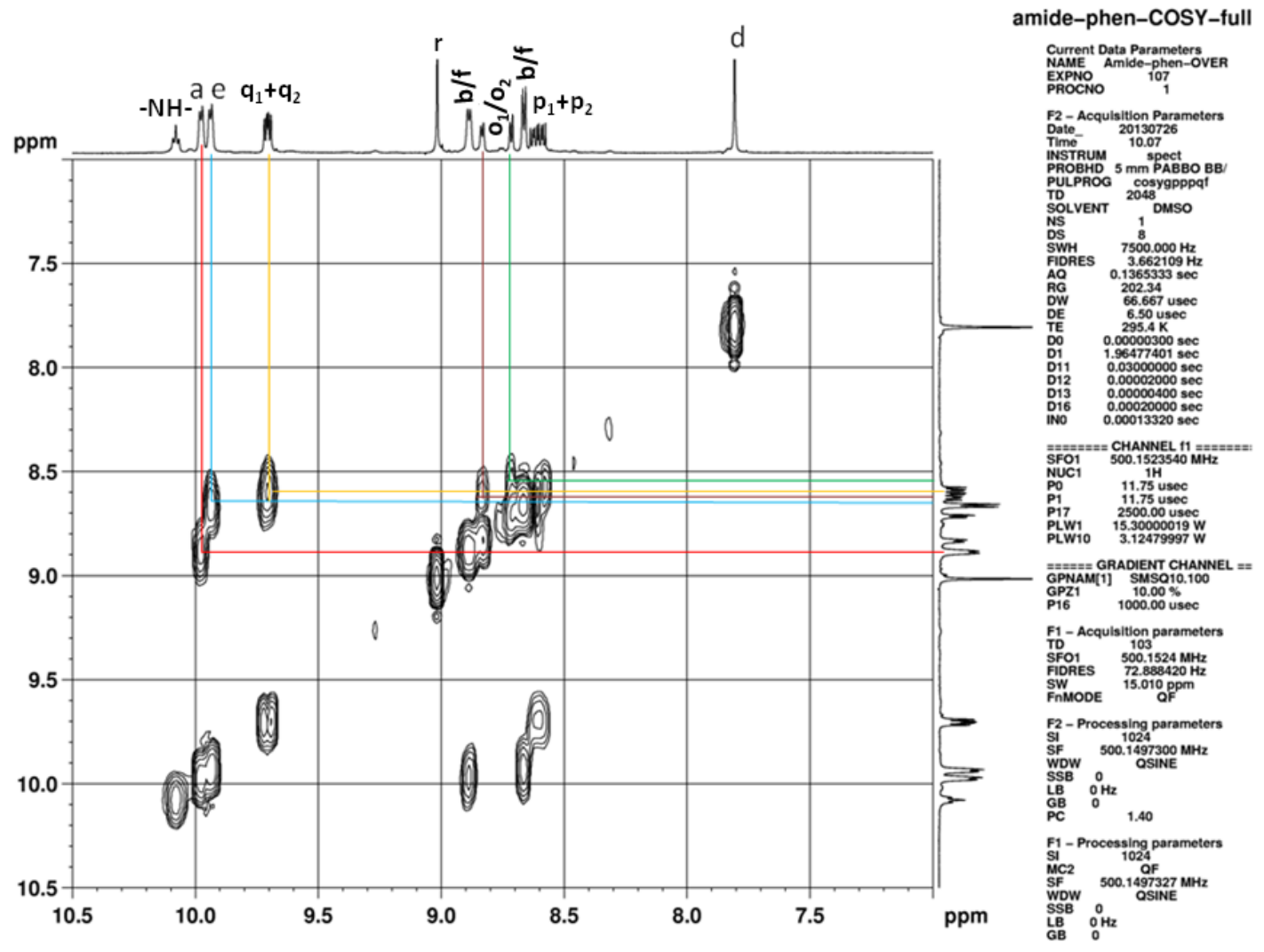

Figure S20. H-H COSY of 1d in DMSO- $d_{6}$.
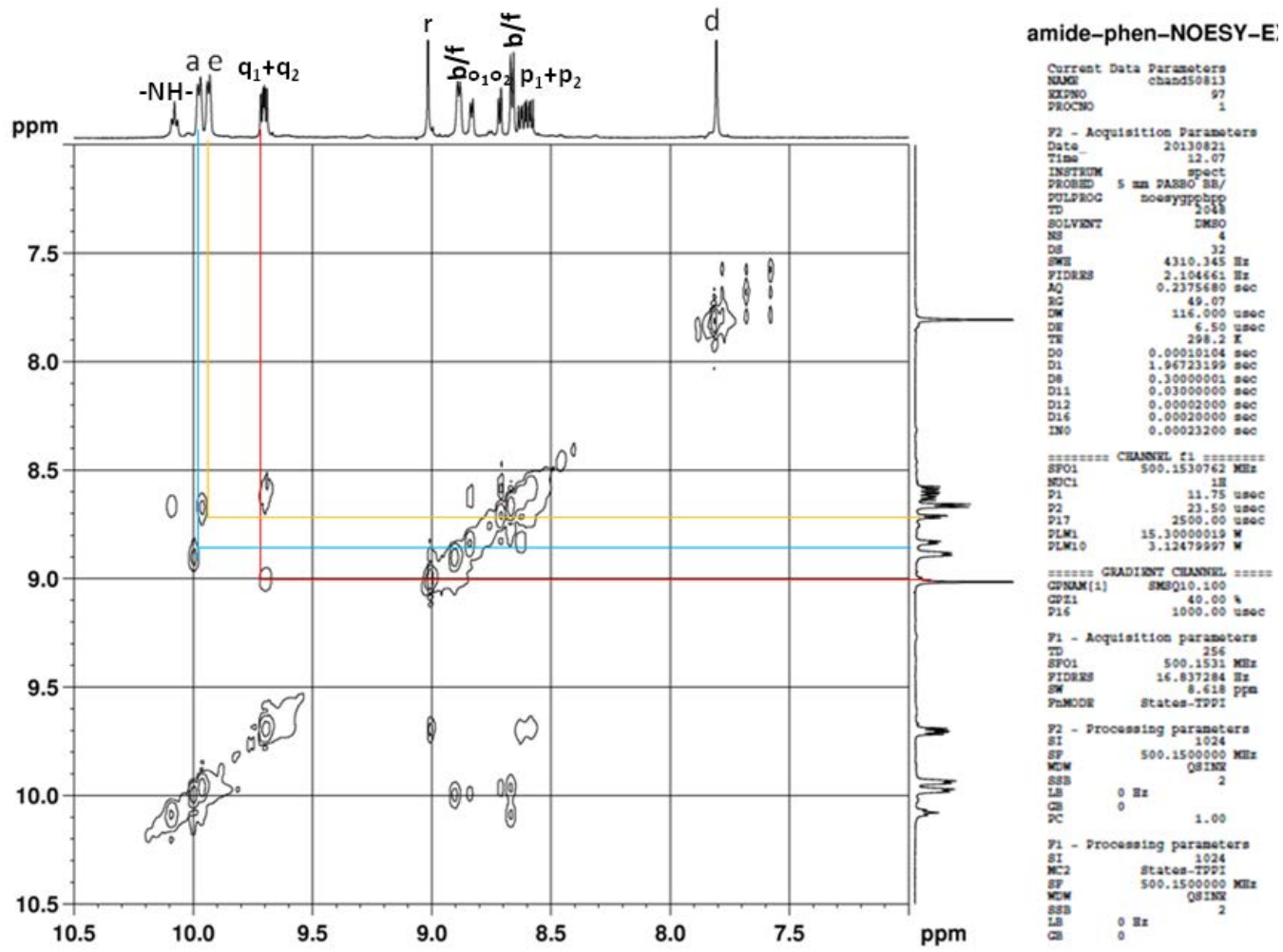

Figure S21. H-H NOESY of 1d in DMSO- $d_{6}$. 

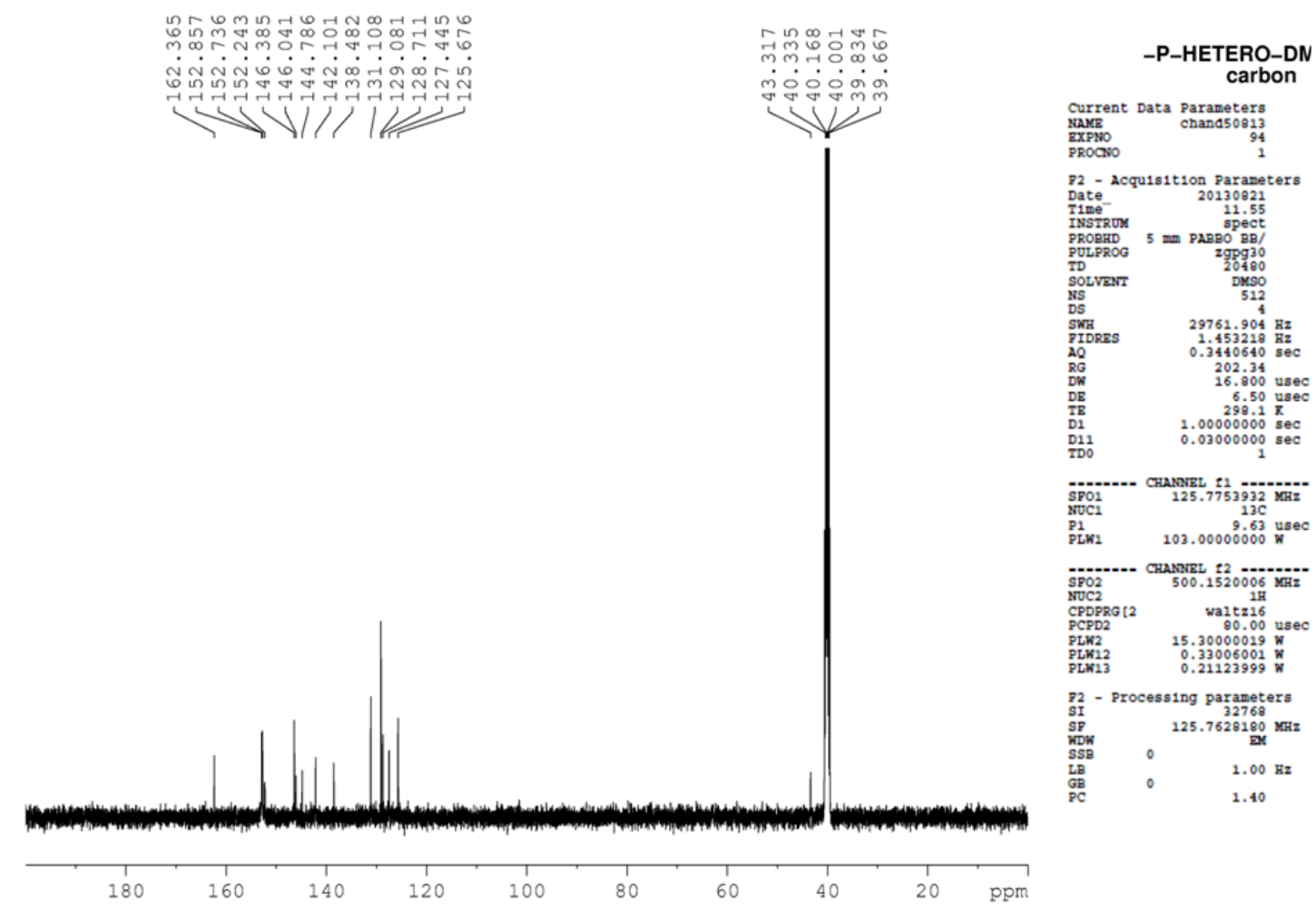

Figure S22. ${ }^{13} \mathrm{C}$ NMR spectrum of complex 1d in DMSO- $d_{6}$.

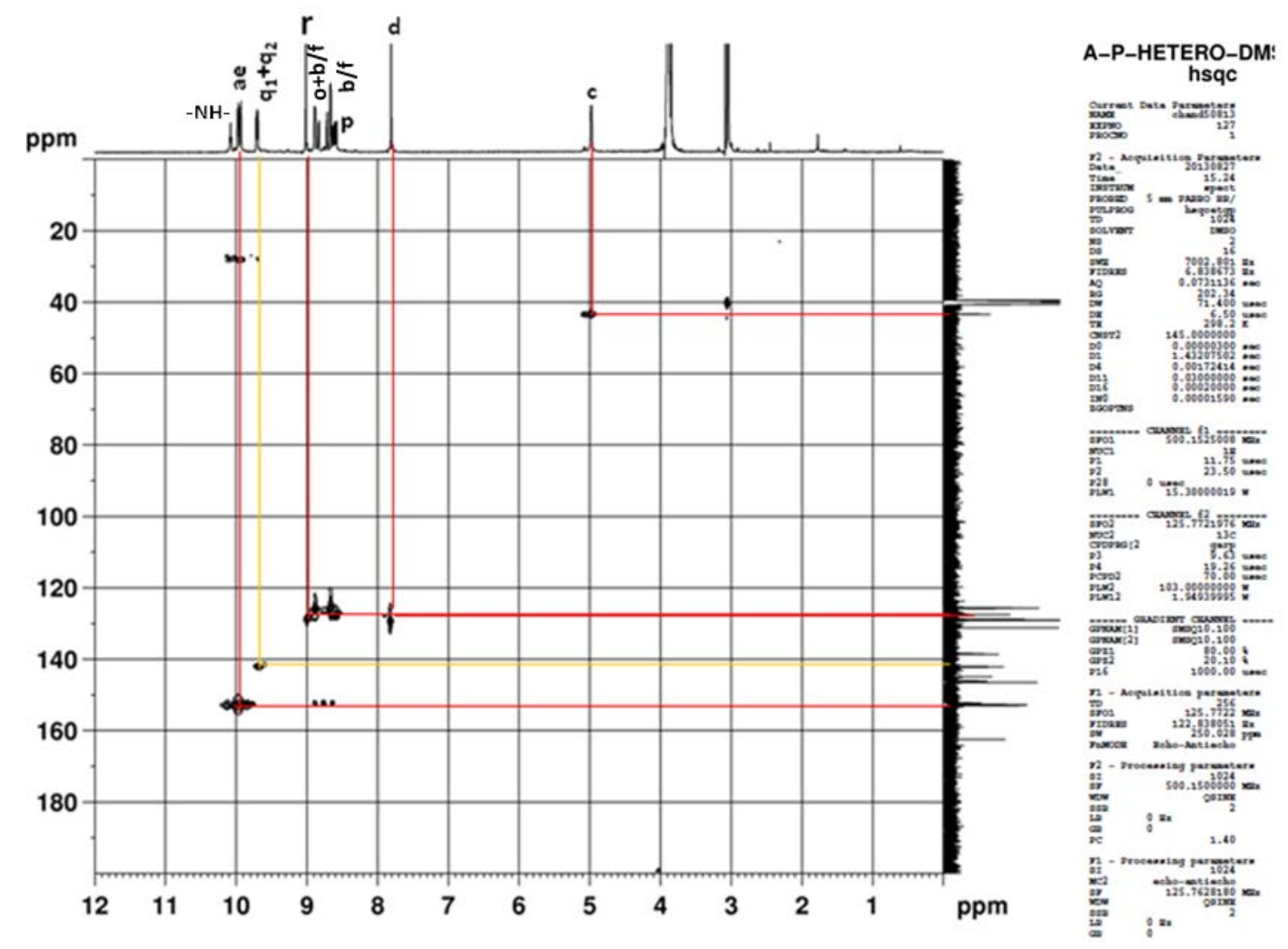

Figure S23. HSQC of 1d in DMSO- $d_{6}$. 


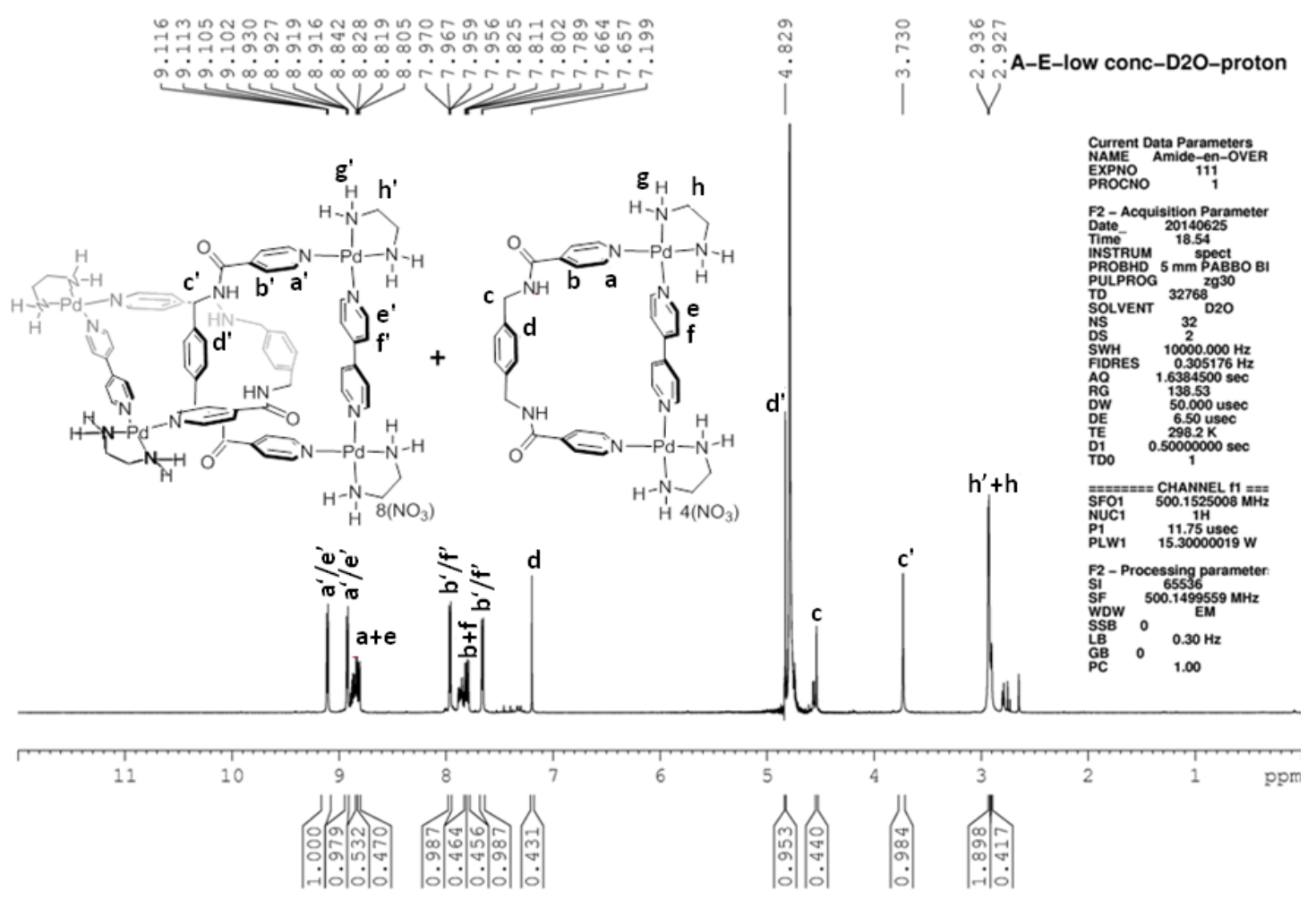

Figure S24. $500 \mathrm{MHz}{ }^{1} \mathrm{H}$ NMR spectrum of 1a/2a in $\mathrm{D}_{2} \mathrm{O}$ at $10 \mathrm{mM}$.

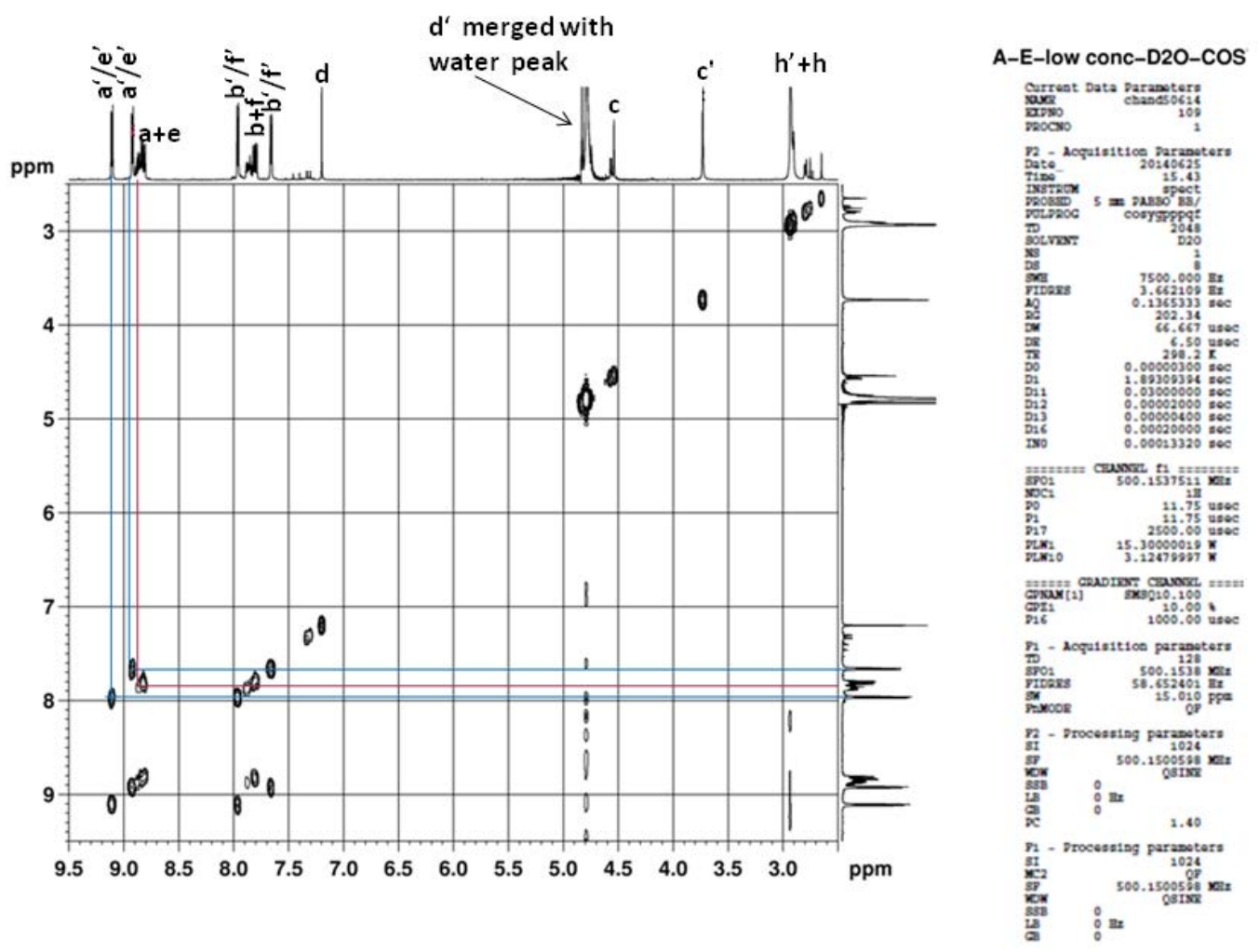

Figure S25. H-H COSY of $\mathbf{1 a} / \mathbf{2 a}$ in $\mathrm{D}_{2} \mathrm{O}$ at $10 \mathrm{mM}$. 


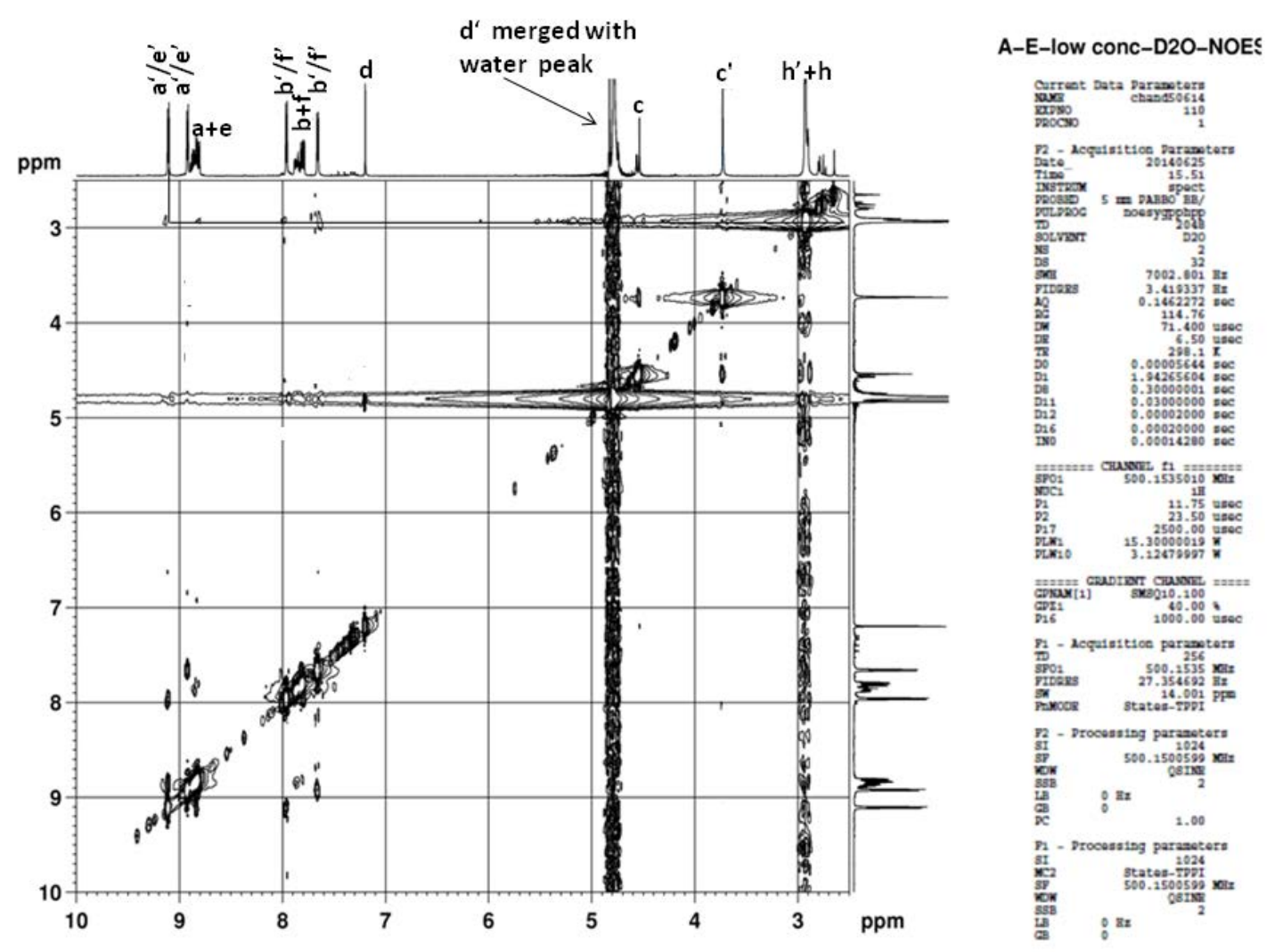

Figure S26. H-H NOESY of $\mathbf{1 a} / \mathbf{2 a}$ in $\mathrm{D}_{2} \mathrm{O}$ at $10 \mathrm{mM}$.

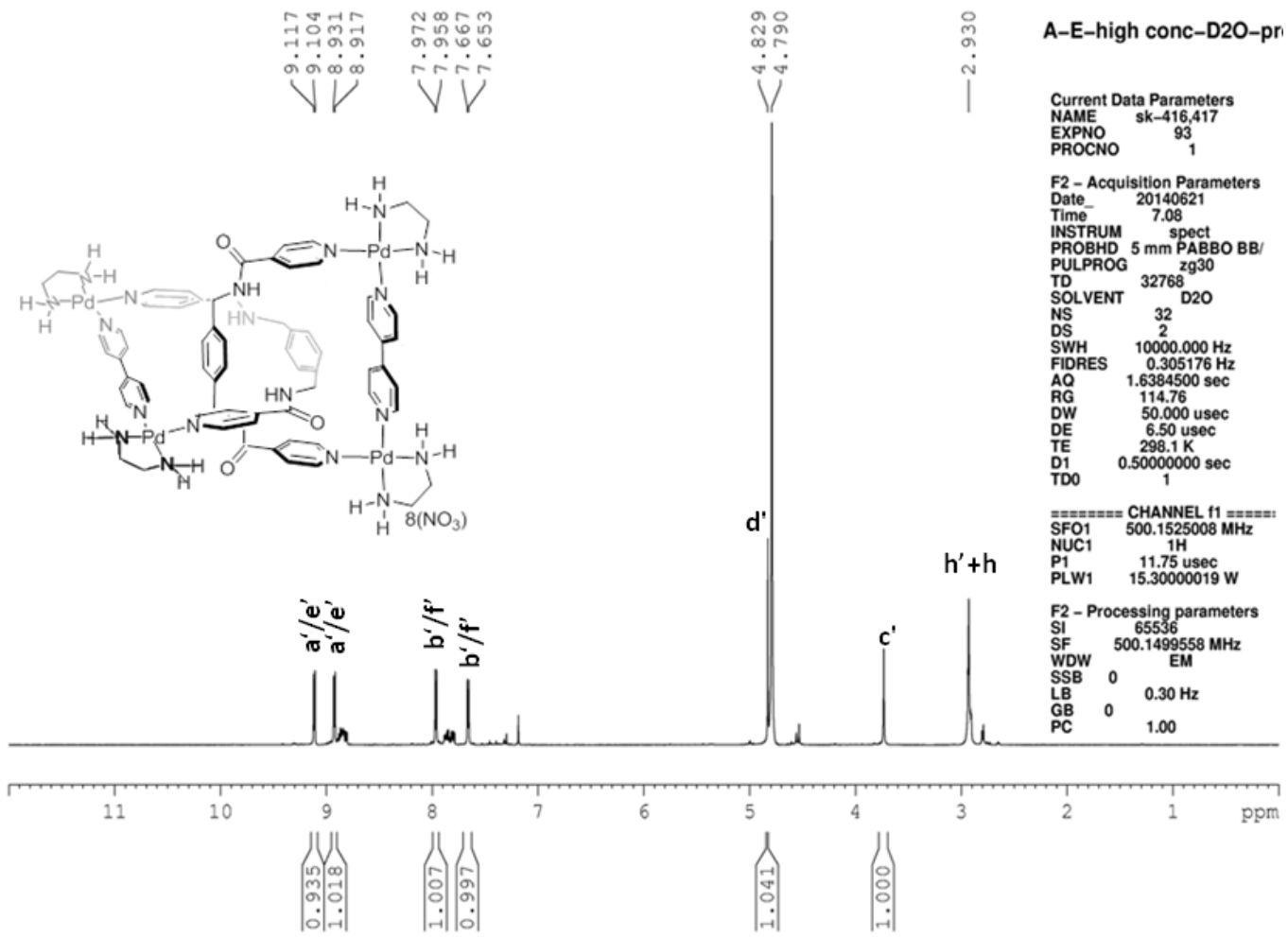

Figure S27. $500 \mathrm{MHz}{ }^{1} \mathrm{H}$ NMR spectrum of $\mathbf{1 a} / \mathbf{2 a}$ in $\mathrm{D}_{2} \mathrm{O}$ at $50 \mathrm{mM}$. 


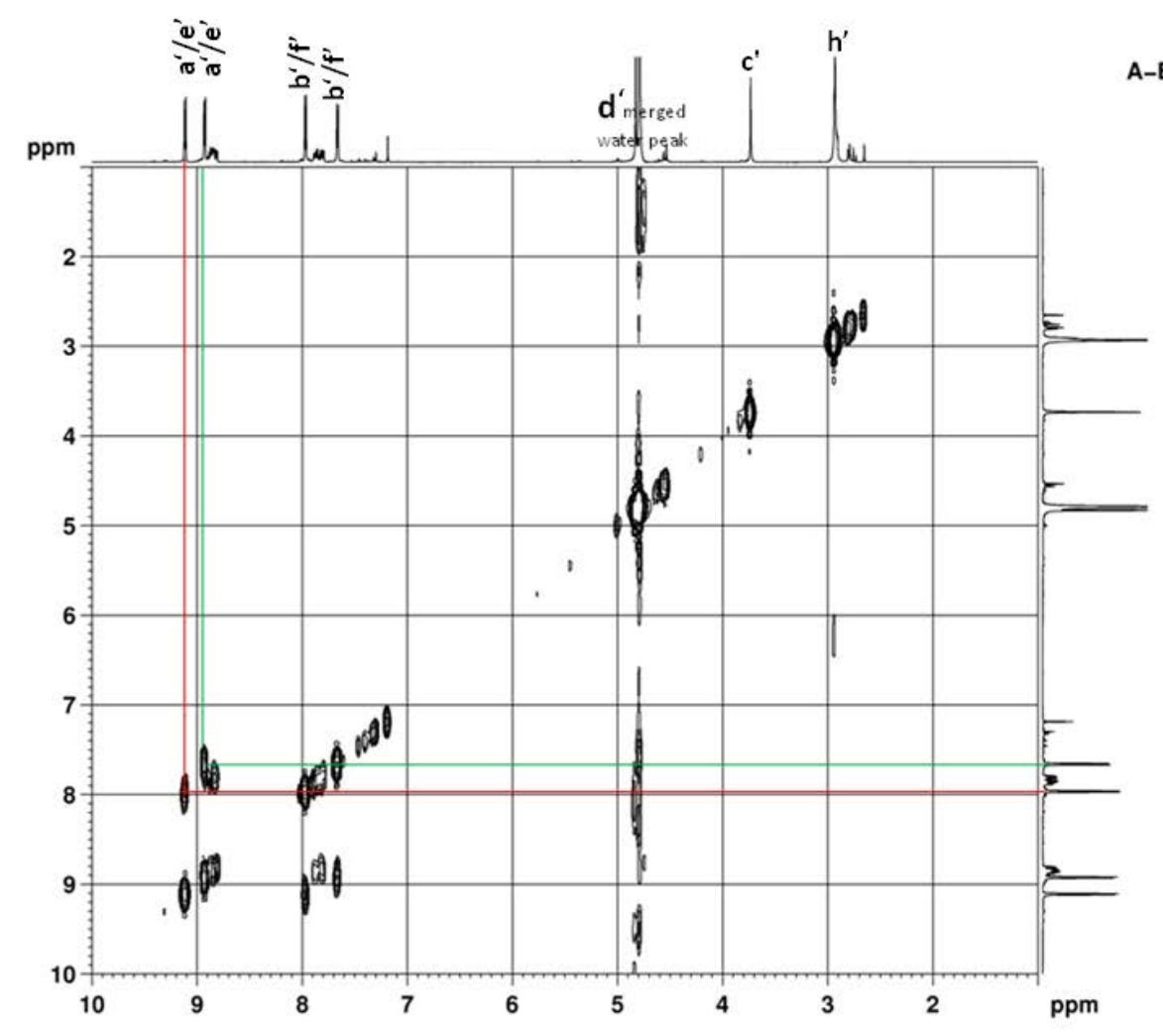

A-E-high conc-D2O-COSY

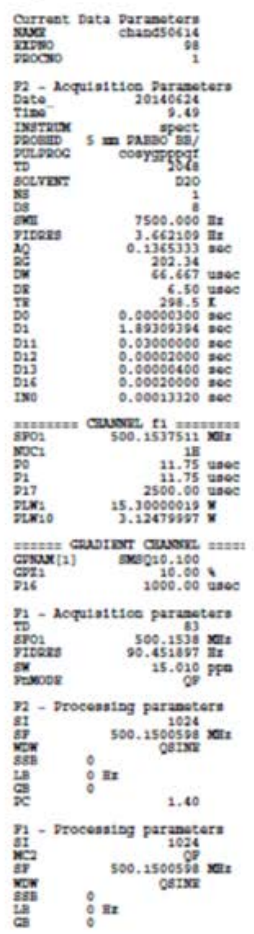

Figure S28. H-H COSY of $\mathbf{1 a} / \mathbf{2 a}$ in $\mathrm{D}_{2} \mathrm{O}$ at $50 \mathrm{mM}$.

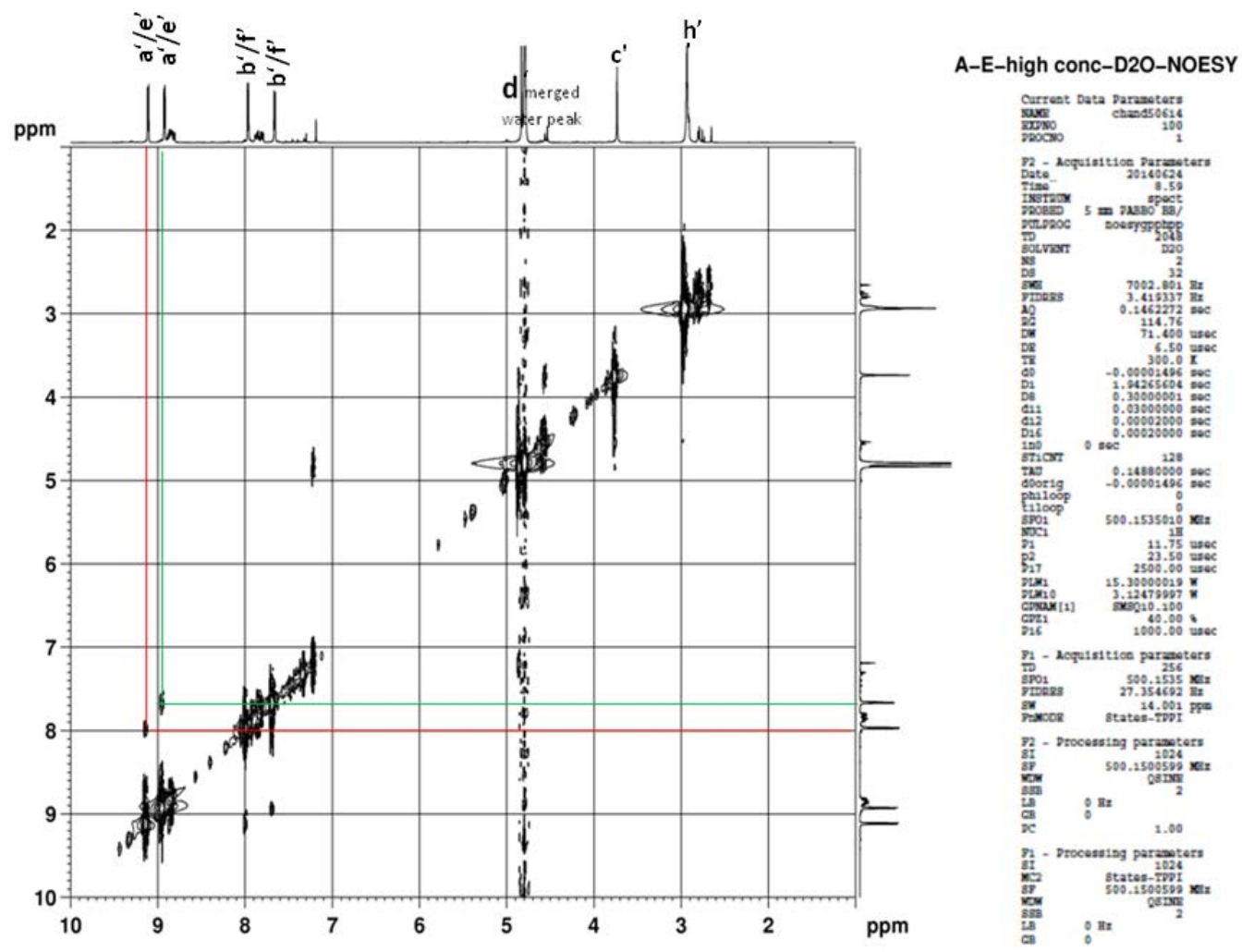

Figure S29. H-H NOESY of 1a/2a in $\mathrm{D}_{2} \mathrm{O}$ at $50 \mathrm{mM}$. 
iitm_carbonshort D2O /opt/topspin iitm 15

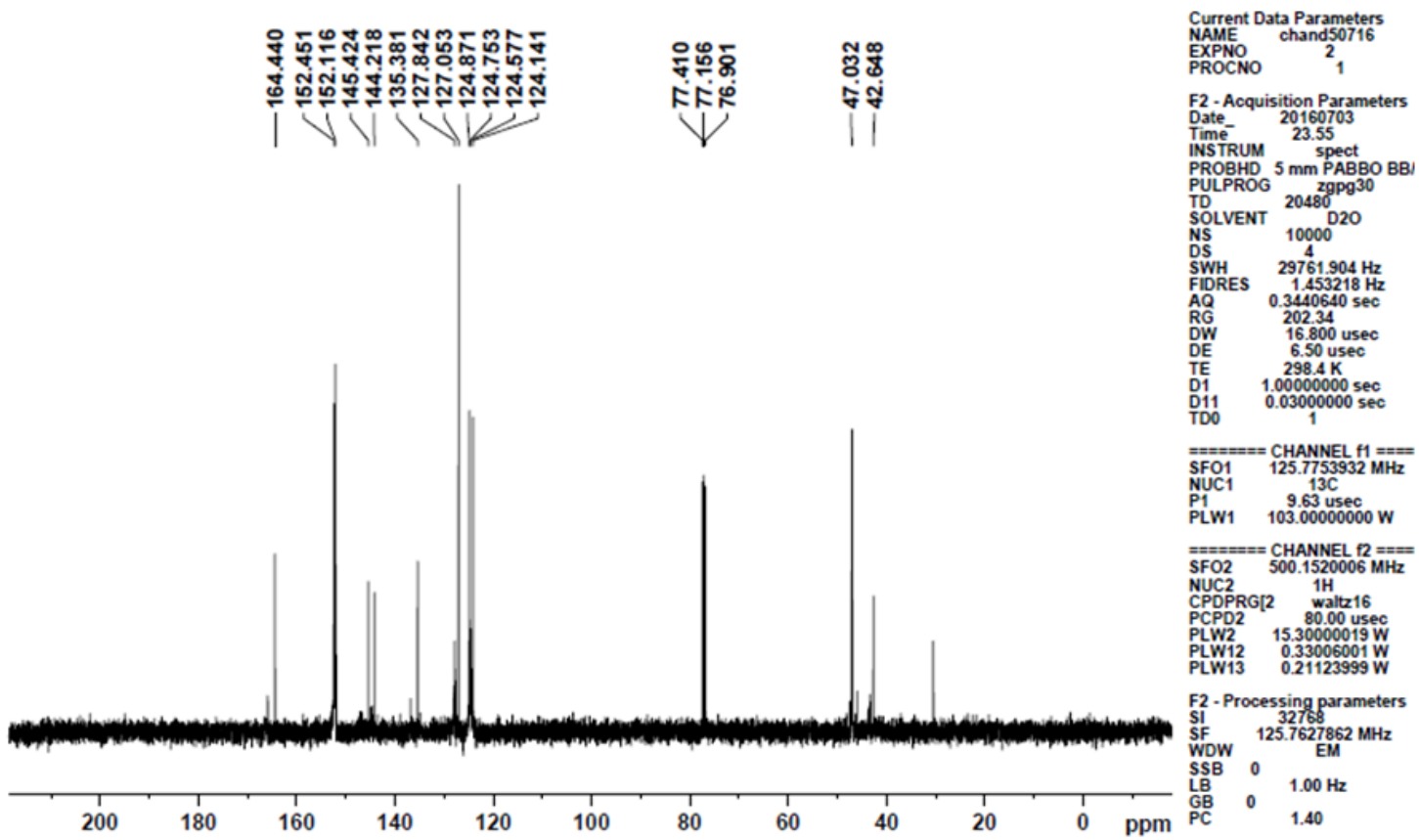

Figure S30. ${ }^{13} \mathrm{C}$ NMR spectrum of $\mathbf{1 a} / \mathbf{2 a}$ in $\mathrm{D}_{2} \mathrm{O}$ at $50 \mathrm{mM}$.

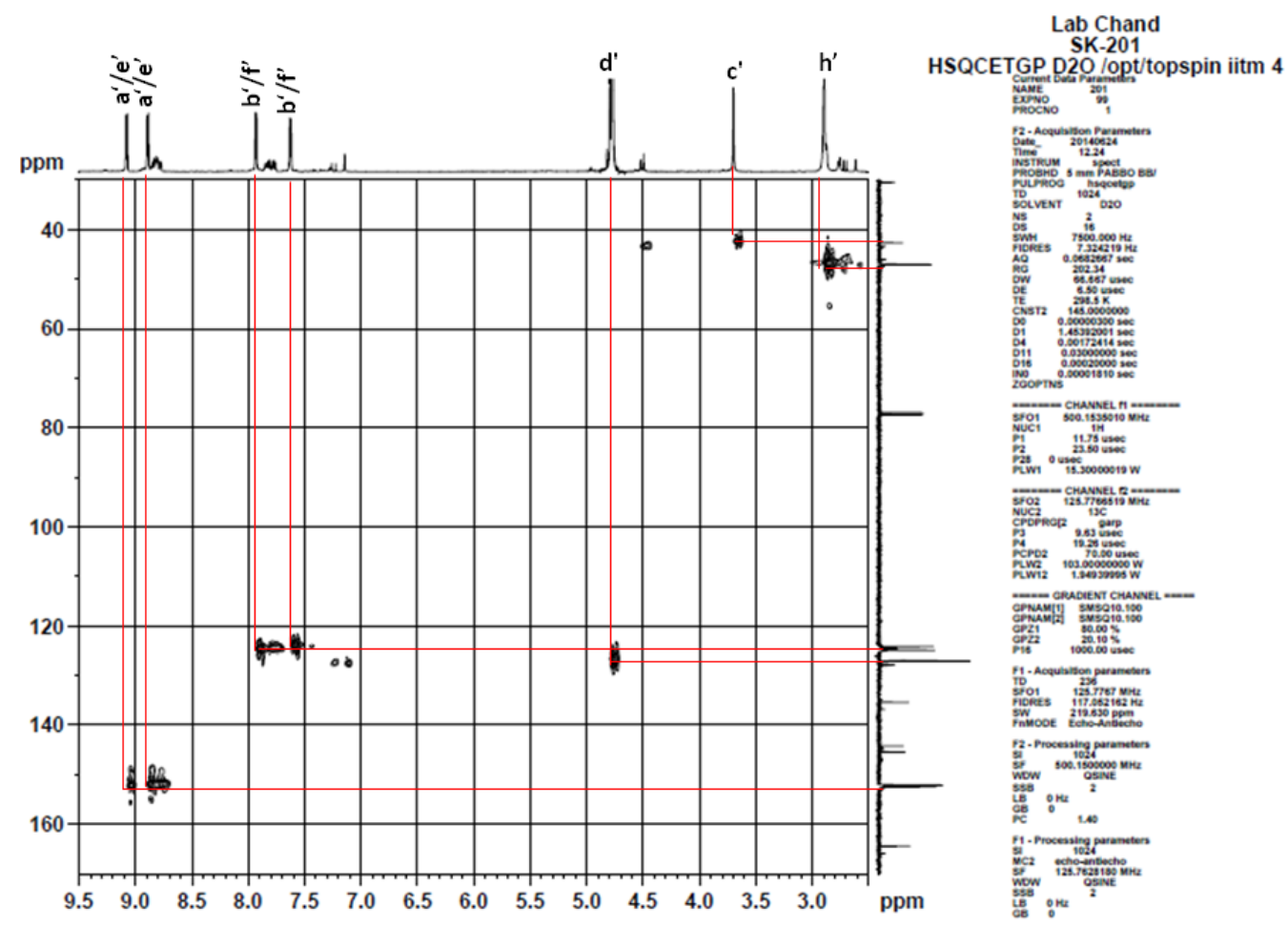

Figure S31. HSQC of 1a/2a in $\mathrm{D}_{2} \mathrm{O}$ at $50 \mathrm{mM}$. 


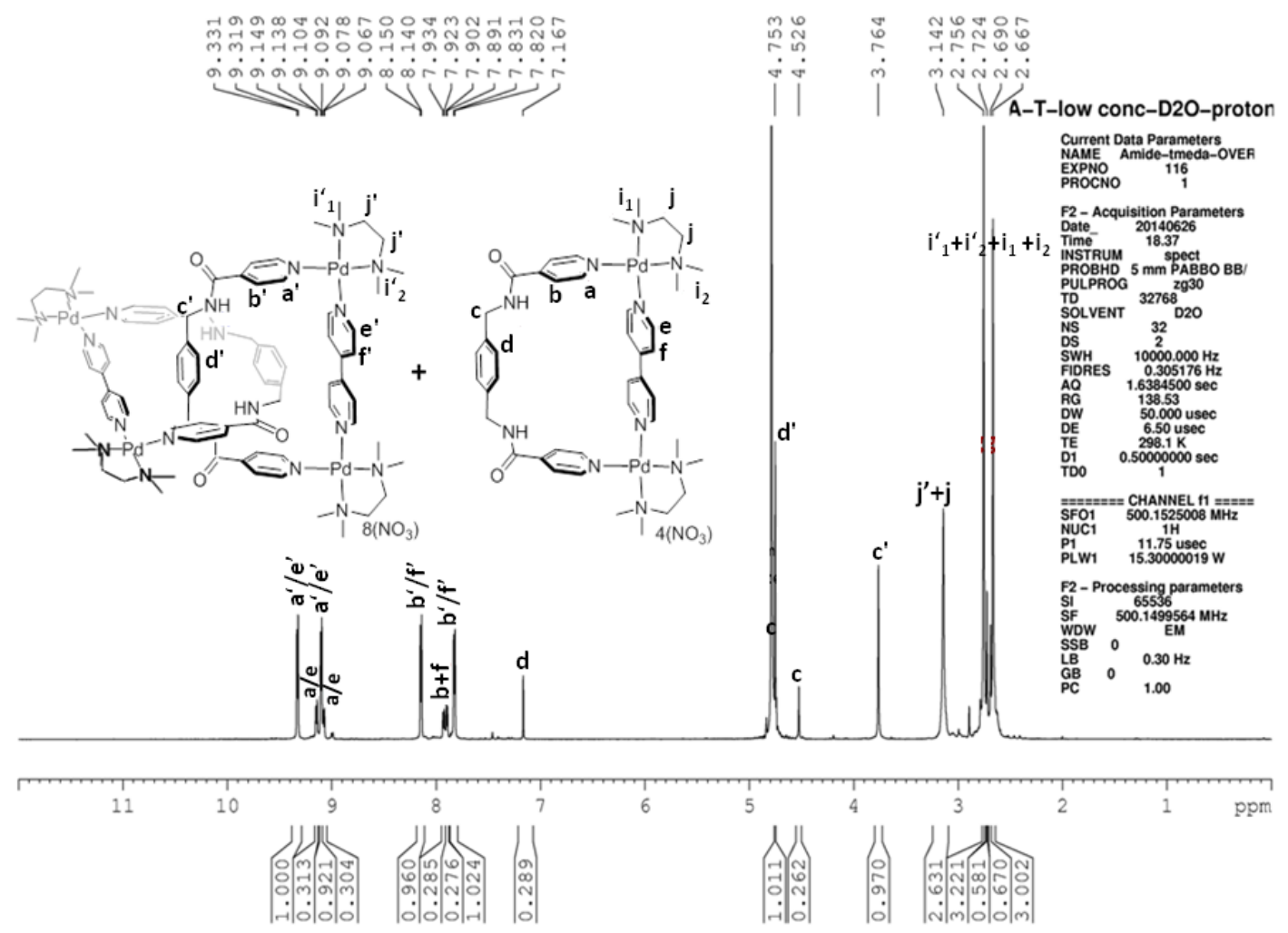

Figure S32. $500 \mathrm{MHz}{ }^{1} \mathrm{H}$ NMR spectrum of $\mathbf{1 b} / \mathbf{2 b}$ in $\mathrm{D}_{2} \mathrm{O}$ at $10 \mathrm{mM}$.
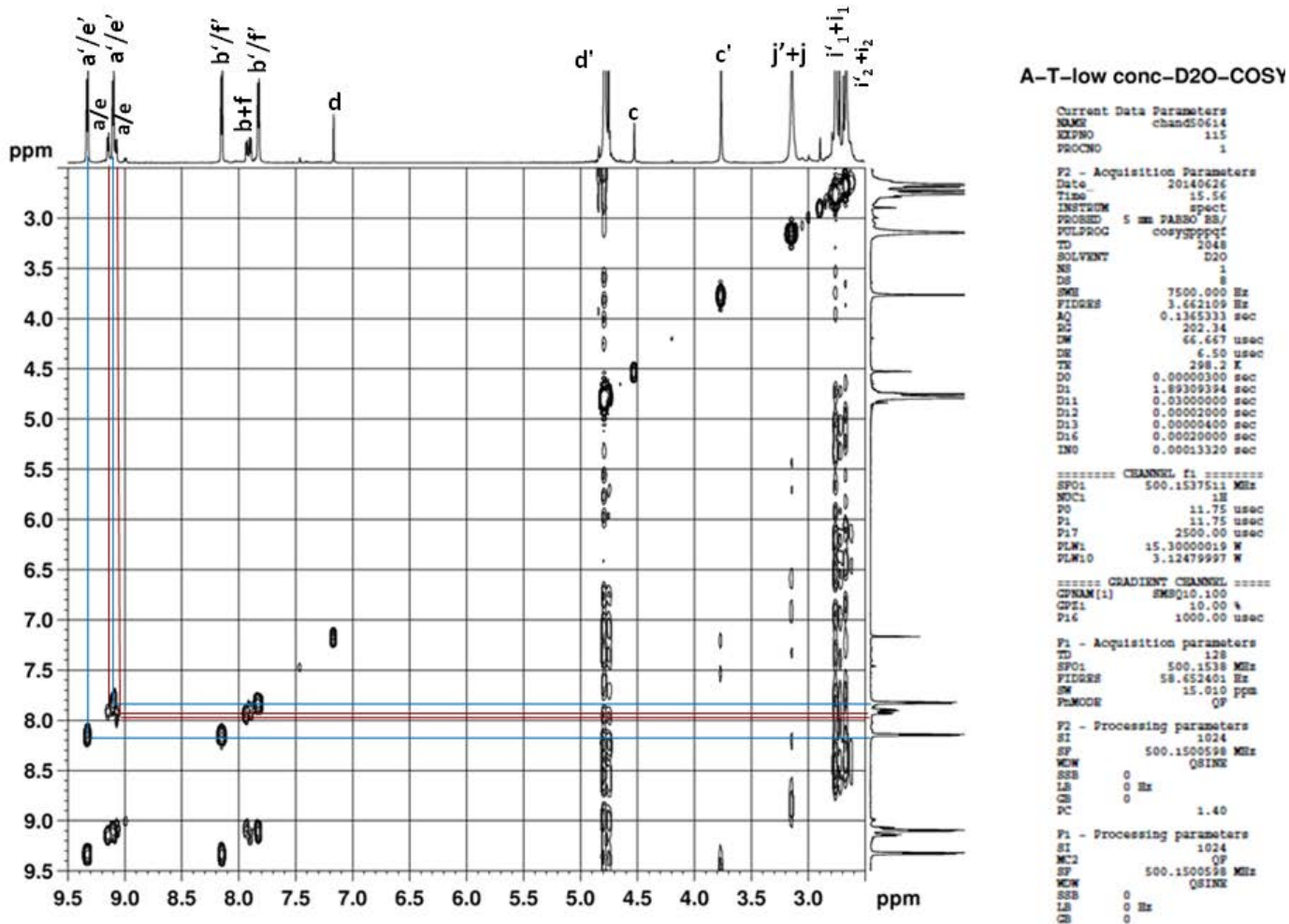

Figure S33. $\mathrm{H}-\mathrm{H}$ COSY of $\mathbf{1 b} / \mathbf{2} \mathbf{b}$ in $\mathrm{D}_{2} \mathrm{O}$ at $10 \mathrm{mM}$. 

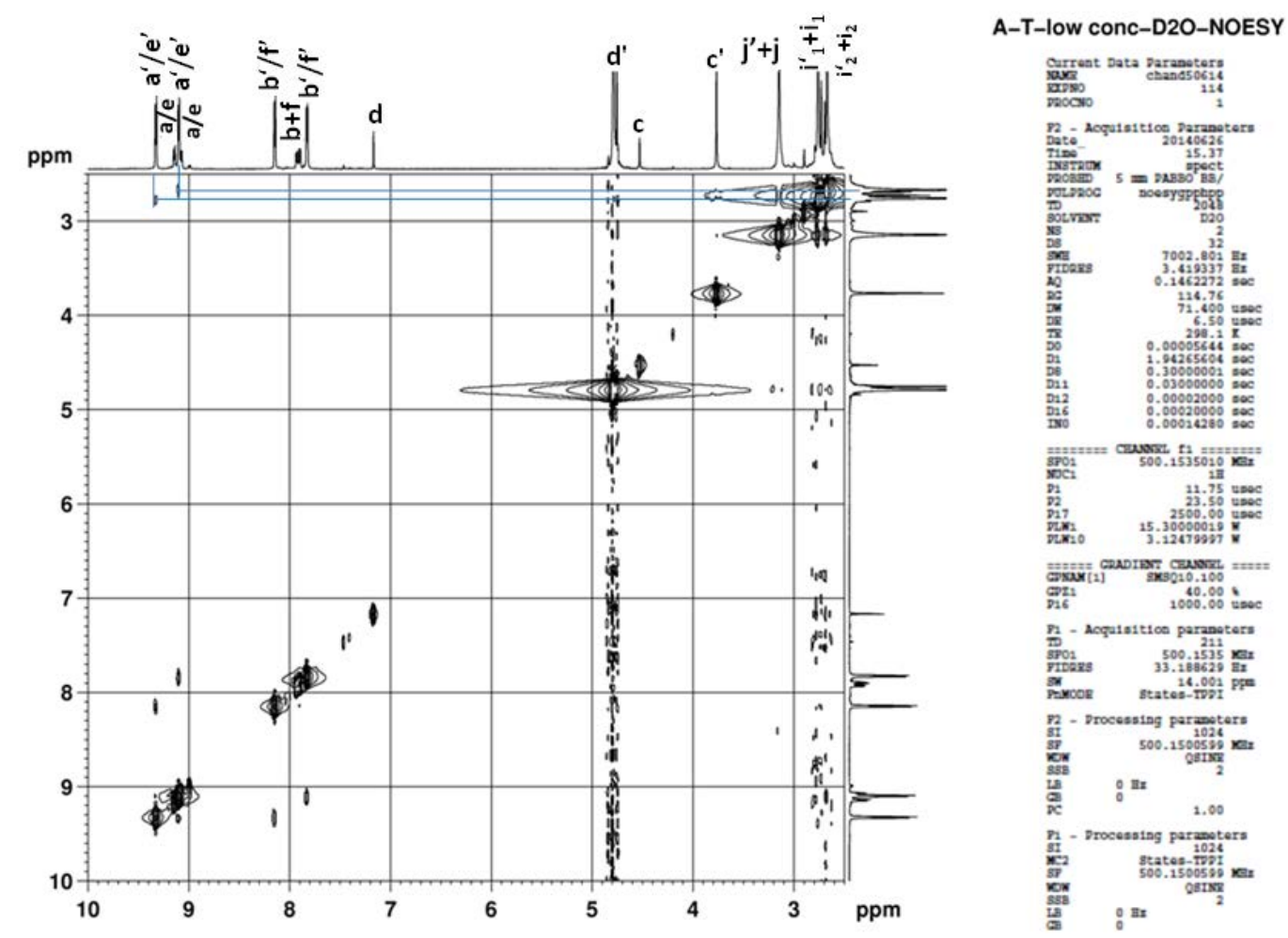

Figure S34. H-H NOESY of $\mathbf{1 b} / \mathbf{2} \mathbf{b}$ in $\mathrm{D}_{2} \mathrm{O}$ at $10 \mathrm{mM}$.

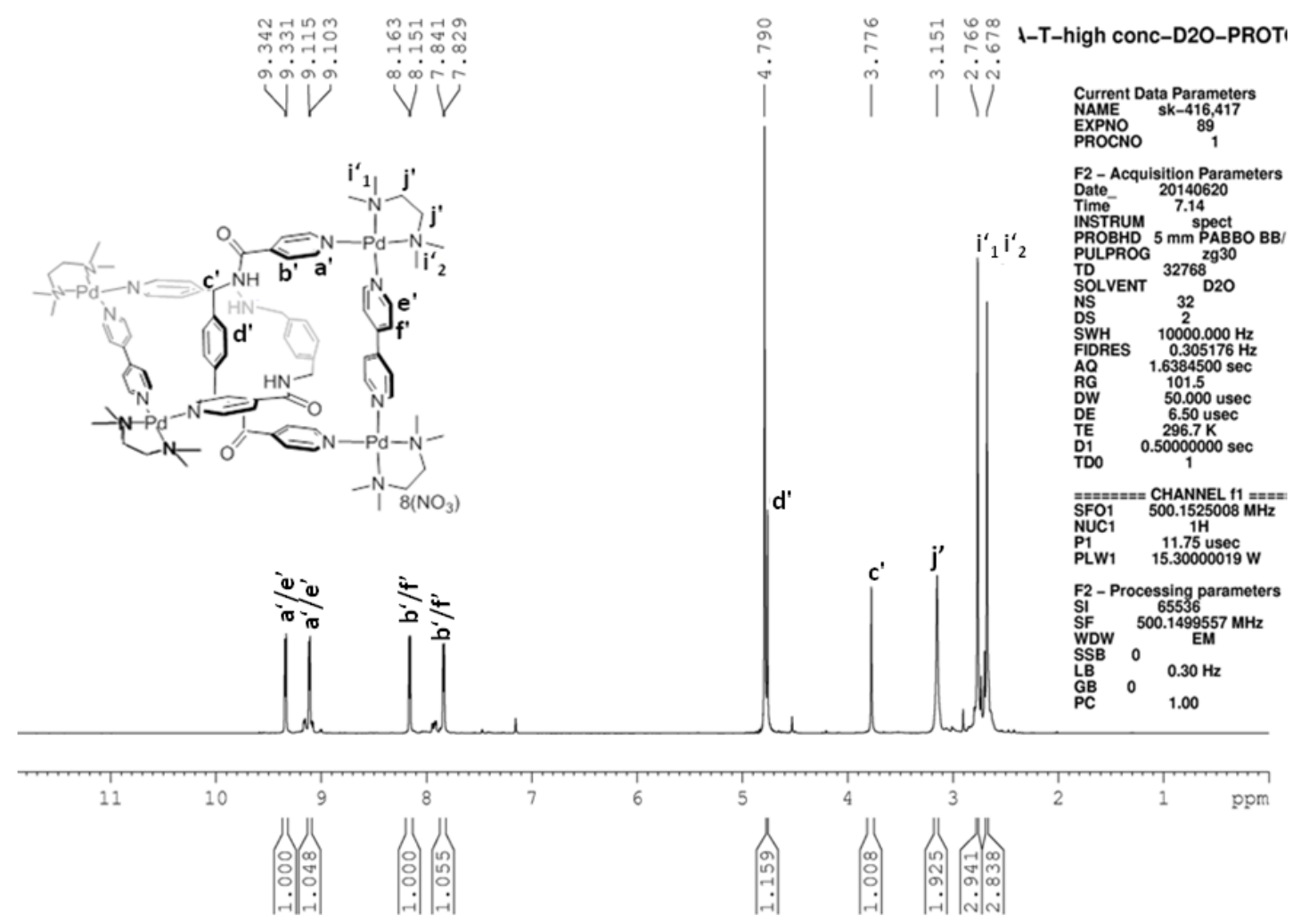

Figure S35. $500 \mathrm{MHz}{ }^{1} \mathrm{H}$ NMR spectrum of $\mathbf{1 b} / \mathbf{2} \mathbf{b}$ in $\mathrm{D}_{2} \mathrm{O}$ at $50 \mathrm{mM}$. 


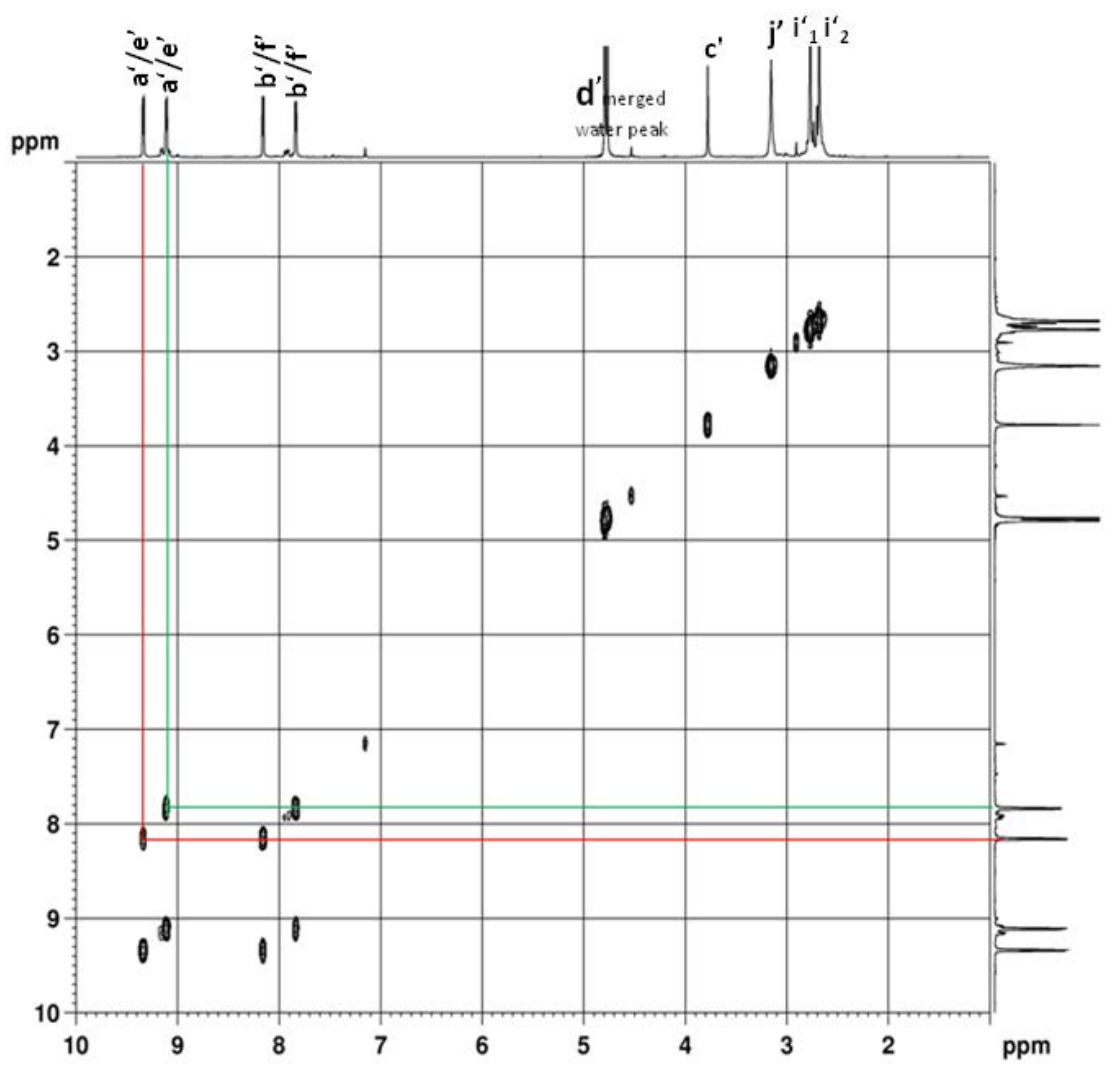

A-T-high conc-D2O-COSY

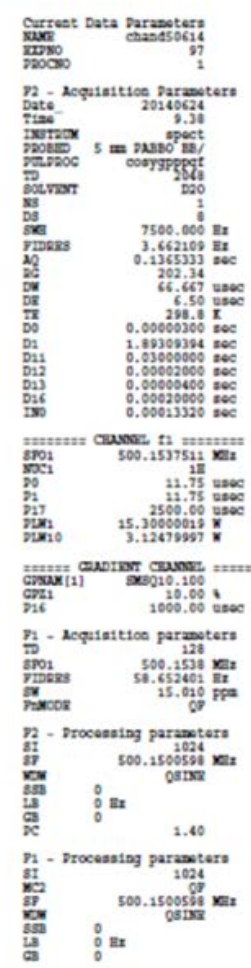

Figure S36. $\mathrm{H}-\mathrm{H}$ COSY of $\mathbf{1 b} / \mathbf{2} \mathbf{b}$ in $\mathrm{D}_{2} \mathrm{O}$ at $50 \mathrm{mM}$.

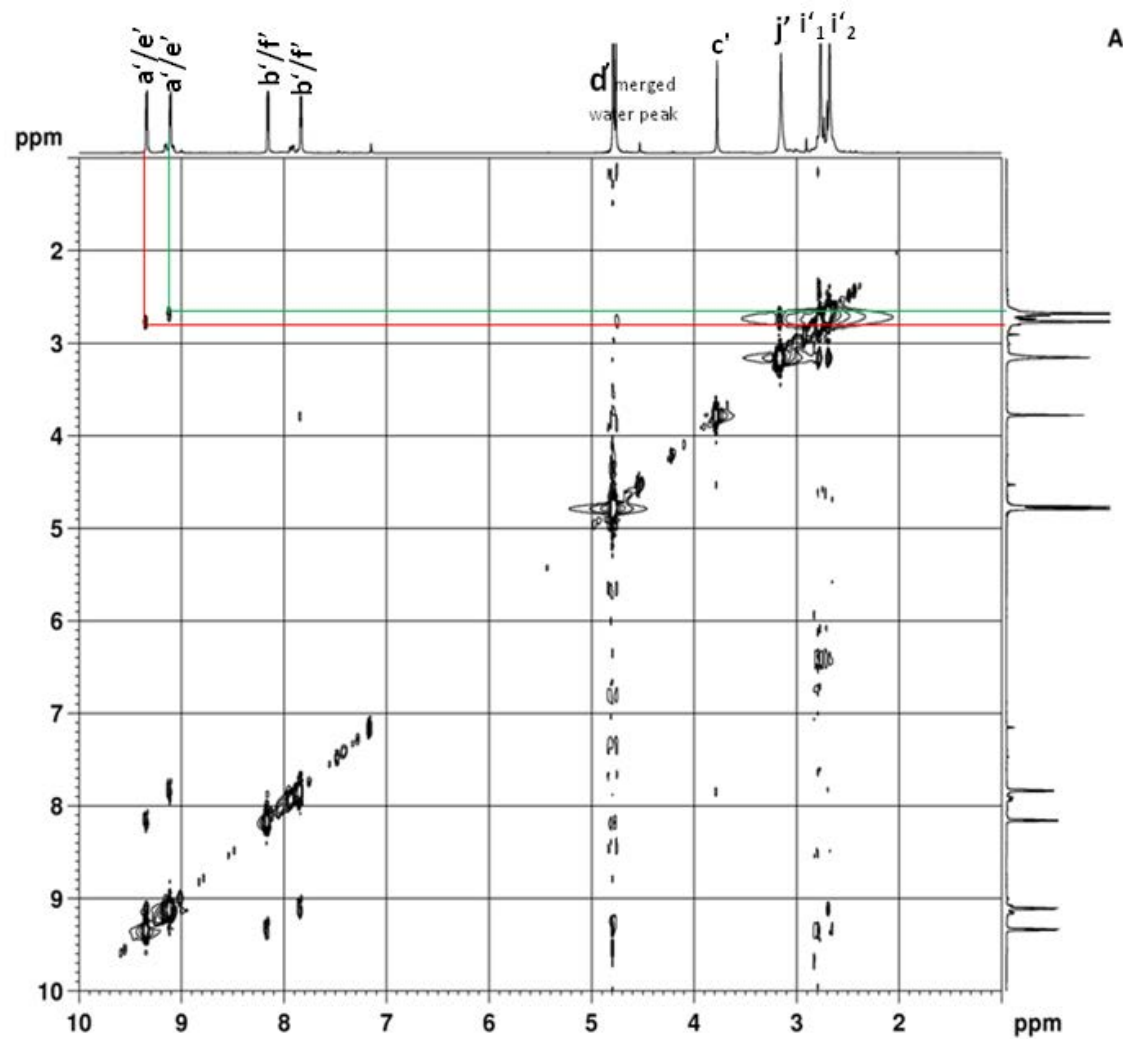

A-T-high conc-D2O-NOES'

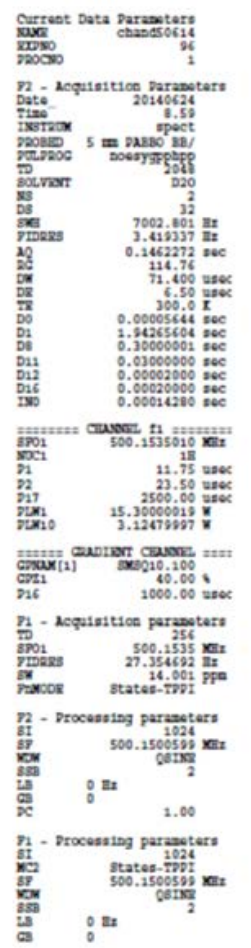

Figure S37. H-H NOESY of $\mathbf{1 b} / \mathbf{2} \mathbf{b}$ in $\mathrm{D}_{2} \mathrm{O}$ at $50 \mathrm{mM}$. 


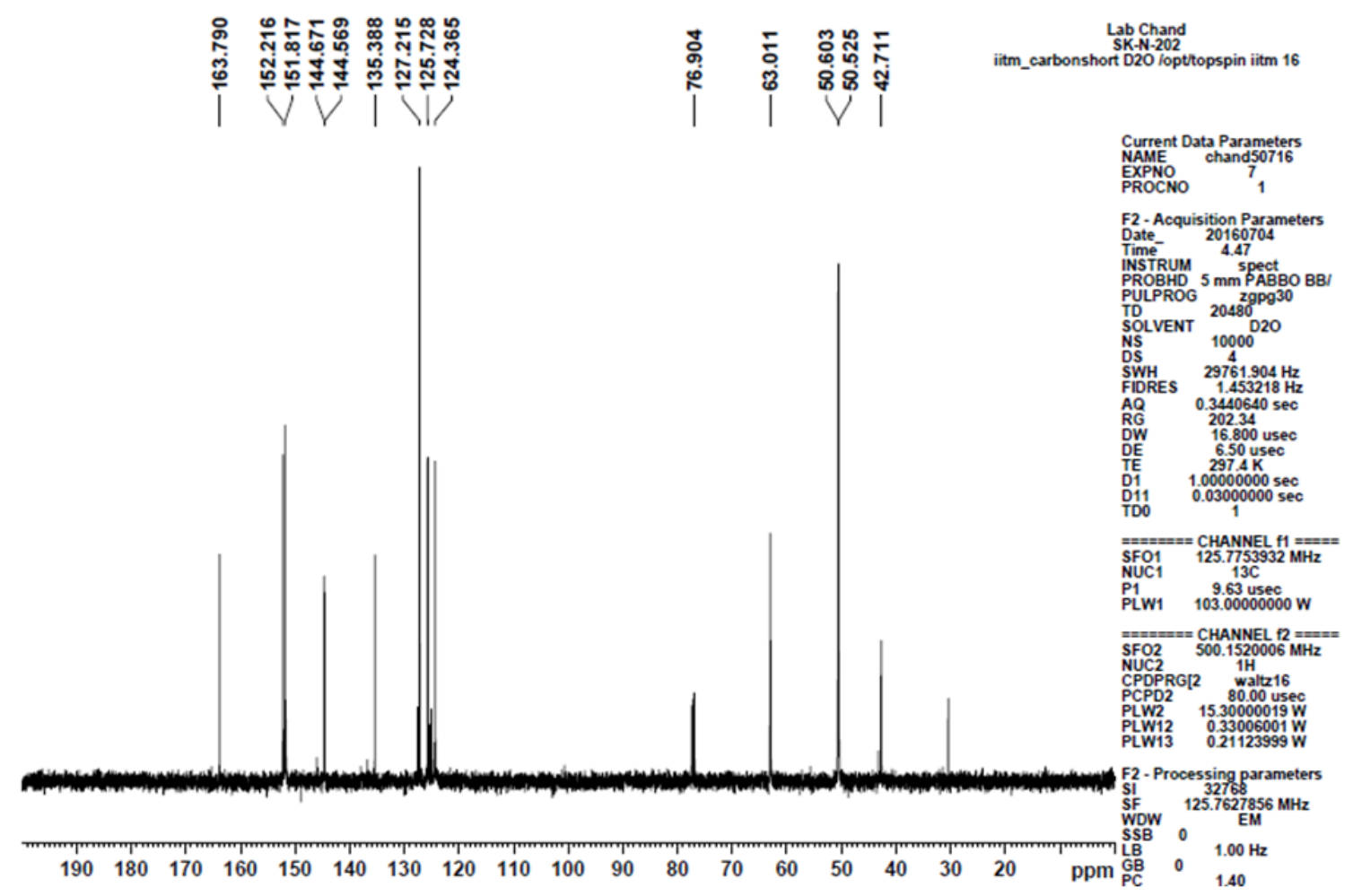

Figure S38. ${ }^{13} \mathrm{C}$ NMR spectrum of $\mathbf{1 b} / \mathbf{2 b}$ in $\mathrm{D}_{2} \mathrm{O}$ at $50 \mathrm{mM}$.

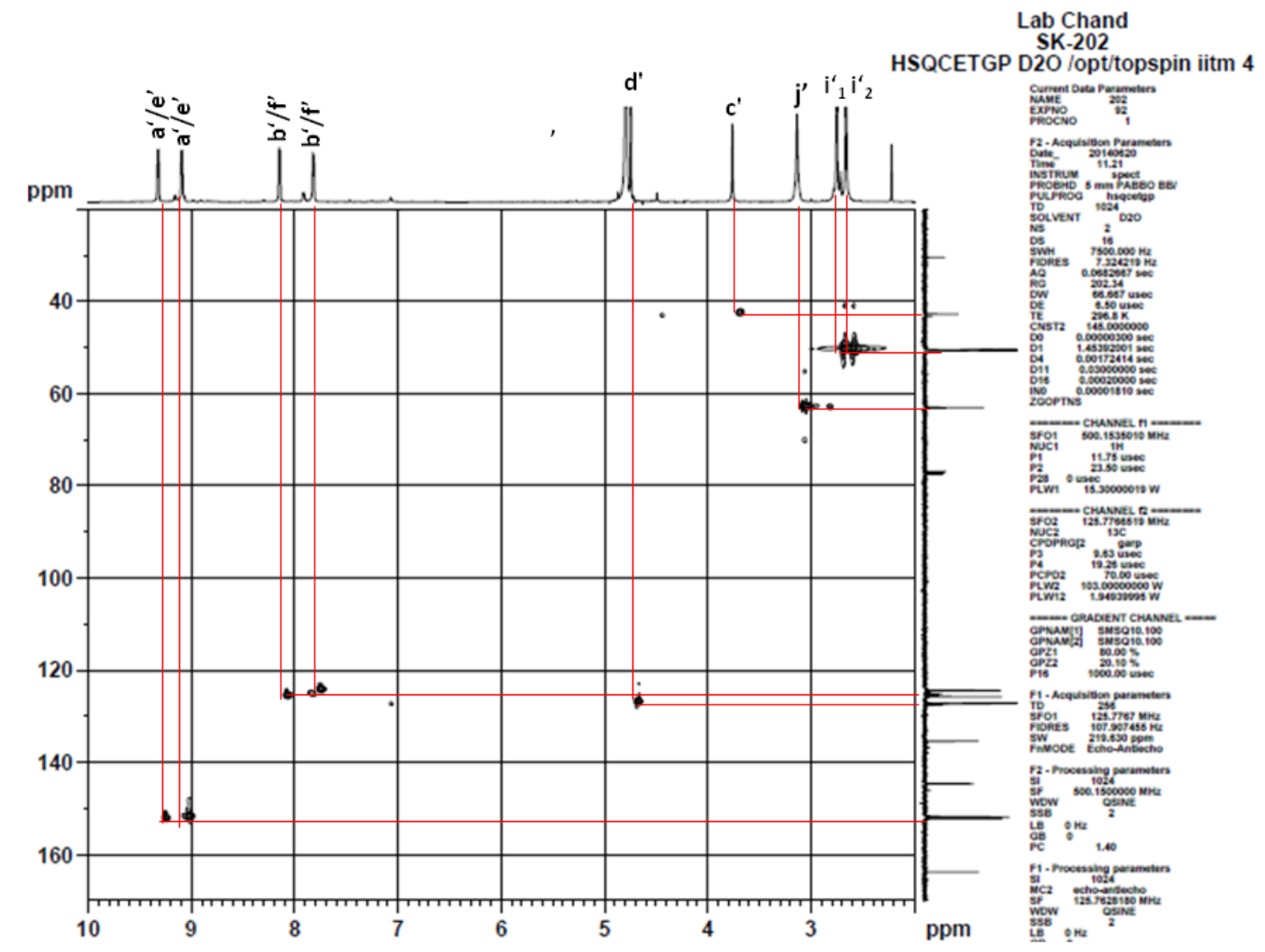

Figure S39. HSQC of $\mathbf{1 b} / \mathbf{2 b}$ in $\mathrm{D}_{2} \mathrm{O}$ at $50 \mathrm{mM}$. 


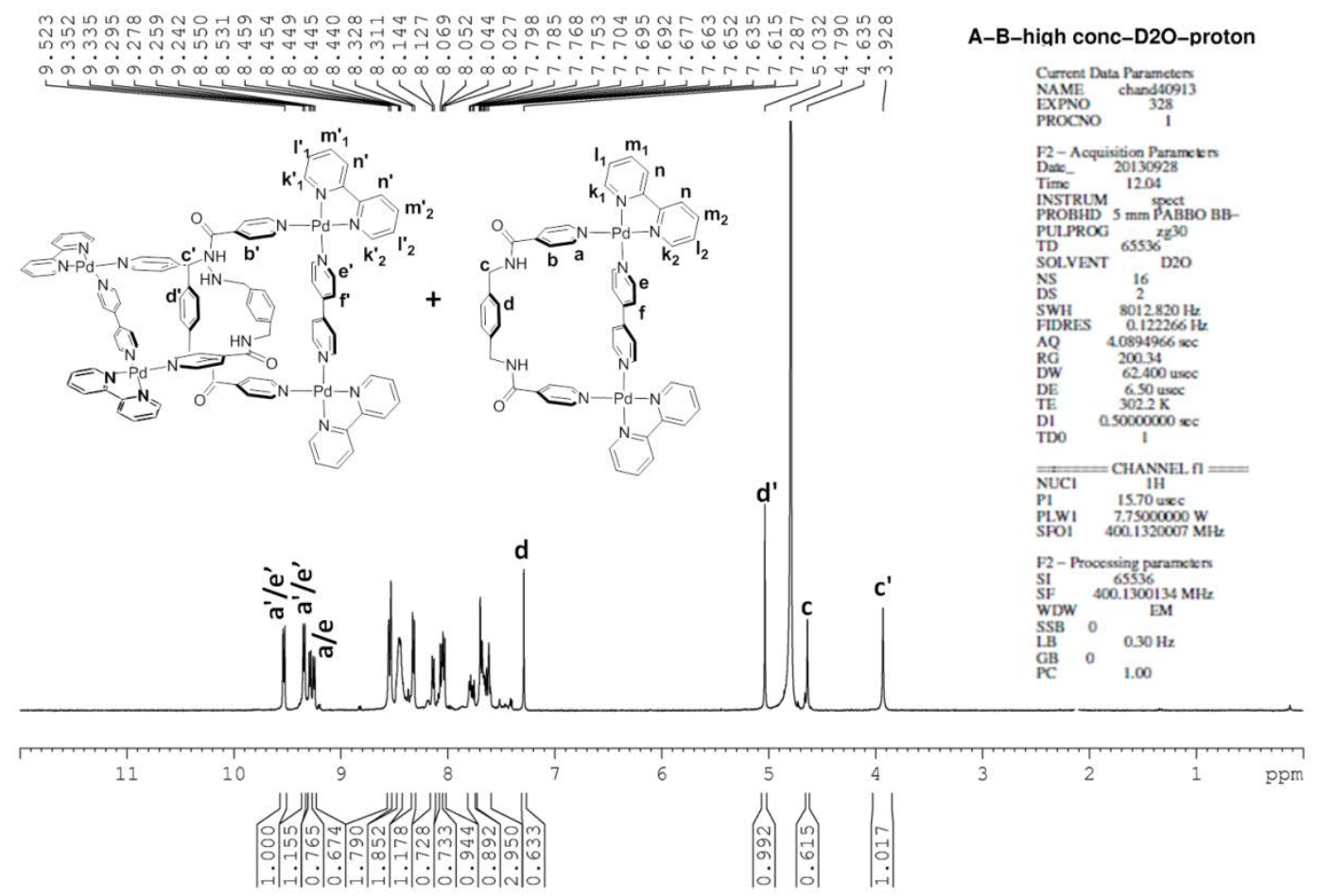

Figure S40. $400 \mathrm{MHz}{ }^{1} \mathrm{H}$ NMR spectrum of $\mathbf{1 c} / 2 \mathrm{c}$ in $\mathrm{D}_{2} \mathrm{O}$ at $16 \mathrm{mM}$.

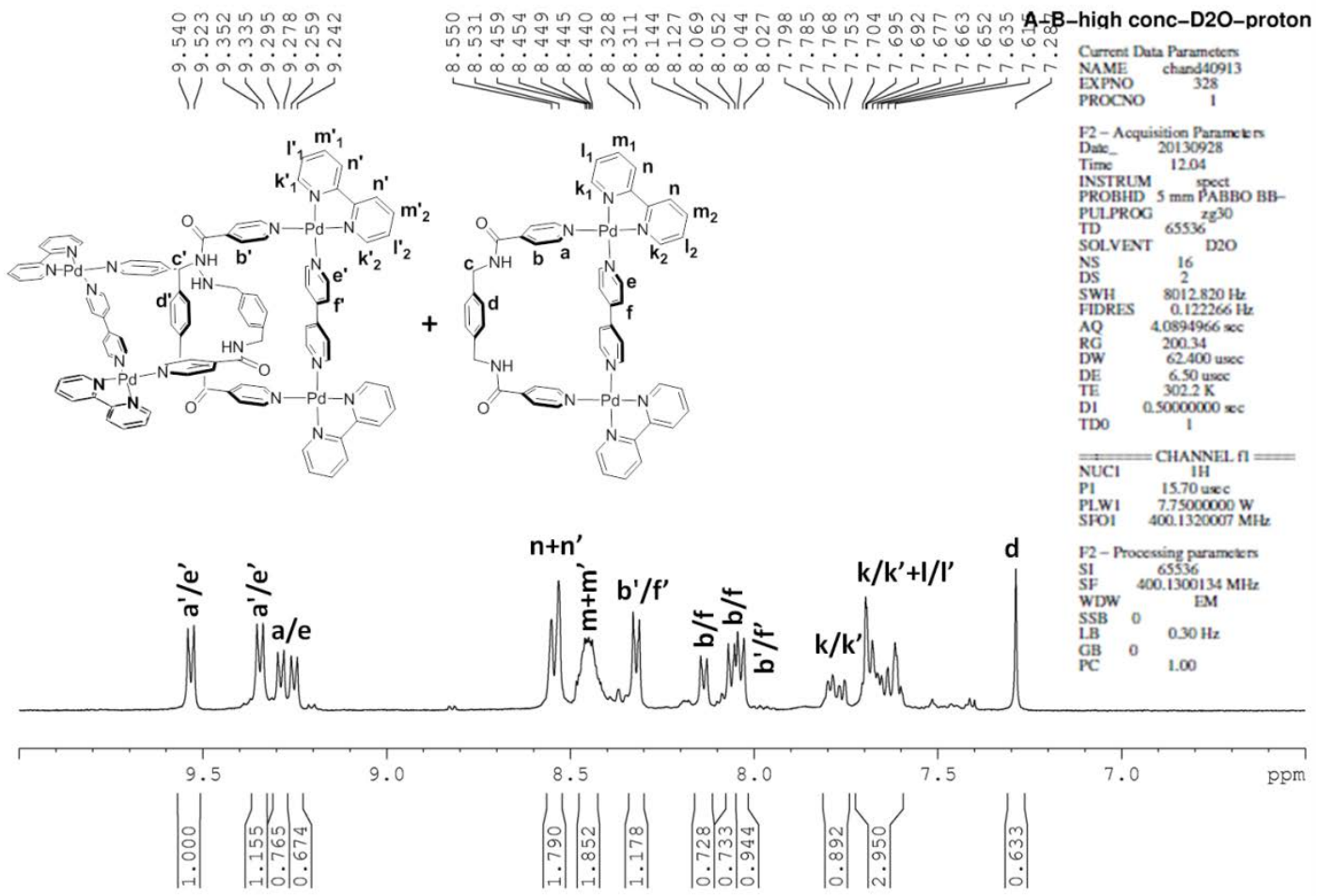

Figure S41. $400 \mathrm{MHz}{ }^{1} \mathrm{H}$ NMR spectrum (partial) of $\mathbf{1 c} / \mathbf{2 c}$ in $\mathrm{D}_{2} \mathrm{O}$ at $16 \mathrm{mM}$. 


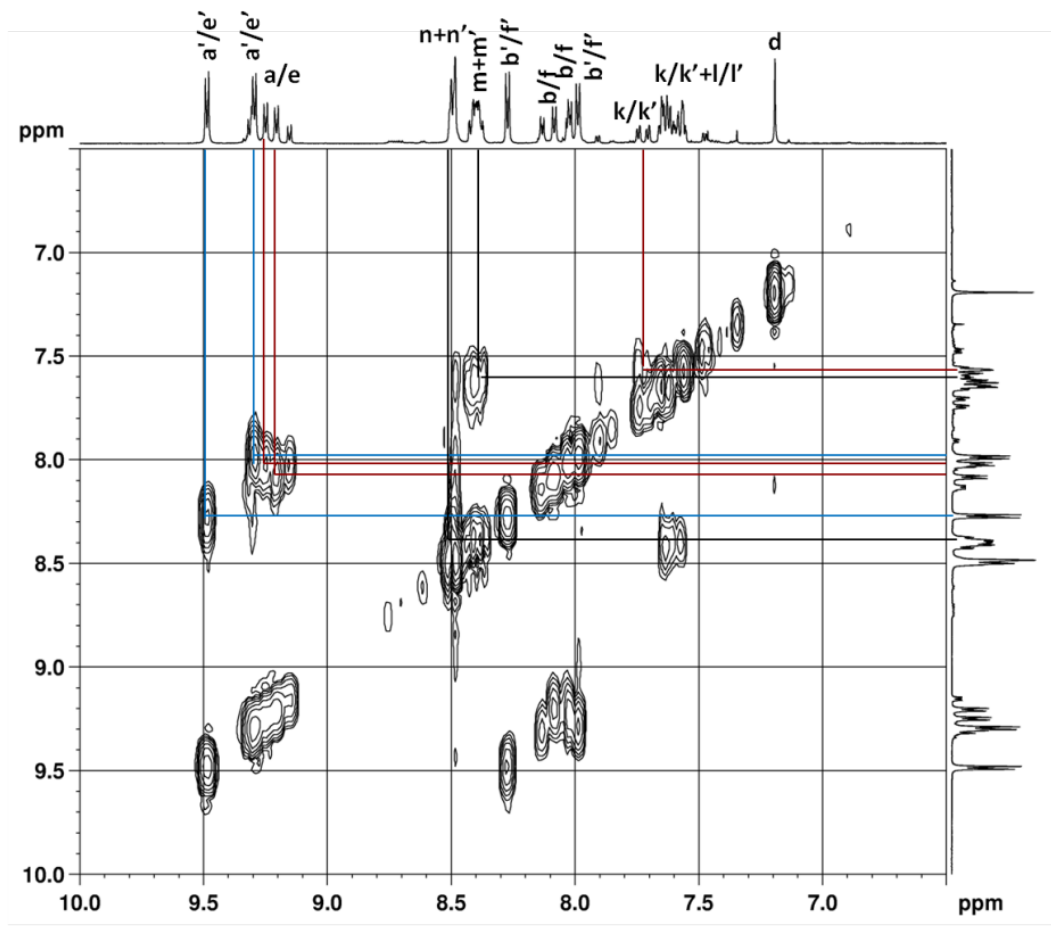

A-B-high conc-D2O-COSY

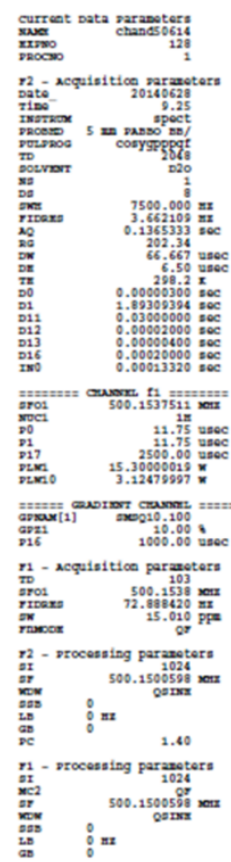

Figure S42. H-H COSY of $1 \mathrm{c} / 2 \mathrm{c}$ in $\mathrm{D}_{2} \mathrm{O}$.

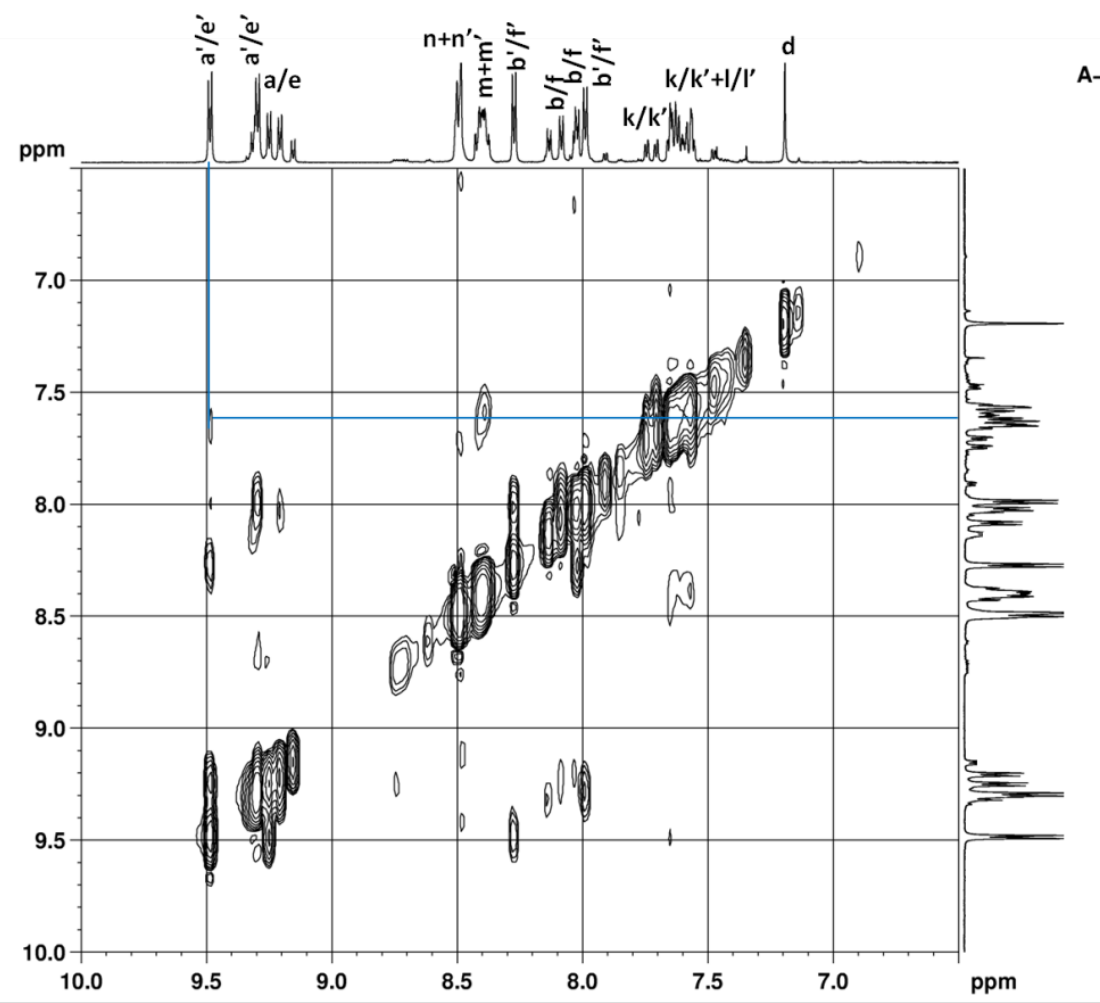

A-B-high conc-D2O-NOESY

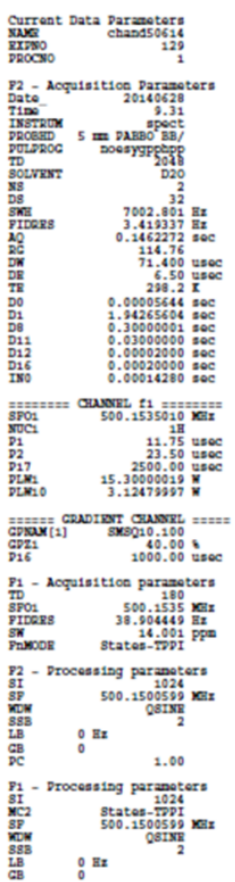

Figure S43. H-H NOESY of $\mathbf{1 c} / \mathbf{2} \mathbf{c}$ in $\mathrm{D}_{2} \mathrm{O}$. 


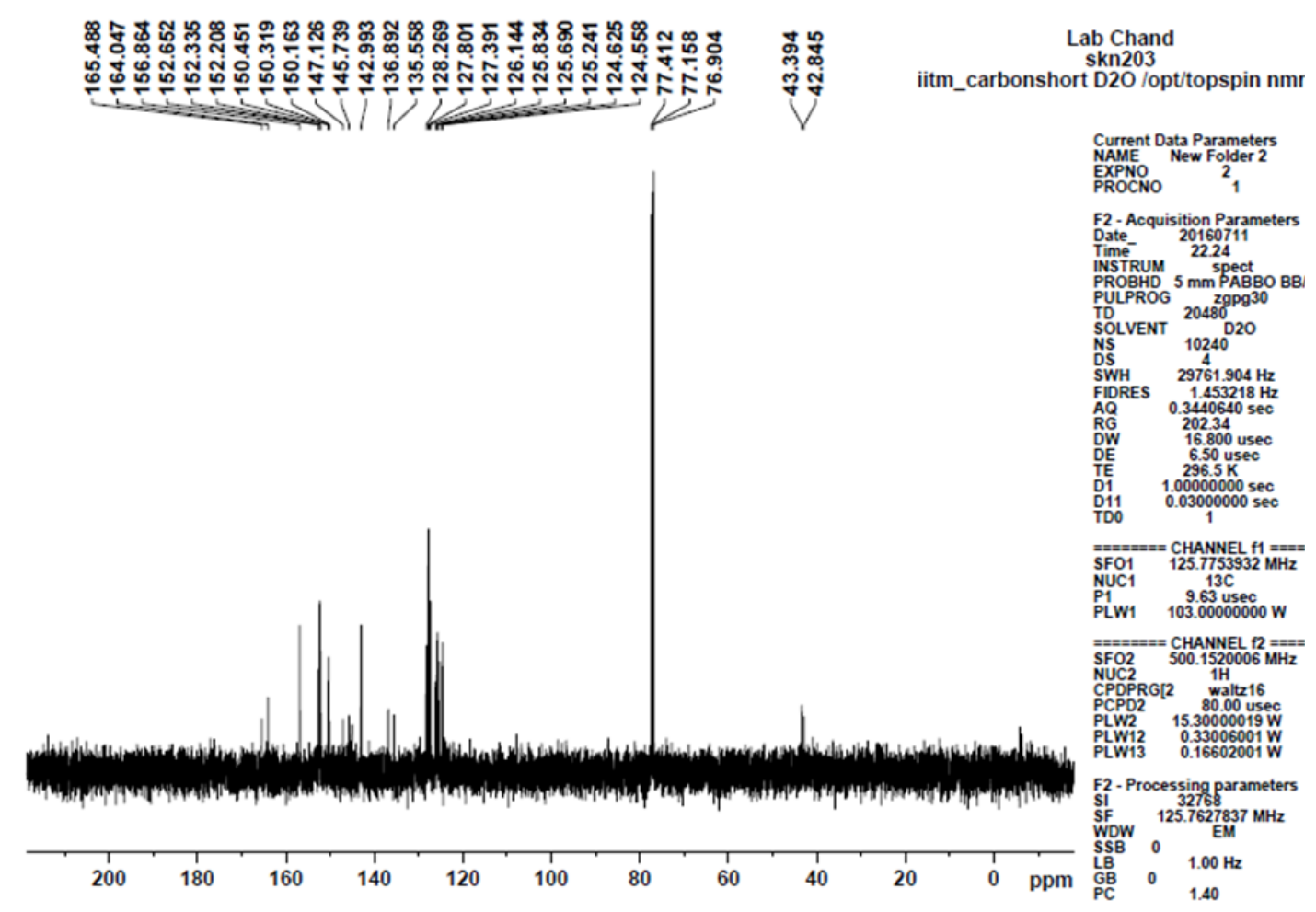

Figure S44. ${ }^{13} \mathrm{C}$ NMR spectrum of $1 \mathrm{c} / \mathbf{2 c}$ in $\mathrm{D}_{2} \mathrm{O}$ at $16 \mathrm{mM}$.

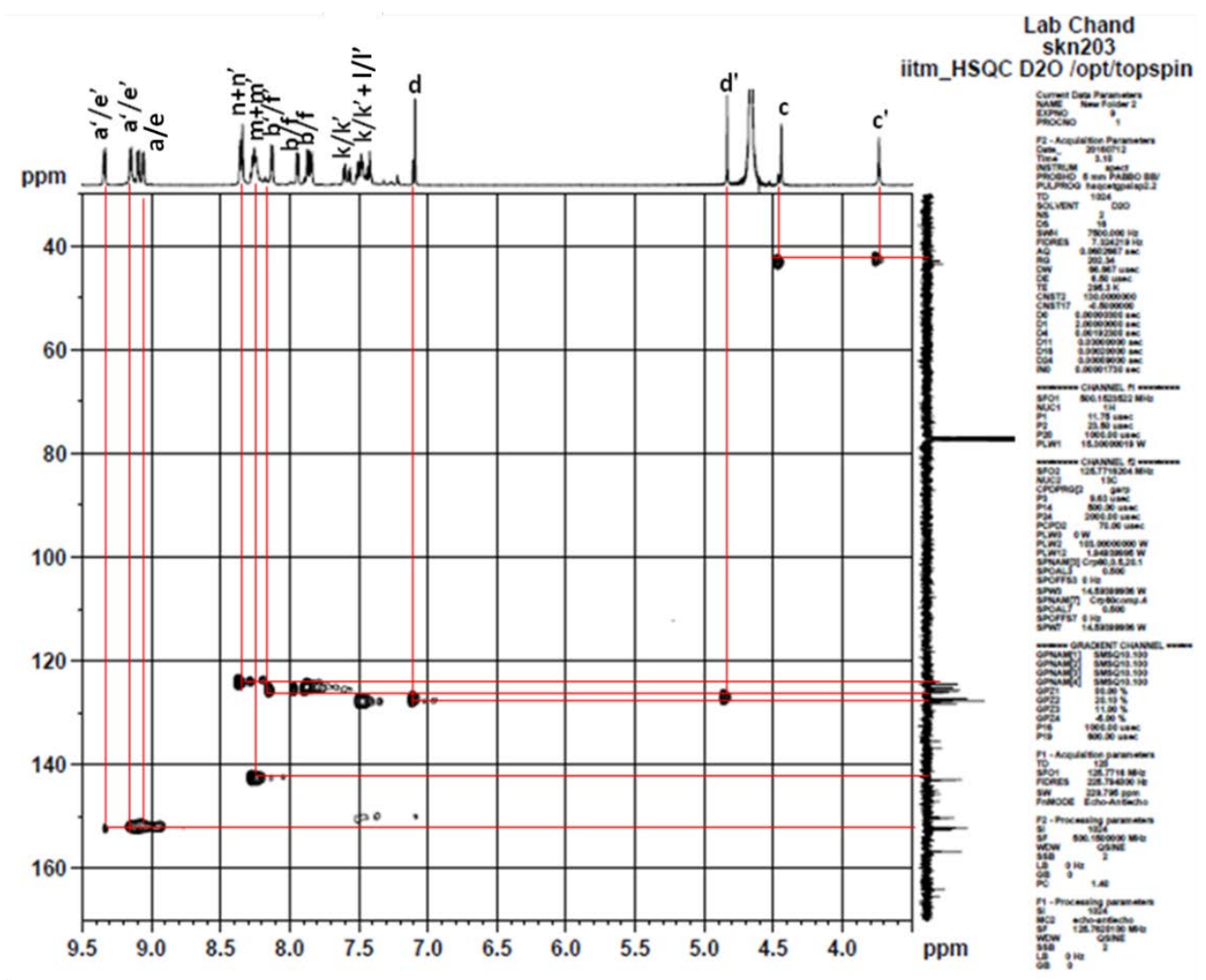

Figure S45. HSQC of $\mathbf{1 c} / \mathbf{2 c}$ in $\mathrm{D}_{2} \mathrm{O}$ at $10 \mathrm{mM}$. 


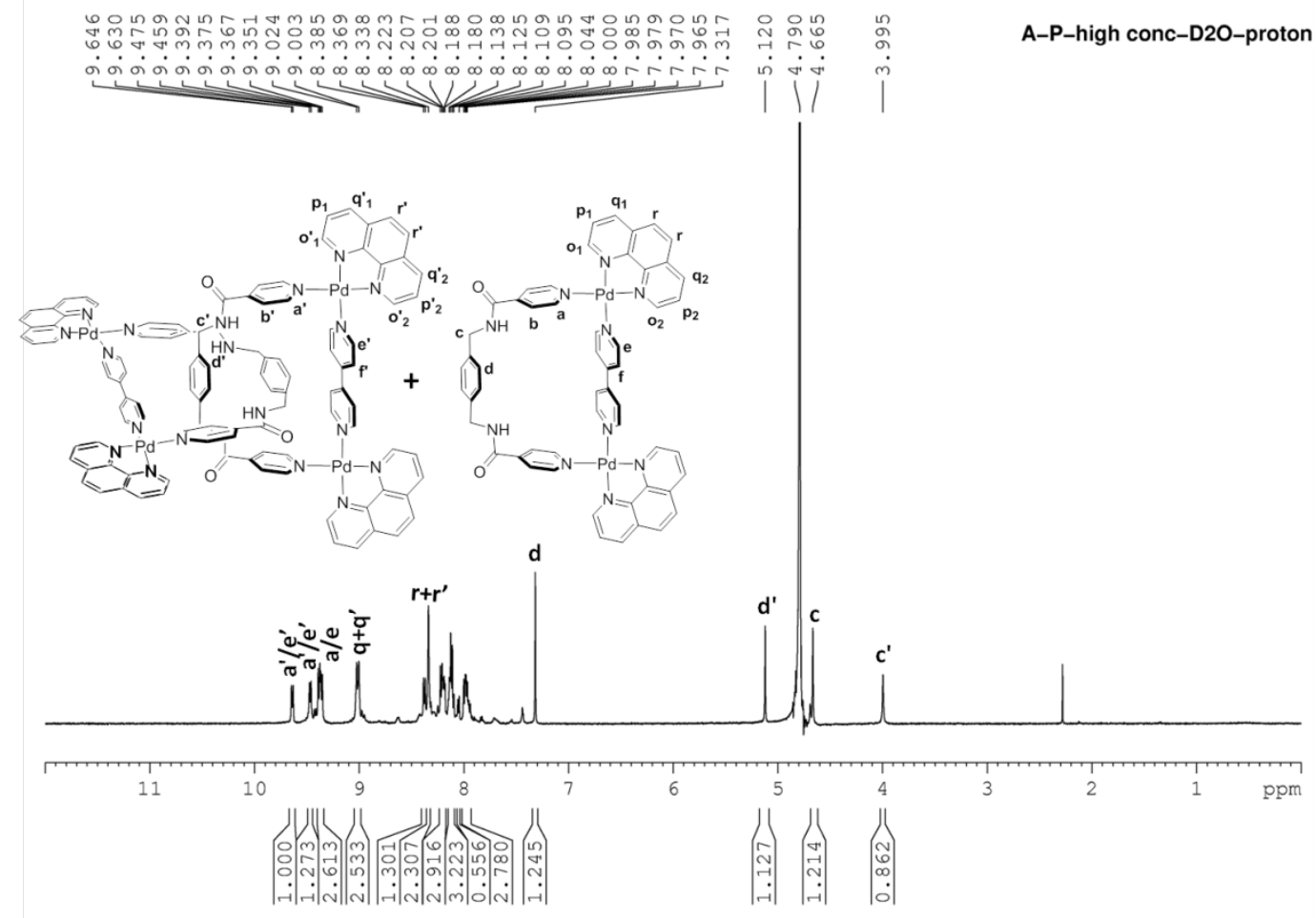

Figure S46. $400 \mathrm{MHz}{ }^{1} \mathrm{H}$ NMR spectrum of $\mathbf{1 d} / \mathbf{2 d}$ in $\mathrm{D}_{2} \mathrm{O}$ at $10 \mathrm{mM}$.

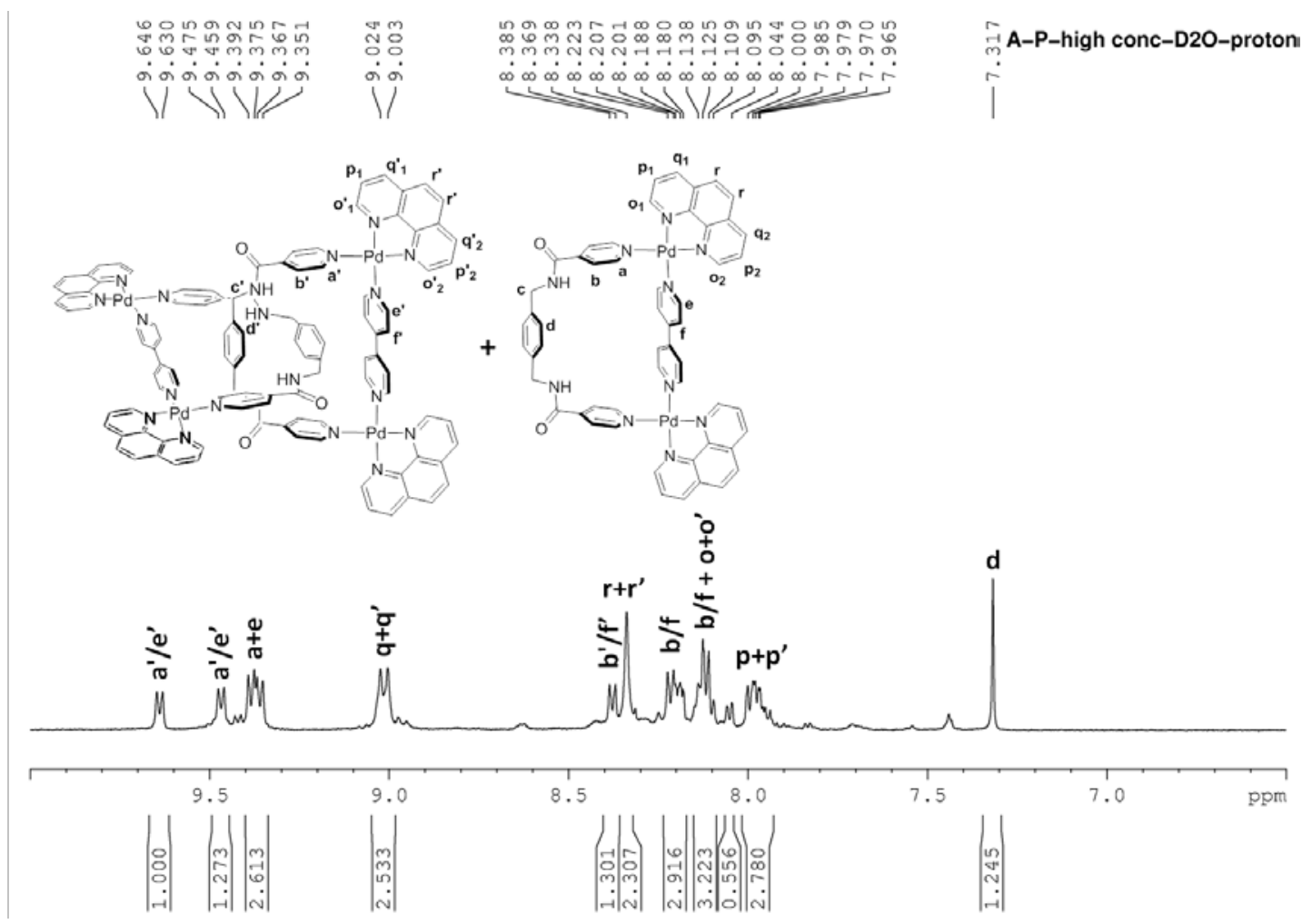

Figure S47. $400 \mathrm{MHz}{ }^{1} \mathrm{H}$ NMR spectrum (partial) of $\mathbf{1 d} / \mathbf{2 d}$ in $\mathrm{D}_{2} \mathrm{O}$ at $10 \mathrm{mM}$. 

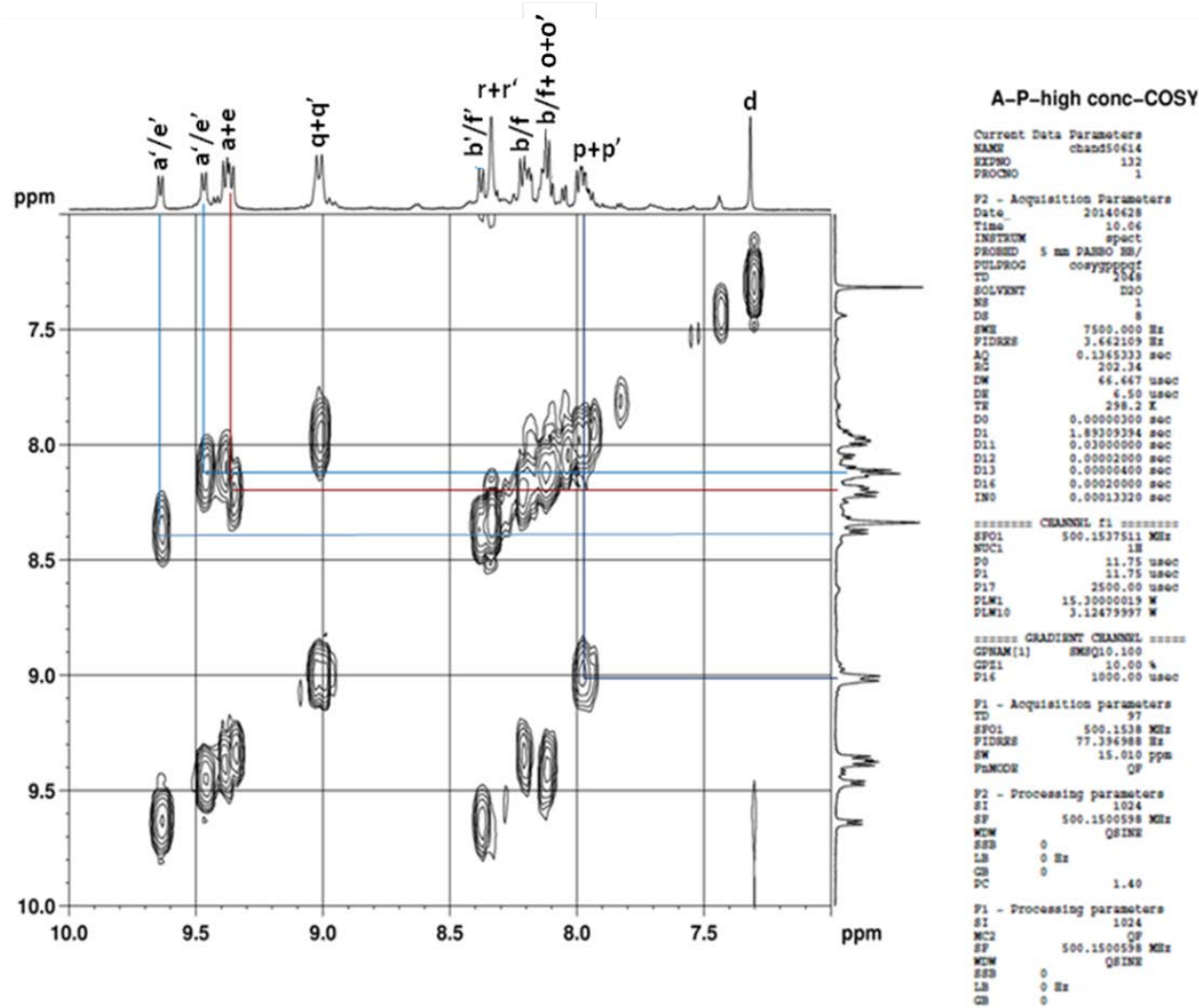

Figure S48. H-H COSY of $\mathbf{1 d} / \mathbf{2 d}$ in $\mathrm{D}_{2} \mathrm{O}$ at $10 \mathrm{mM}$.

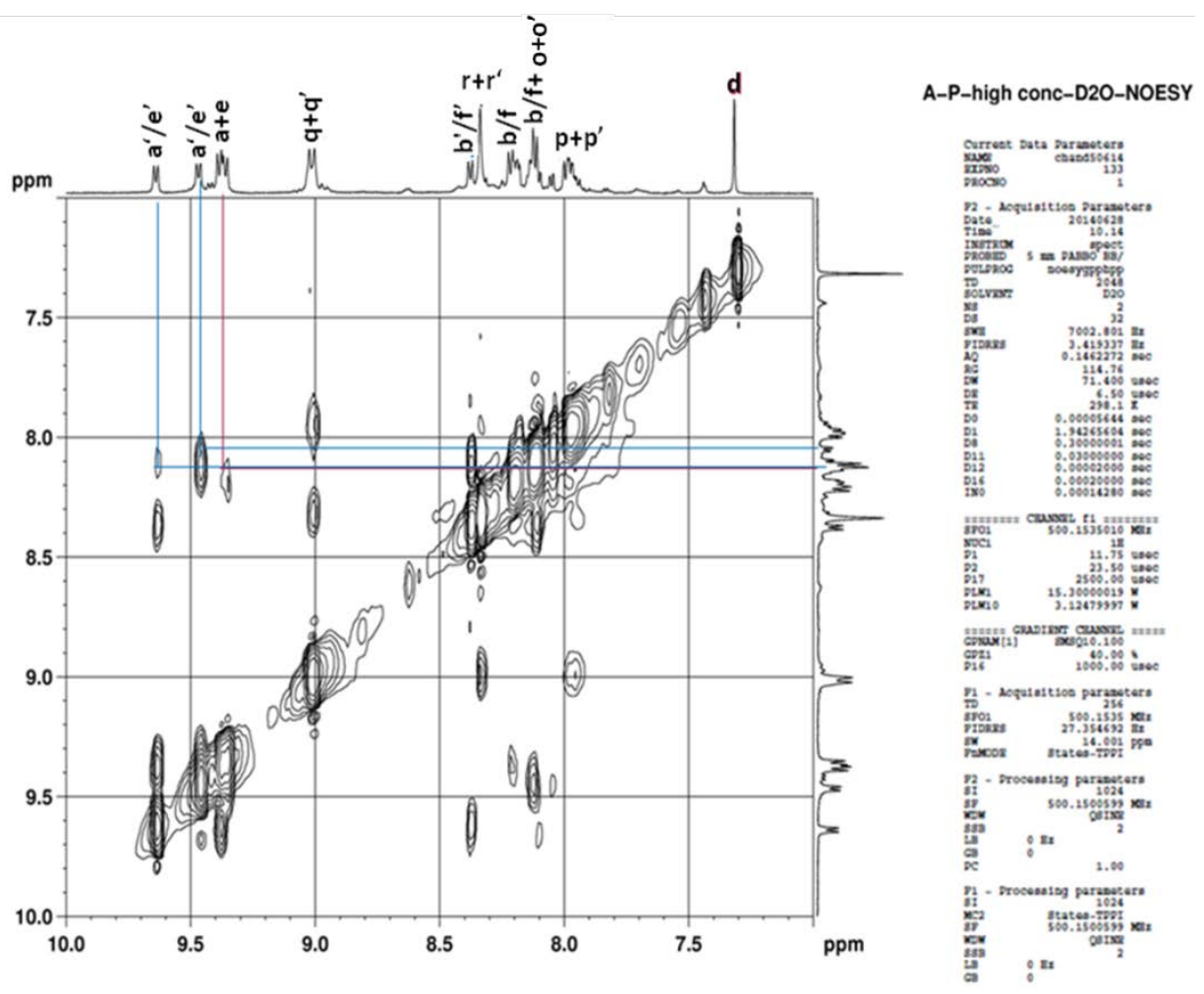

Figure S49. H-H NOESY of $\mathbf{1 d} / \mathbf{2 d}$ in $\mathrm{D}_{2} \mathrm{O}$ at $10 \mathrm{mM}$. 


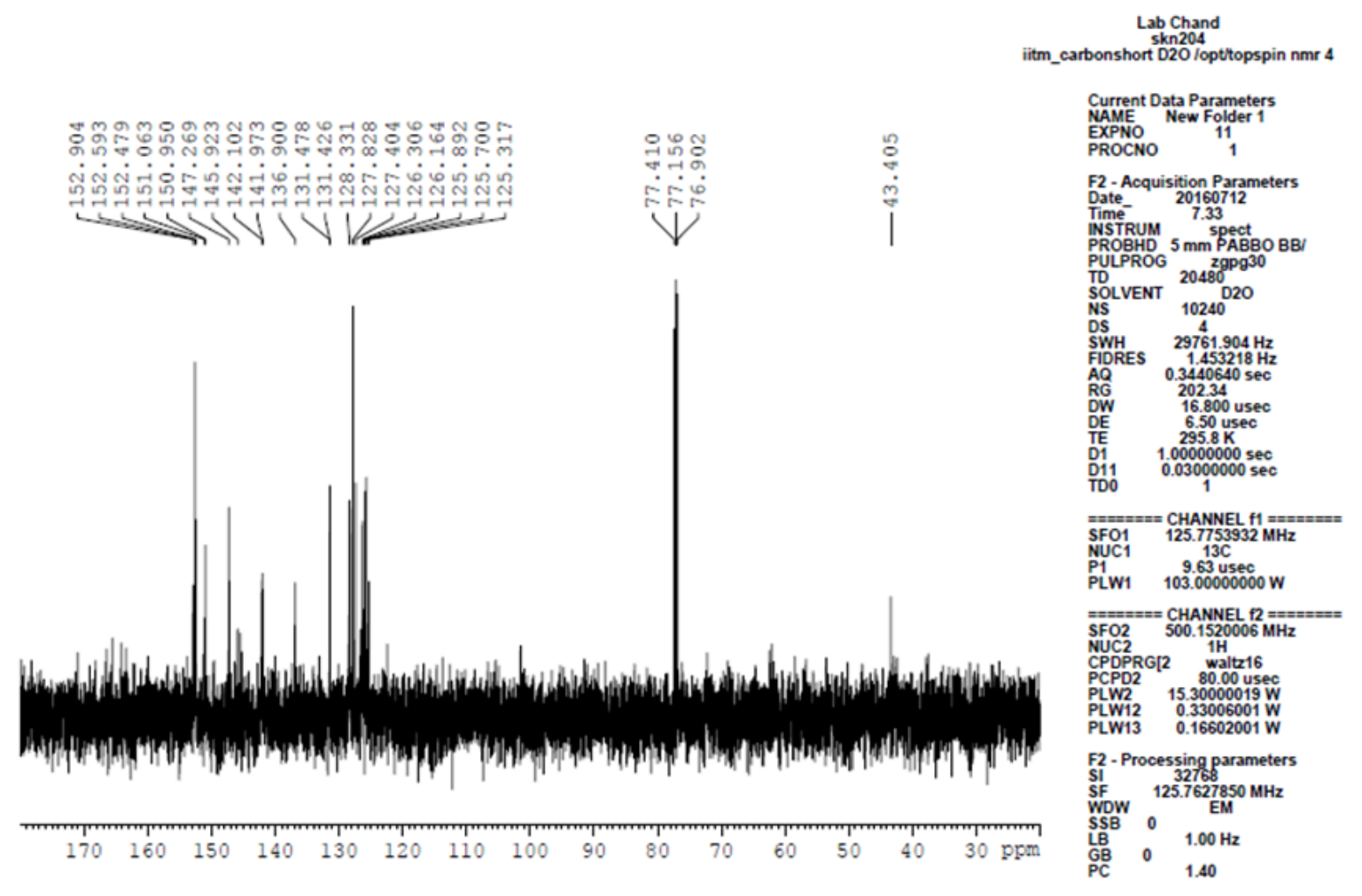

Figure S50. ${ }^{13} \mathrm{C}$ NMR spectrum of $\mathbf{1 d} / \mathbf{2 d}$ in $\mathrm{D}_{2} \mathrm{O}$ at $10 \mathrm{mM}$.

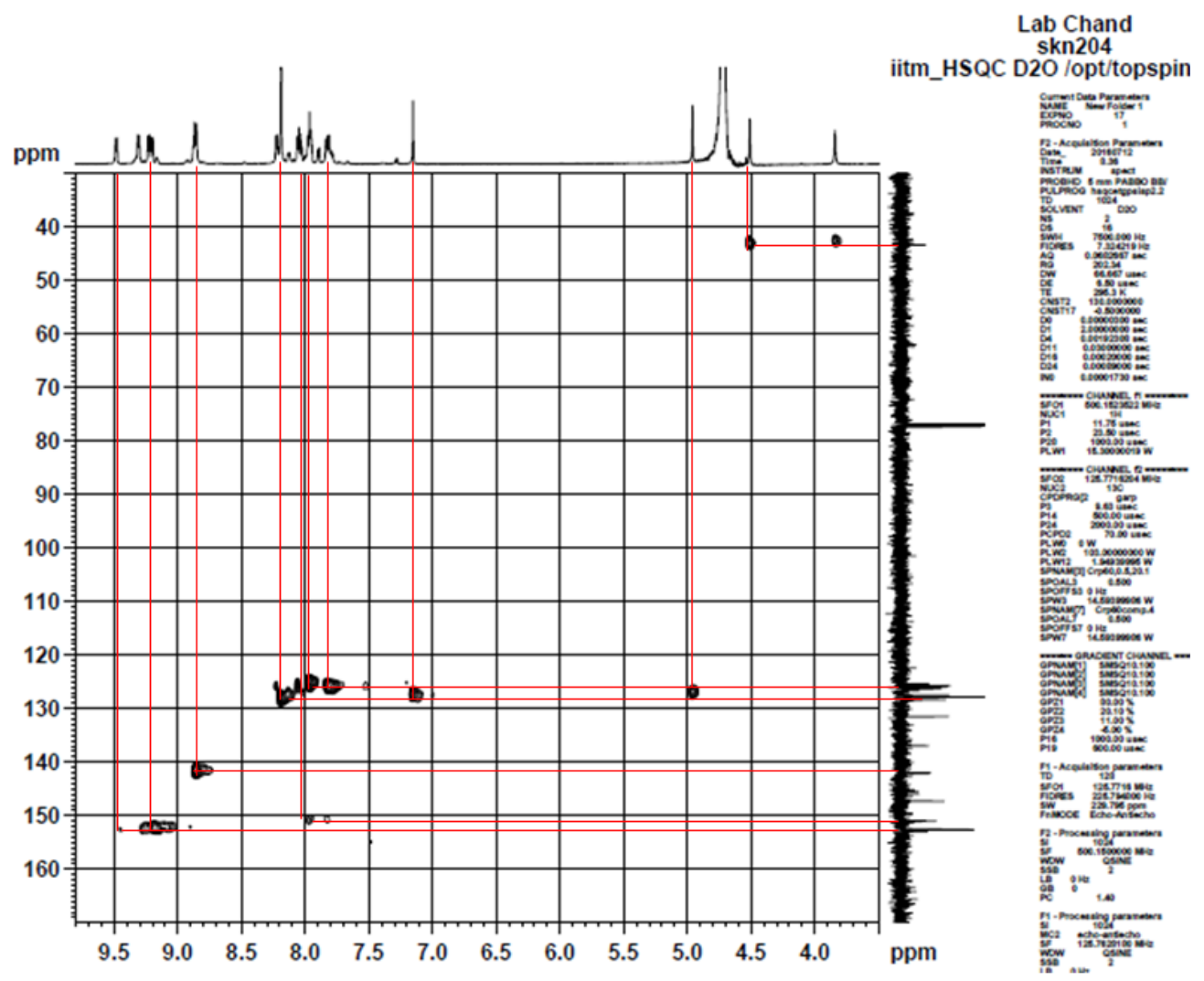

Figure S51. HSQC of $\mathbf{1 d} / \mathbf{2 d}$ in $\mathrm{D}_{2} \mathrm{O}$ at $10 \mathrm{mM}$. 
Table S1. ${ }^{1} \mathrm{H}$ NMR chemical shifts (ppm) for phenylene and methylene protons of the macrocycles 1a-d and [2]catenanes 2a-d in $\mathrm{D}_{2} \mathrm{O}$.

\begin{tabular}{|l|l|l|l|l|l|l|}
\hline Complexes & $\begin{array}{l}\text { Phenylene } \\
\text { proton } \mathrm{H}_{\mathrm{d}}\end{array}$ & $\begin{array}{l}\text { Phenylene } \\
\text { proton } \mathrm{H}_{\mathrm{d}^{\prime}}\end{array}$ & $\begin{array}{l}\Delta \delta \text { due to } \\
{[2] \text { catenane }} \\
\text { formation }\end{array}$ & $\begin{array}{l}\text { Methylene } \\
\text { proton } \mathrm{H}_{\mathrm{c}}\end{array}$ & $\begin{array}{l}\text { Methylene } \\
\text { proton } \mathrm{H}_{\mathrm{c}^{\prime}}\end{array}$ & $\begin{array}{l}\Delta \delta \text { due to } \\
\text { [2]catenane } \\
\text { formation }\end{array}$ \\
\hline $\mathbf{1 a} / \mathbf{2 a}$ & 7.19 & 4.82 & -2.37 & 4.53 & 3.73 & -0.80 \\
\hline $\mathbf{1 b} / \mathbf{2 b}$ & 7.16 & 4.76 & -2.40 & 4.52 & 3.76 & -0.76 \\
\hline $\mathbf{1 c / 2 c}$ & 7.28 & 5.03 & -2.25 & 4.63 & 3.92 & -0.71 \\
\hline $\mathbf{1 d} / \mathbf{2 d}$ & 7.31 & 5.12 & -2.19 & 4.66 & 3.99 & -0.67 \\
\hline
\end{tabular}




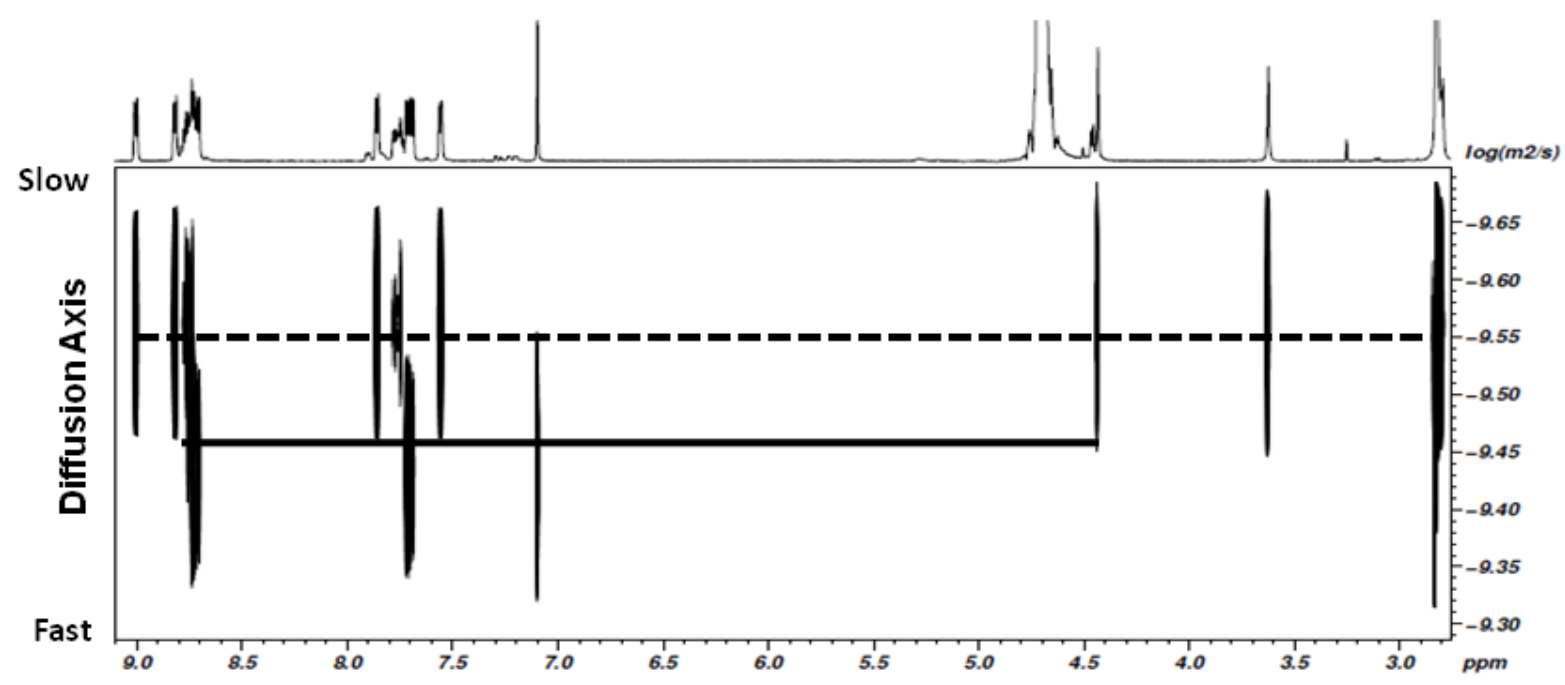

Figure S52. Diffusion-ordered ${ }^{1} \mathrm{H}$ NMR (DOSY) spectrum of 1a/2a in $\mathrm{D}_{2} \mathrm{O}$ (8 $\mathrm{mM}$ with respect to $\mathrm{Pd}(\mathrm{II}))$. Bold line corresponds to macrocycle, 1a and dotted line corresponds to [2]catenane, 2a. Diffusion coefficients for 1a and 2a are $(2.82 \pm 0.03) \times 10^{-10} \mathrm{~m}^{2} / \mathrm{s}$ and $(2.22$ $\pm 0.01) \times 10^{-10} \mathrm{~m}^{2} / \mathrm{s}$, respectively.

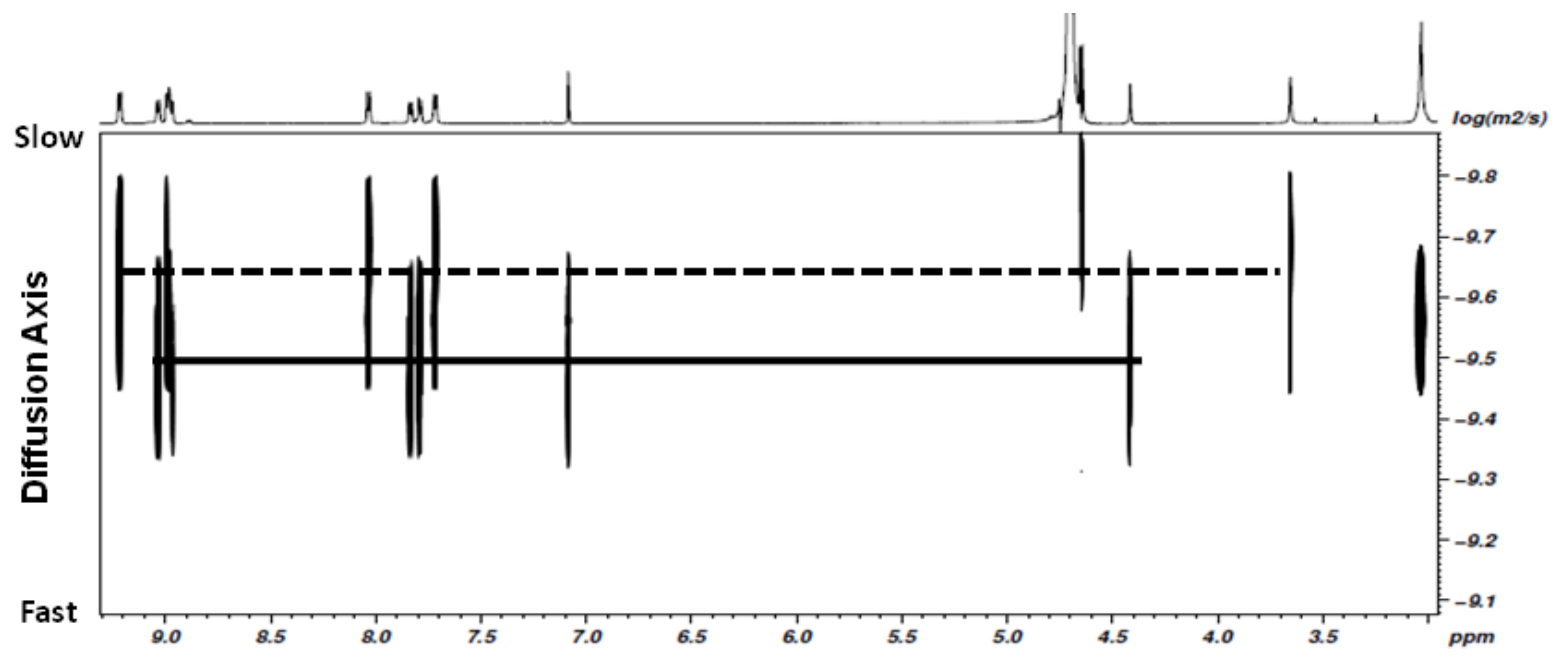

Figure S53. Diffusion-ordered ${ }^{1} \mathrm{H}$ NMR (DOSY) spectrum of $\mathbf{1 b} / \mathbf{2} \mathbf{b}$ in $\mathrm{D}_{2} \mathrm{O}$ (8 $\mathrm{mM}$ with respect to $\mathrm{Pd}(\mathrm{II})$ ). Bold line corresponds to macrocycle, $\mathbf{1 b}$ and dotted line corresponds to [2]catenane, $\mathbf{2 b}$. Diffusion coefficients for $\mathbf{1 b}$ and $\mathbf{2 b}$ are $(2.69 \pm 0.04) \times 10^{-10} \mathrm{~m}^{2} / \mathrm{s}$ and $(2.07 \pm$ $0.01) \times 10^{-10} \mathrm{~m}^{2} / \mathrm{s}$, respectively. 


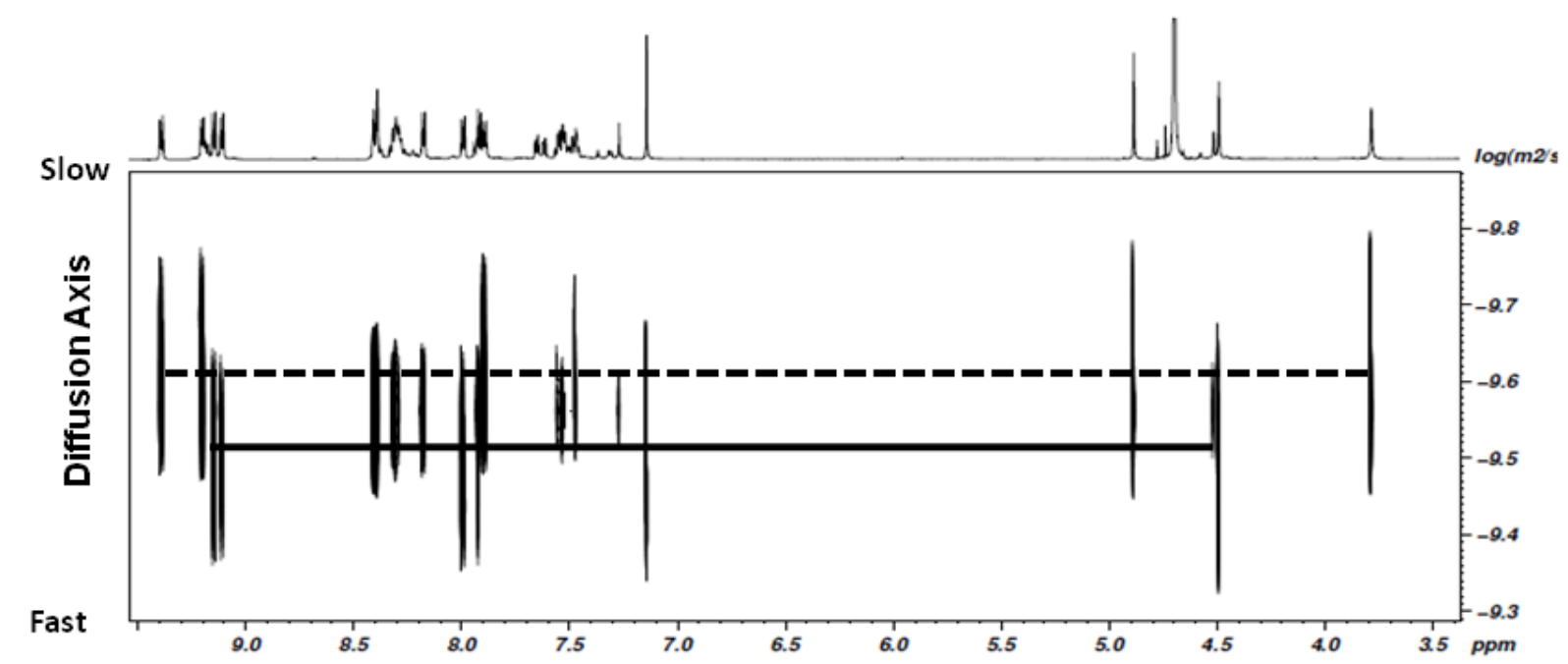

Figure S54. Diffusion-ordered ${ }^{1} \mathrm{H}$ NMR (DOSY) spectrum of $\mathbf{1 c} / \mathbf{2 c}$ in $\mathrm{D}_{2} \mathrm{O}$ (10 mM with respect to $\mathrm{Pd}(\mathrm{II})$ ). Bold line corresponds to macrocycle, $\mathbf{1 c}$ and dotted line corresponds to [2]catenane, 2c. Diffusion coefficients for $\mathbf{1 c}$ and $\mathbf{2 c}$ are $(2.724 \pm 0.002) \times 10^{-10} \mathrm{~m}^{2} / \mathrm{s}$ and $(2.05$ $\pm 0.02) \times 10^{-10} \mathrm{~m}^{2} / \mathrm{s}$, respectively.

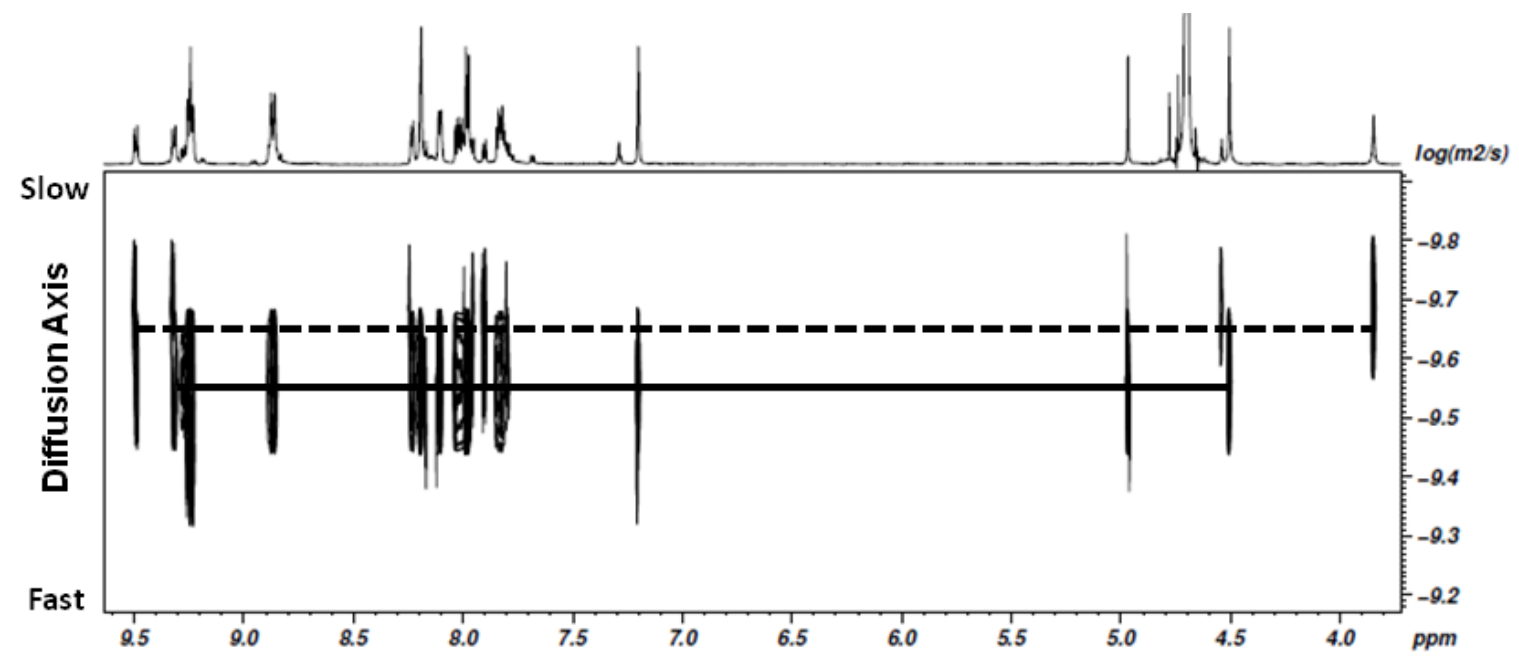

Figure S55. Diffusion-ordered ${ }^{1} \mathrm{H}$ NMR (DOSY) spectrum of a $\mathbf{1 d} / \mathbf{2 d}$ in $\mathrm{D}_{2} \mathrm{O}$ (5 mM with respect to $\mathrm{Pd}(\mathrm{II})$ ). Bold line corresponds to macrocycle, 1d and dotted line corresponds to [2]catenane, 2d. Diffusion coefficients for $1 \mathbf{d}$ and $2 \mathbf{d}$ are $(2.47 \pm 0.03) \times 10^{-10} \mathrm{~m}^{2} / \mathrm{s}$ and $(2.01 \pm$ $0.01) \times 10^{-10} \mathrm{~m}^{2} / \mathrm{s}$, respectively. 


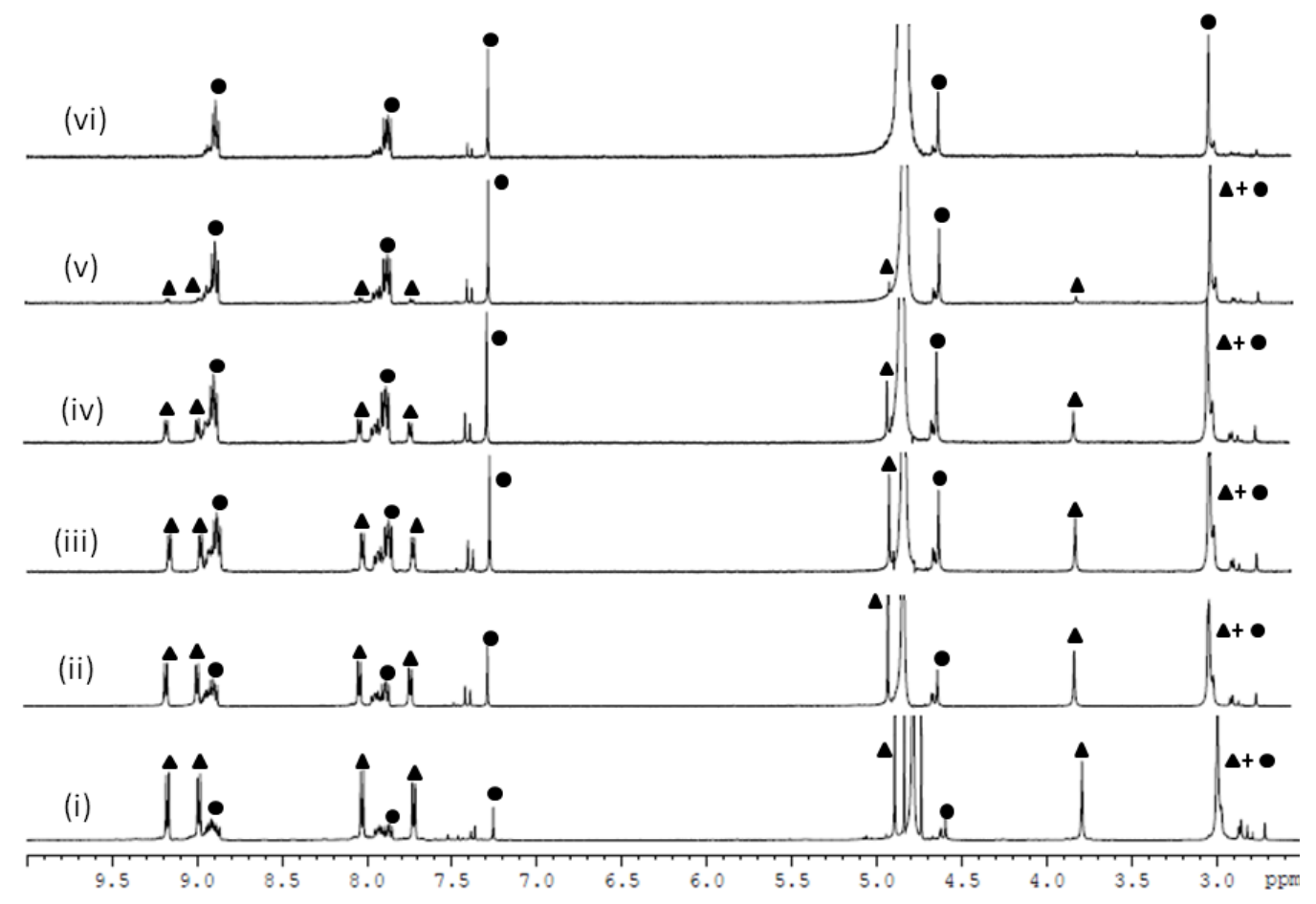

Figure S56. Concentration variation ${ }^{1} \mathrm{H}$ NMR study of (1a/2a) in $\mathrm{D}_{2} \mathrm{O}$ at (i) $40 \mathrm{mM}$, (ii) 15 $\mathrm{mM}$ (iii) $8 \mathrm{mM}$ (iv) $4 \mathrm{mM}$ (v) $2 \mathrm{mM}$ (vi) $0.5 \mathrm{mM}$ concentrations with respect to $\mathrm{Pd}(\mathrm{II})$. The triangle and circle symbols represent the [2]catenane, 2a and the macrocycle, 1a respectively.

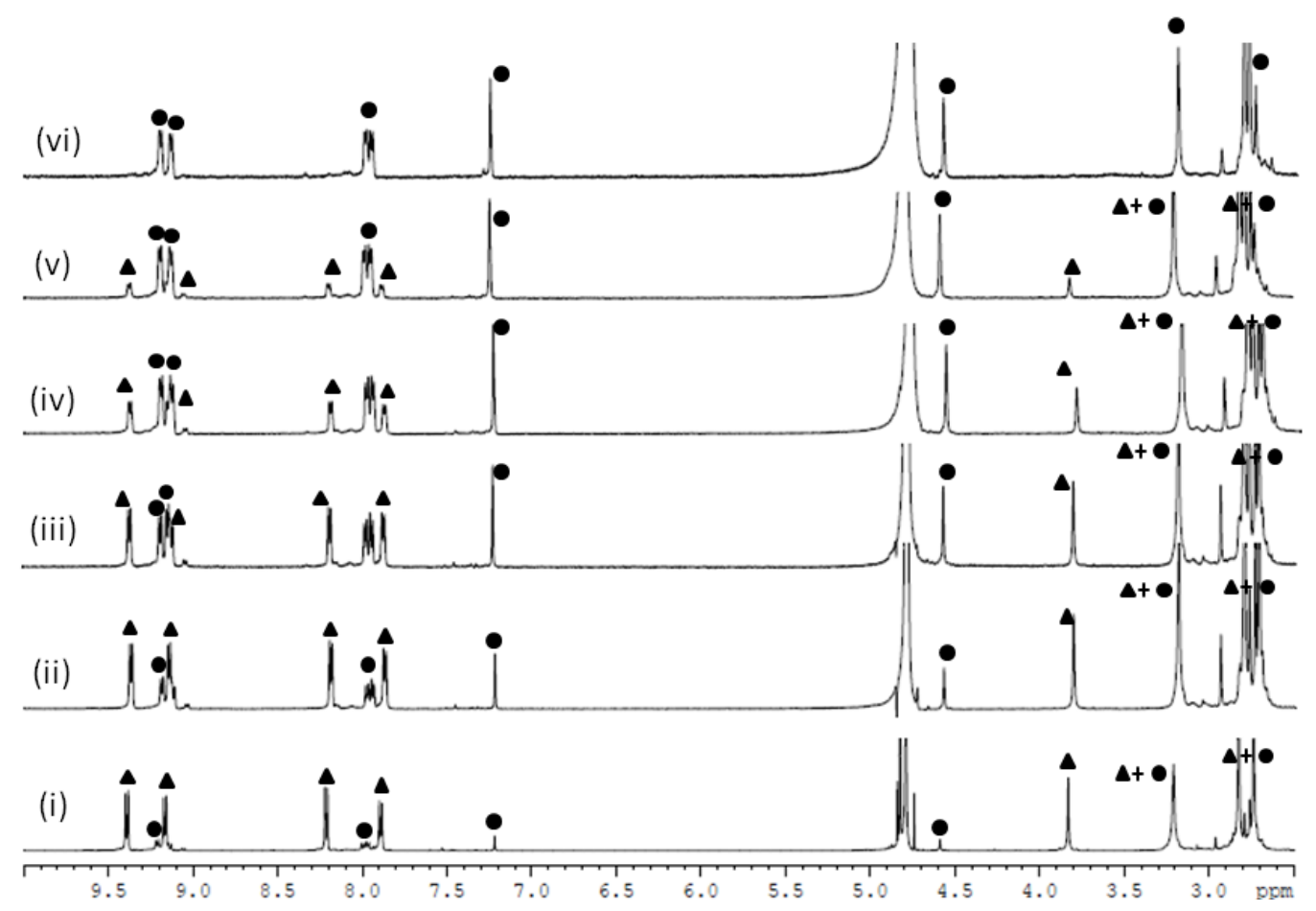

Figure S57. Concentration variation ${ }^{1} \mathrm{H}$ NMR study of (1/b/2b) in $\mathrm{D}_{2} \mathrm{O}$ at (i) $50 \mathrm{mM}$, (ii) 15 $\mathrm{mM}$ (iii) $8 \mathrm{mM}$ (iv) $4 \mathrm{mM}$ (v) $2 \mathrm{mM}$ (vi) $0.5 \mathrm{mM}$ concentrations with respect to Pd(II). The triangle and circle symbols represent the [2]catenane, $\mathbf{2} \mathbf{b}$ and the macrocycle, $\mathbf{1} \mathbf{b}$ respectively. 


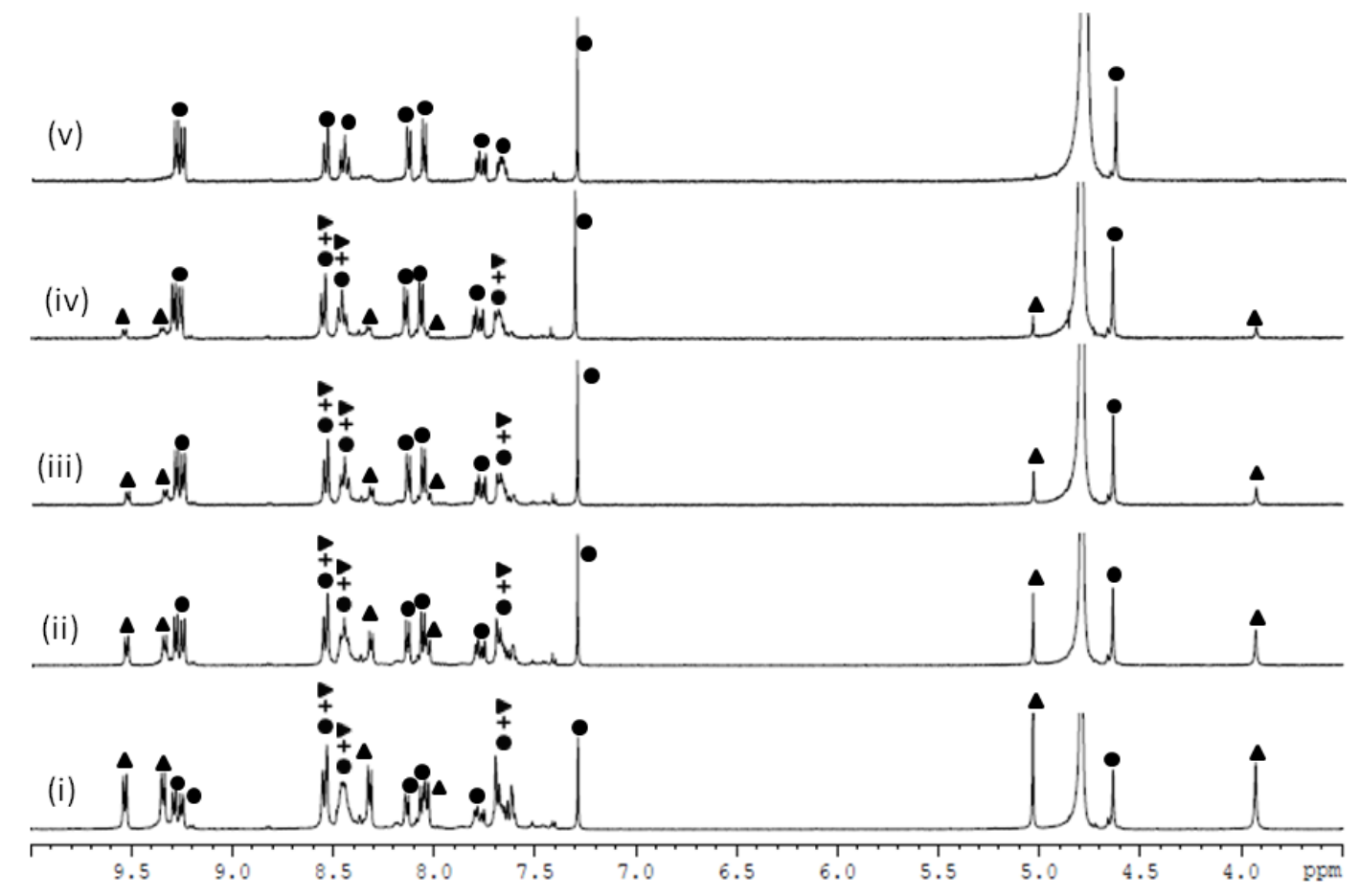

Figure S58. Concentration variation ${ }^{1} \mathrm{H}$ NMR study of (1c/2c) in $\mathrm{D}_{2} \mathrm{O}$ at (i) $10 \mathrm{mM}$, (ii) $7 \mathrm{mM}$, (iii) $5 \mathrm{mM}$, (iv) $2.5 \mathrm{mM}$, (v) $1 \mathrm{mM}$ concentrations with respect to $\mathrm{Pd}(\mathrm{II})$. The triangle and circle symbols represent the [2]catenane, $2 \mathrm{c}$ and the macrocycle, $\mathbf{1 c}$ respectively.

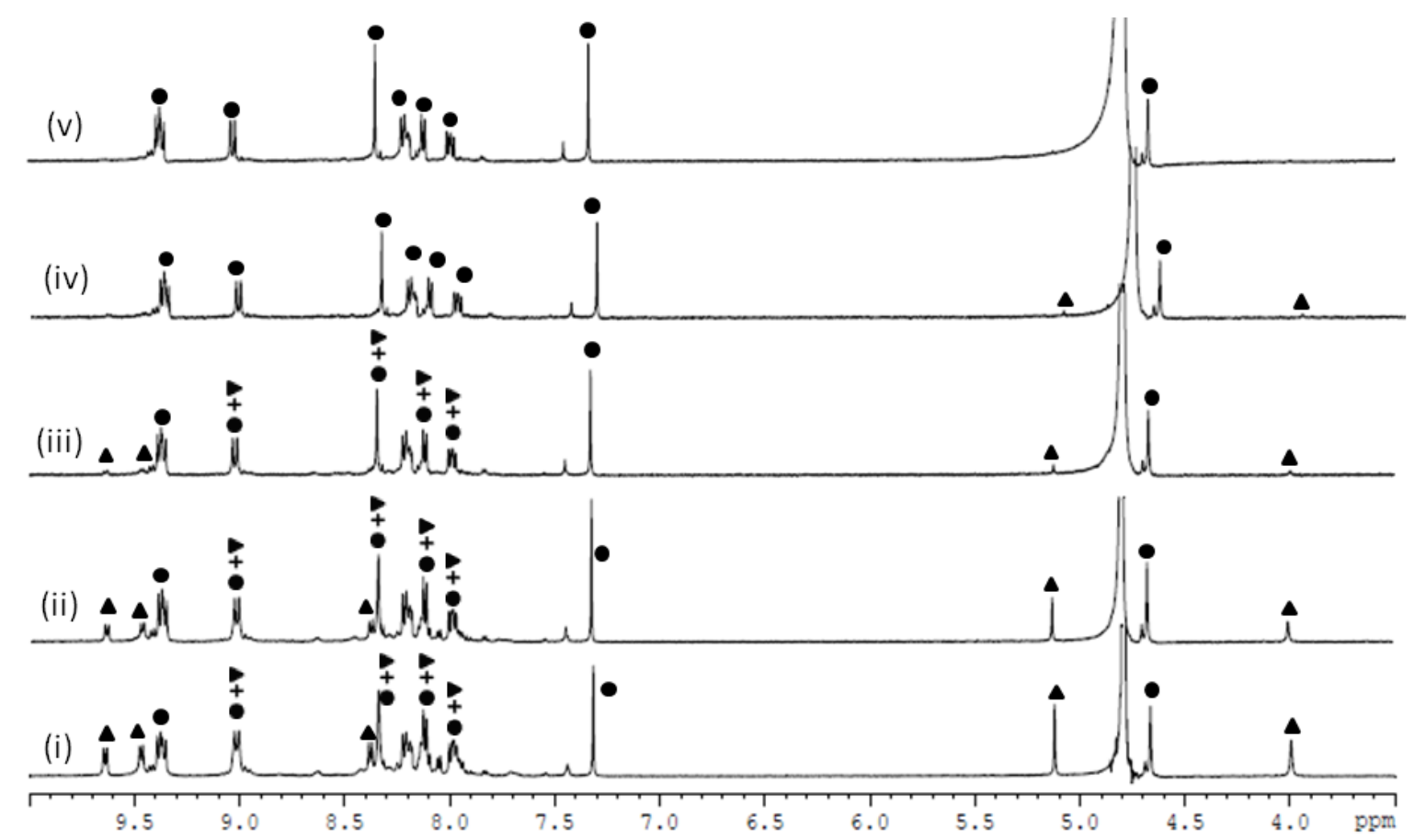

Figure S59. Concentration variation ${ }^{1} \mathrm{H}$ NMR study of (1d/2d) in $\mathrm{D}_{2} \mathrm{O}$ at (i) $10 \mathrm{mM}$, (ii) $5 \mathrm{mM}$ (iii) $2.5 \mathrm{mM}$ (iv) $1.25 \mathrm{mM}$ (v) $0.5 \mathrm{mM}$ (vi) $0.1 \mathrm{mM}$ concentrations with respect to $\mathrm{Pd}$ (II). The triangle and circle symbols represent the [2]catenane, $\mathbf{2 d}$ and the macrocycle, $\mathbf{1 d}$ respectively. 


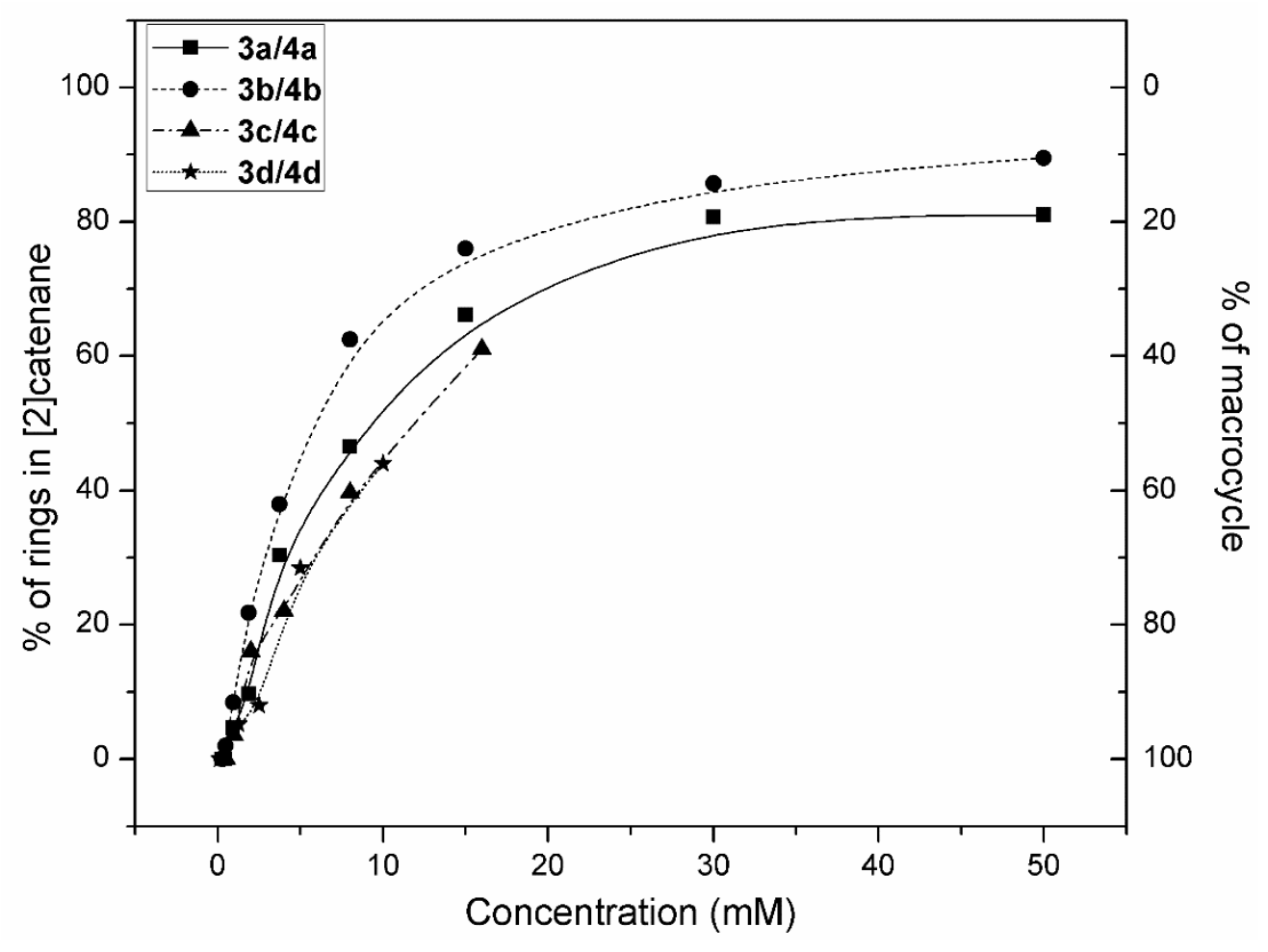

Figure S60. Plot of the percentage of rings in the [2]catenane (2a-d) and the macrocycle (1ad) under aqueous conditions as a function of the concentration. (Concentrations shown are with respect to $\left.\mathrm{Pd}^{\mathrm{II}}\right)$. 
Table S2. Equilibrium constants calculated at different concentrations of $\mathbf{1 a} / \mathbf{2 a}, \mathbf{1 b} / \mathbf{2 b}, \mathbf{1 c} / \mathbf{2 c}$ and $\mathbf{1 d} / \mathbf{2 d}$ in $\mathrm{D}_{2} \mathrm{O}$.

\begin{tabular}{|c|c|c|c|c|c|c|c|}
\hline Complex & $\begin{array}{l}\text { Entry } \\
\text { No. }\end{array}$ & $\begin{array}{l}{\left[\mathrm{Pd}^{\mathrm{II}}\right]} \\
\mathrm{mM}\end{array}$ & $\begin{array}{l}\text { Catenane } \\
\%\end{array}$ & $\begin{array}{l}\text { Macrocycle } \\
\%\end{array}$ & $\begin{array}{l}\mathrm{C}] \\
\mathrm{mM}\end{array}$ & $\begin{array}{l}{[\mathrm{M}]} \\
\mathrm{mM}\end{array}$ & $\begin{array}{l}\mathrm{K}_{\mathrm{c}} \\
\left(\mathrm{mmol}^{-1} \mathrm{~L}\right)\end{array}$ \\
\hline $1 a / 2 a$ & 1 & 50 & 86.60 & 13.40 & 10.82 & 3.35 & 0.96 \\
\hline & 2 & 40 & 84.75 & 15.25 & 8.47 & 3.05 & 0.91 \\
\hline & 3 & 30 & 81.65 & 18.35 & 6.12 & 2.75 & 0.81 \\
\hline & \multicolumn{7}{|c|}{ Average $K_{c}$ : } \\
\hline \multirow[t]{4}{*}{$1 \mathbf{b} / 2 \mathbf{b}$} & 4 & 50 & 89.67 & 10.32 & 11.21 & 2.58 & 1.68 \\
\hline & 5 & 30 & 86.65 & 13.35 & 6.50 & 2.00 & 1.62 \\
\hline & 6 & 20 & 82.95 & 17.05 & 4.15 & 1.71 & 1.43 \\
\hline & \multicolumn{7}{|c|}{ Average $K_{c}$ : 1.58} \\
\hline \multirow[t]{4}{*}{$1 c / 2 c$} & 7 & 16 & 61 & 39 & 2.44 & 3.12 & 0.25 \\
\hline & 8 & 8 & 43.3 & 56.7 & 0.87 & 2.27 & 0.17 \\
\hline & 9 & 4 & 26.2 & 73.8 & 0.26 & 1.48 & 0.12 \\
\hline & \multicolumn{7}{|c|}{ Average $K_{c}: \quad \mathbf{0 . 1 8}$} \\
\hline \multirow[t]{4}{*}{$1 d / 2 d$} & 10 & 10 & 45.78 & 54.21 & 1.14 & 2.71 & 0.16 \\
\hline & 11 & 5 & 31.5 & 68.5 & 0.39 & 1.71 & 0.13 \\
\hline & 12 & 2.5 & 12.88 & 87.12 & 0.08 & 1.09 & 0.07 \\
\hline & & & & & & Average $\mathrm{K}_{\mathrm{c}}$ : & 0.12 \\
\hline
\end{tabular}




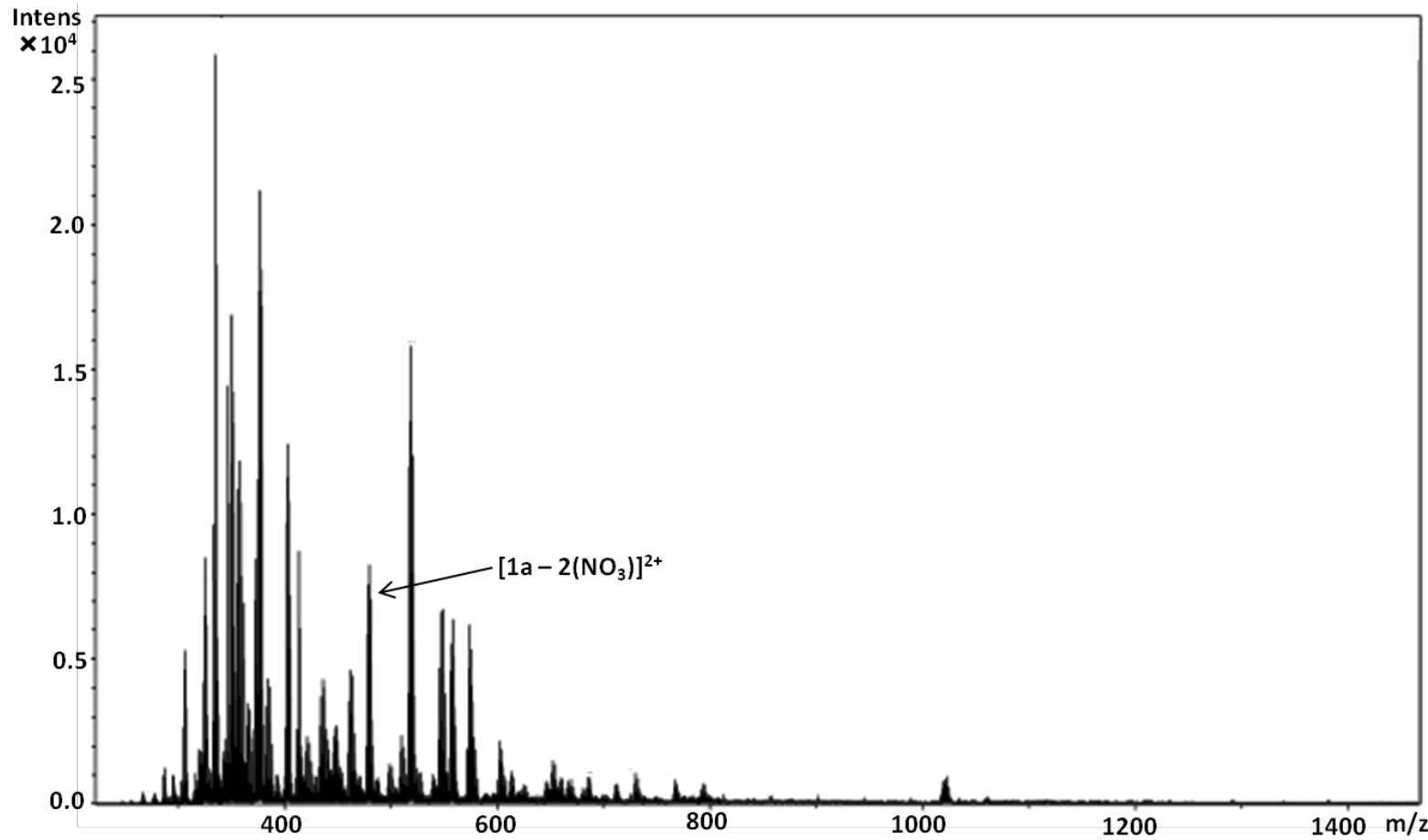

Figure S61. CSI-MS spectrum for 1a recorded in DMSO.

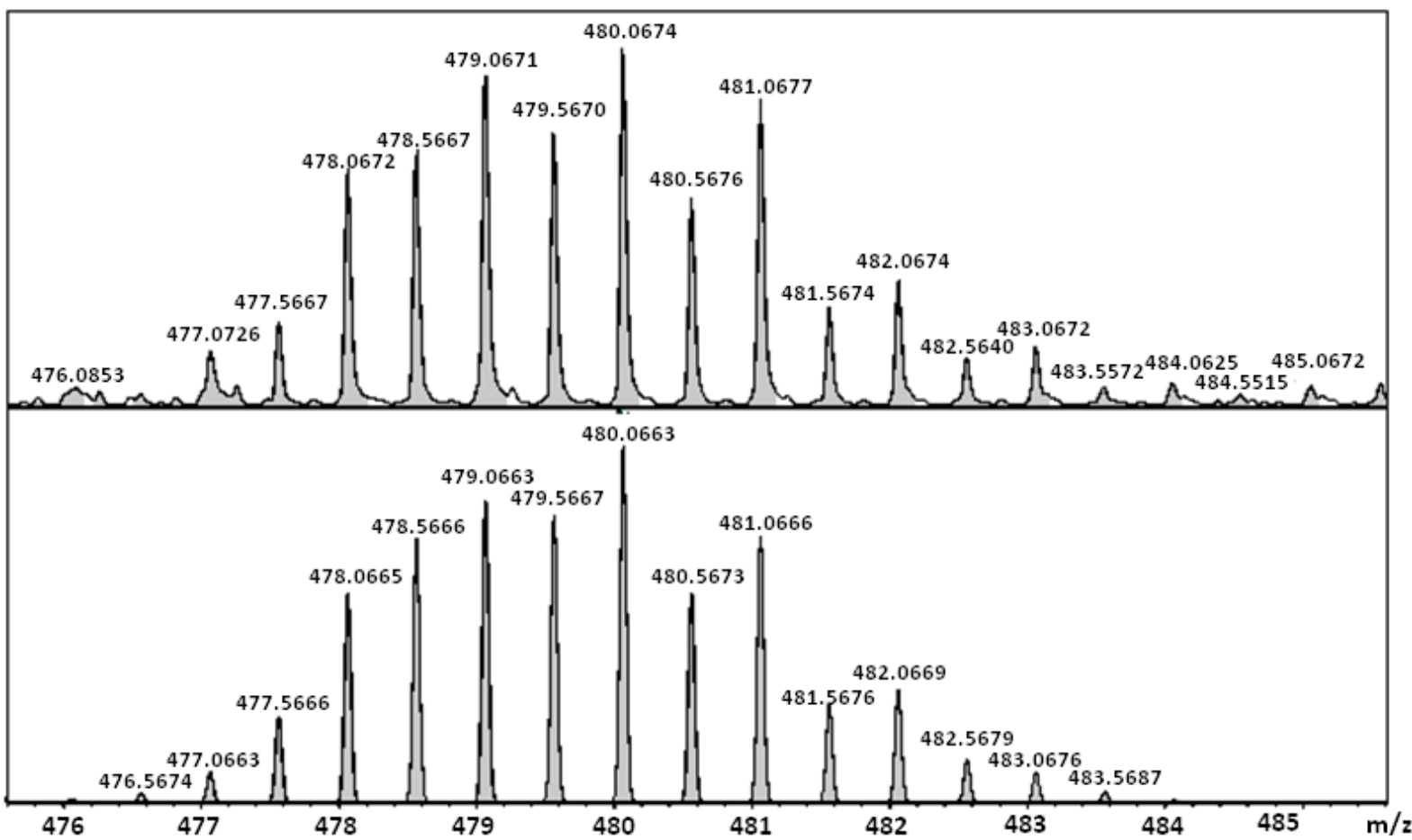

Figure S62. Isotopic pattern of $\left[1 \mathbf{a}-2 \mathrm{NO}_{3}\right]^{2+}$ recorded in DMSO (top) and simulated pattern (bottom). 


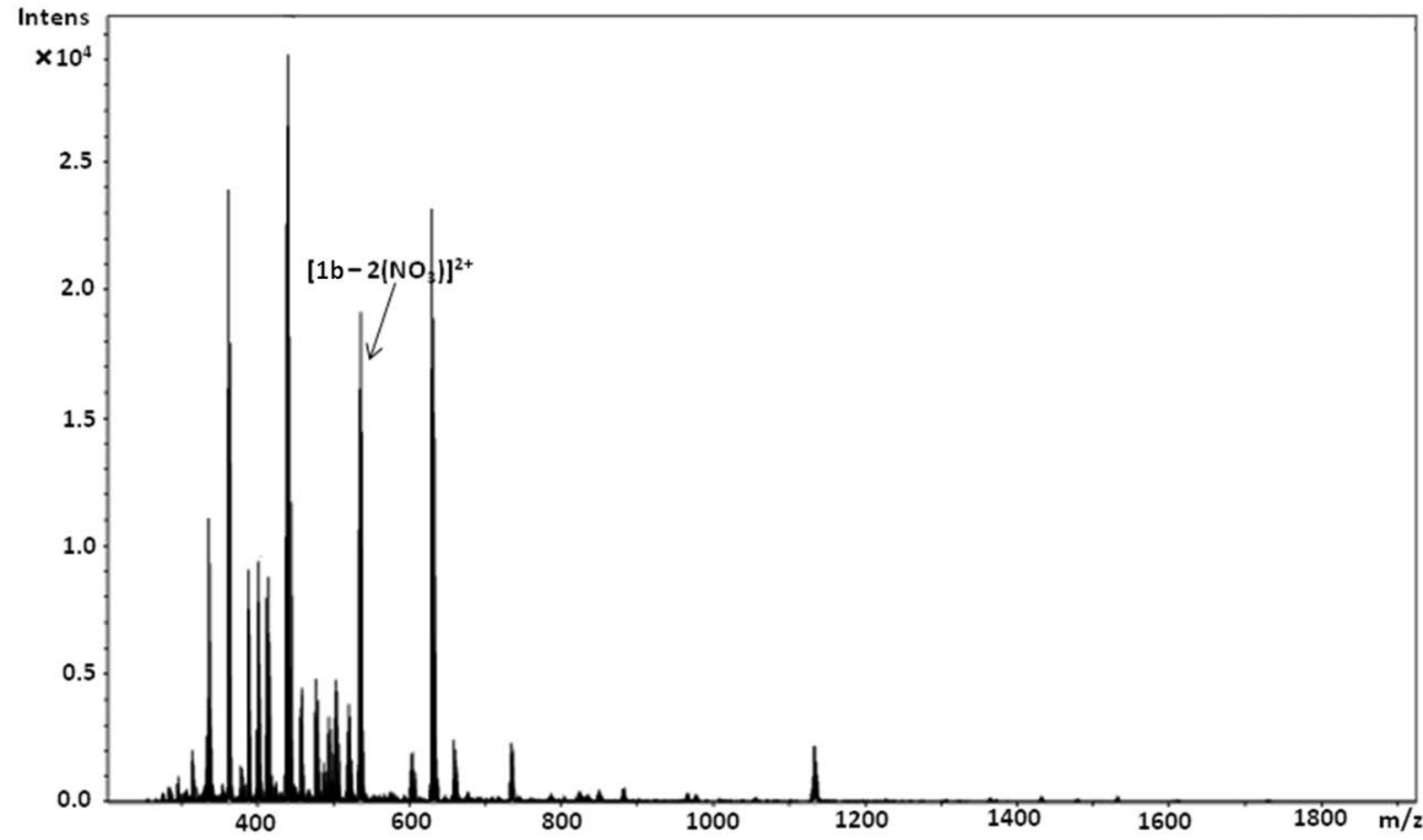

Figure S63. CSI-MS spectrum for $\mathbf{1 b}$ recorded in DMSO.

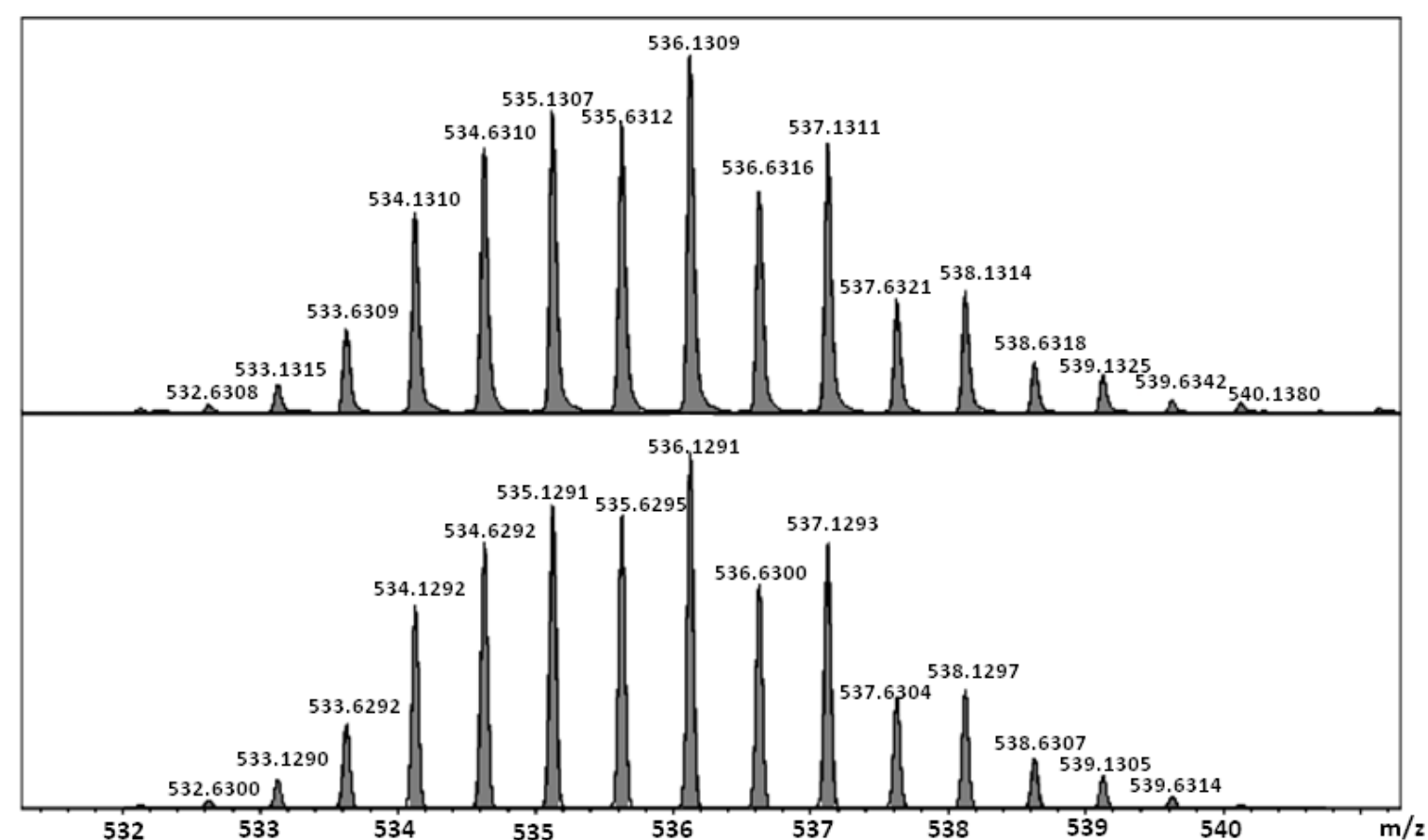

Figure S64. Isotopic pattern of $\left[\mathbf{1 b}-2 \mathrm{NO}_{3}\right]^{2+}$ recorded in DMSO (top) and simulated pattern (bottom). 


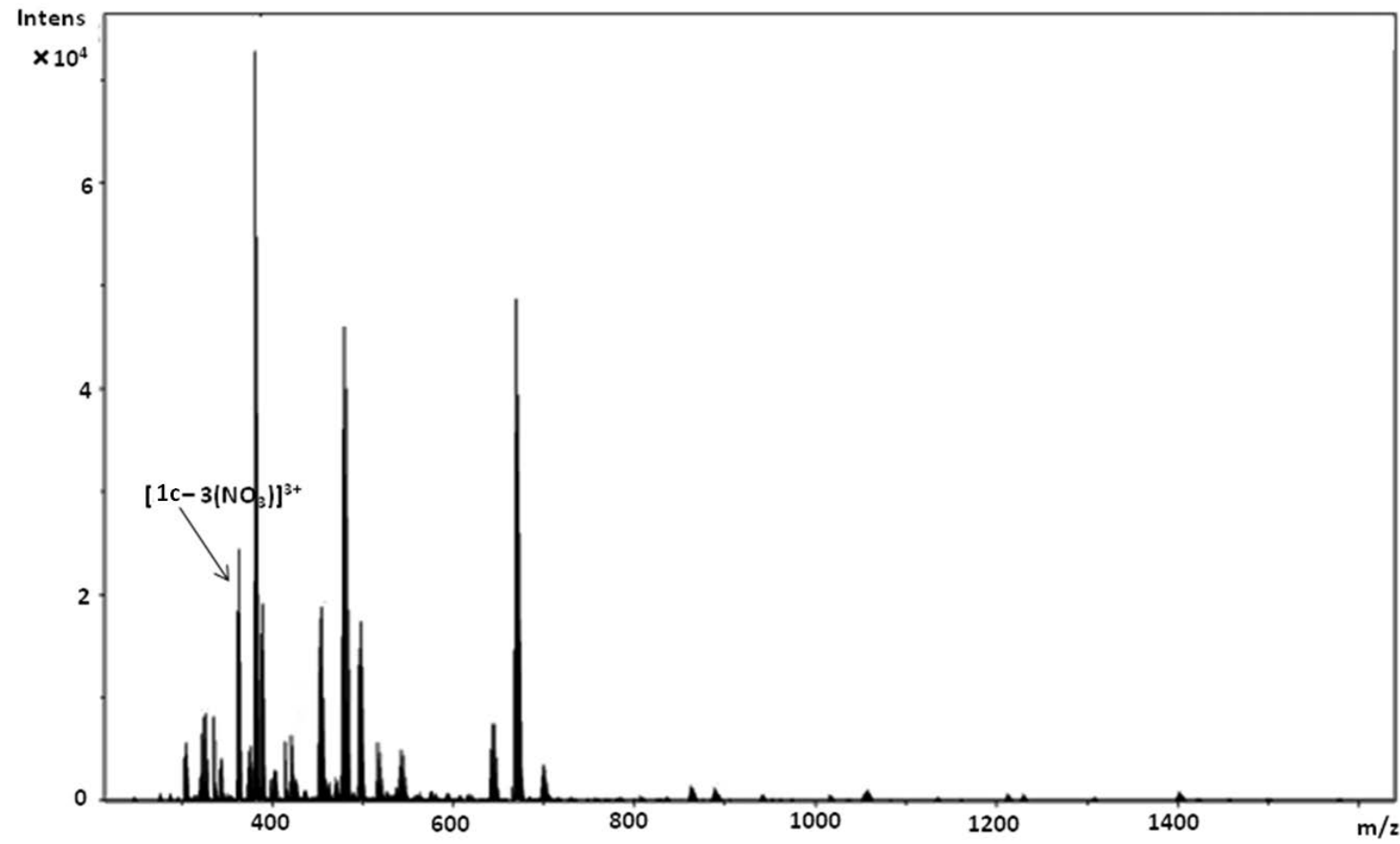

Figure S65. CSI-MS spectrum for 1c recorded in DMSO.

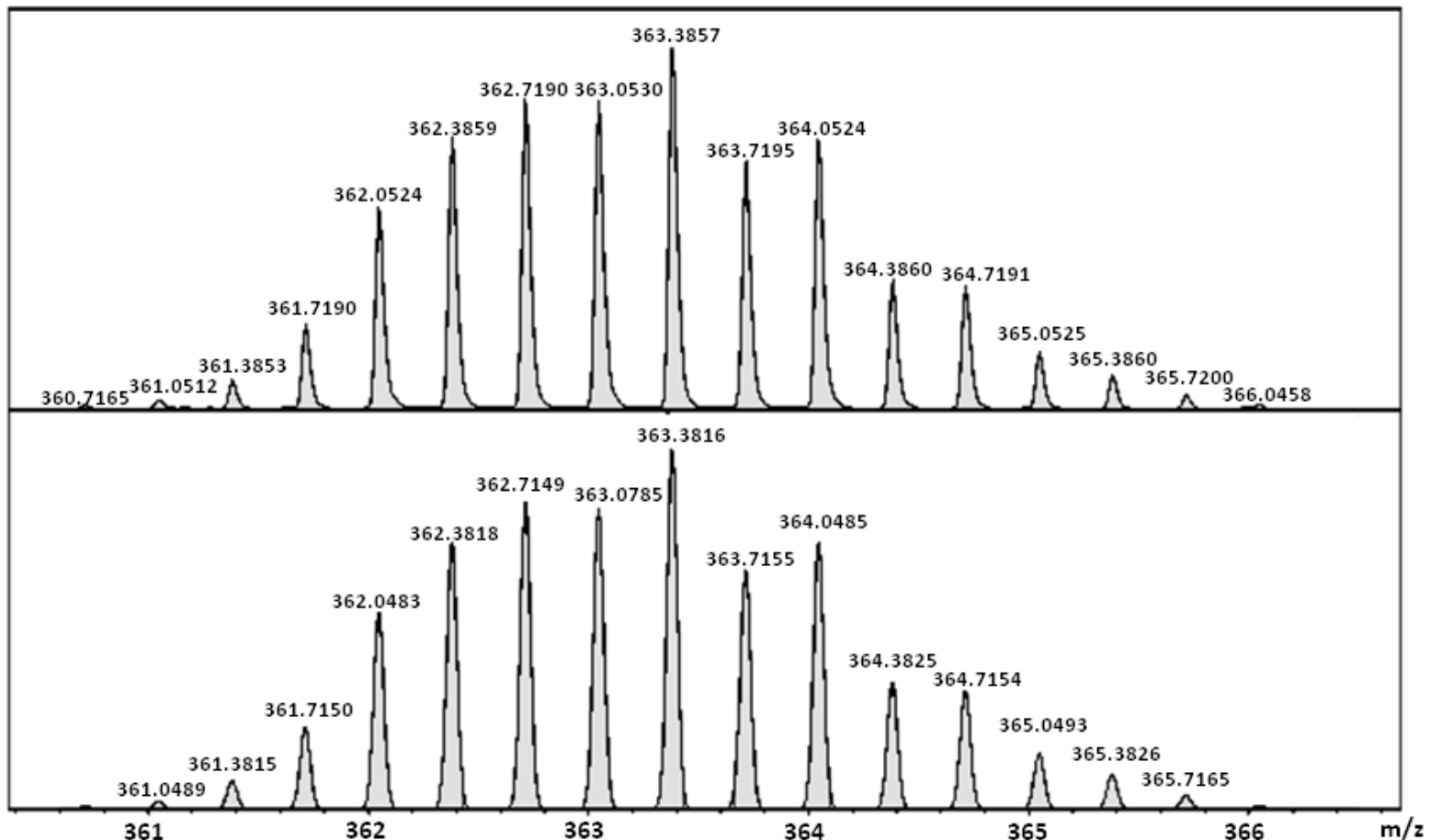

Figure S66. Isotopic pattern of $\left[1 \mathbf{c}-3 \mathrm{NO}_{3}\right]^{3+}$ recorded in DMSO (top) and simulated pattern (bottom). 


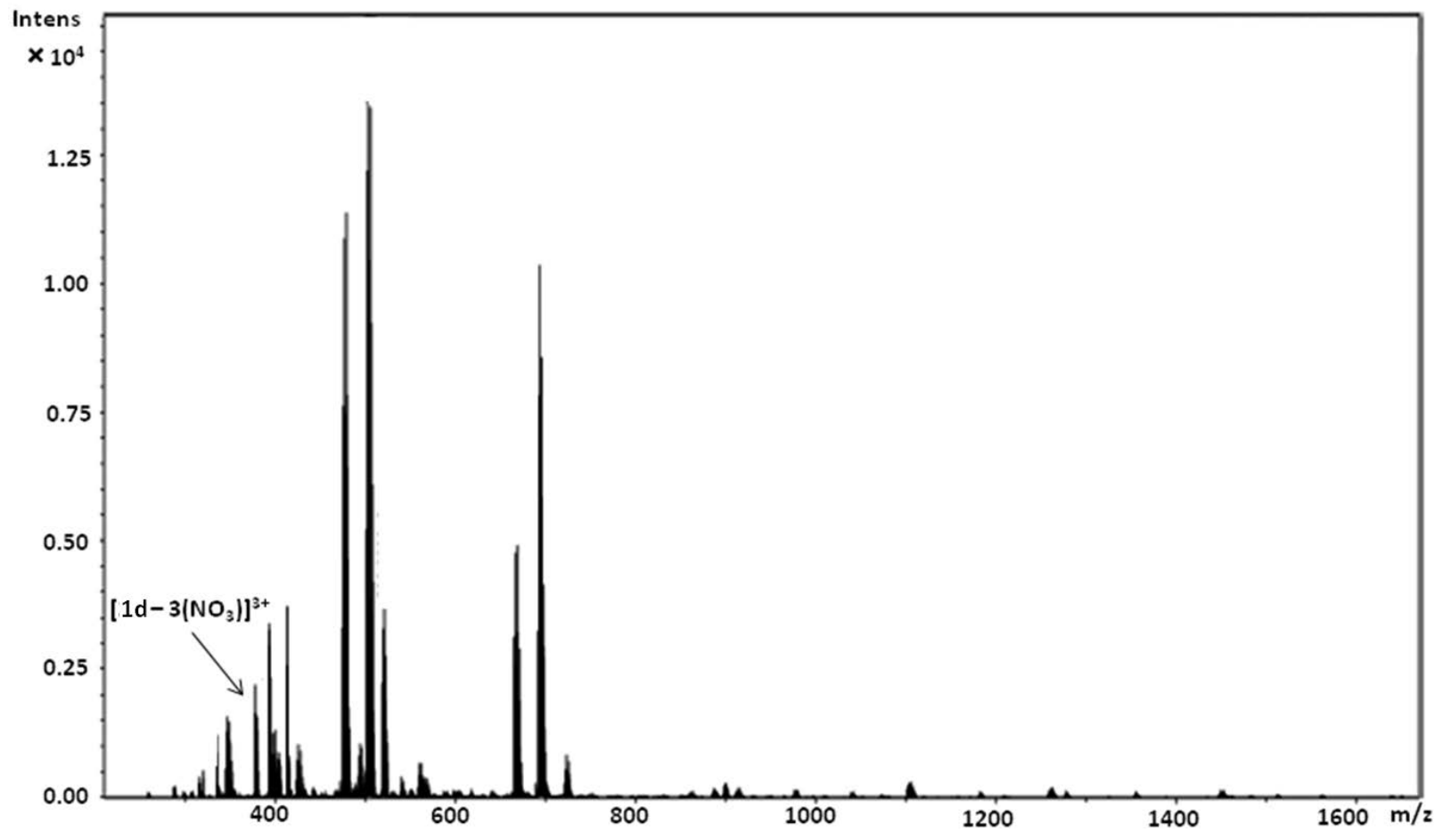

Figure S67. CSI-MS spectrum for 1d recorded in DMSO.

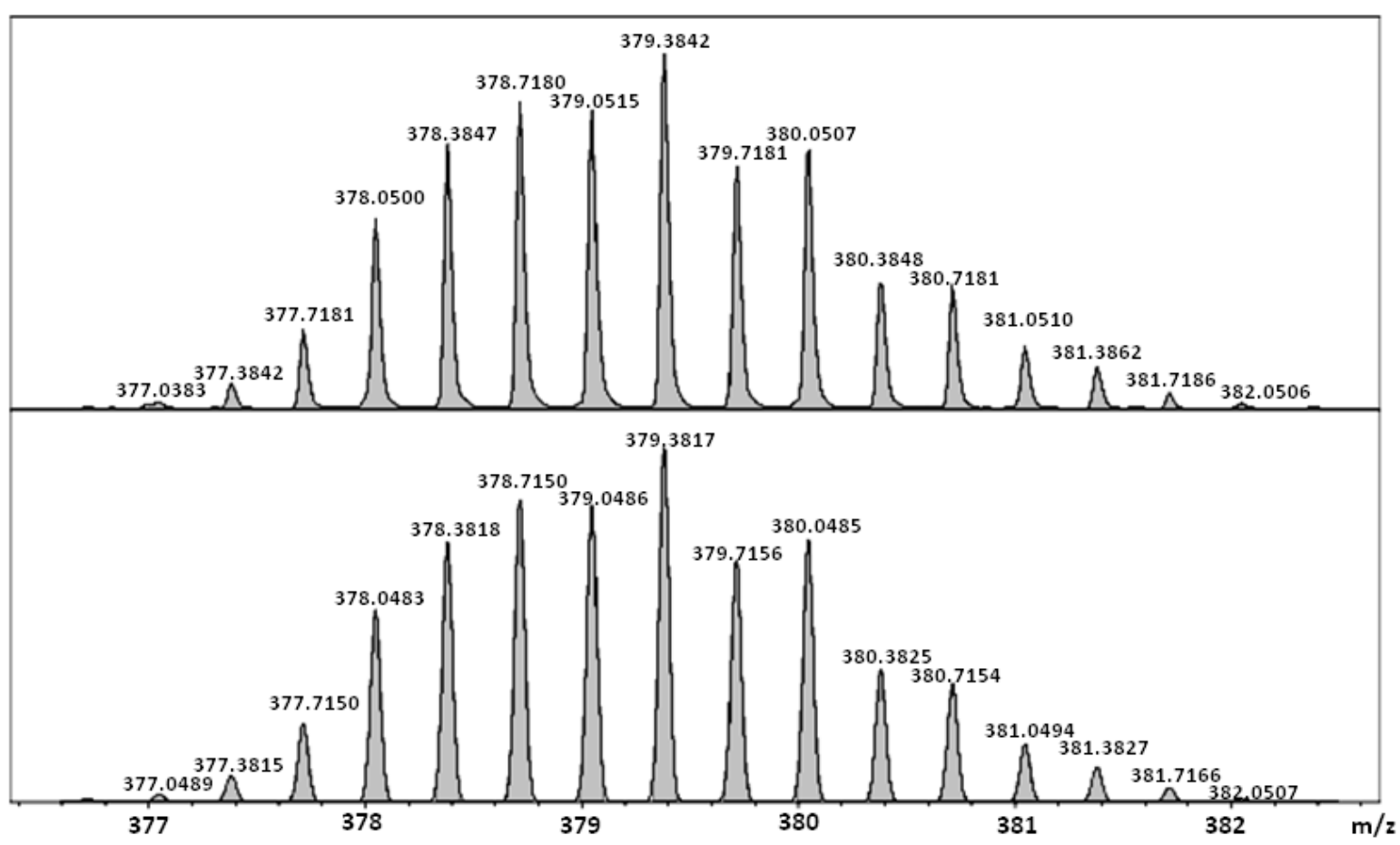

Figure S68. Isotopic pattern of $\left[\mathbf{1 d}-3 \mathrm{NO}_{3}\right]^{3+}$ recorded in DMSO (top) and simulated pattern (bottom). 


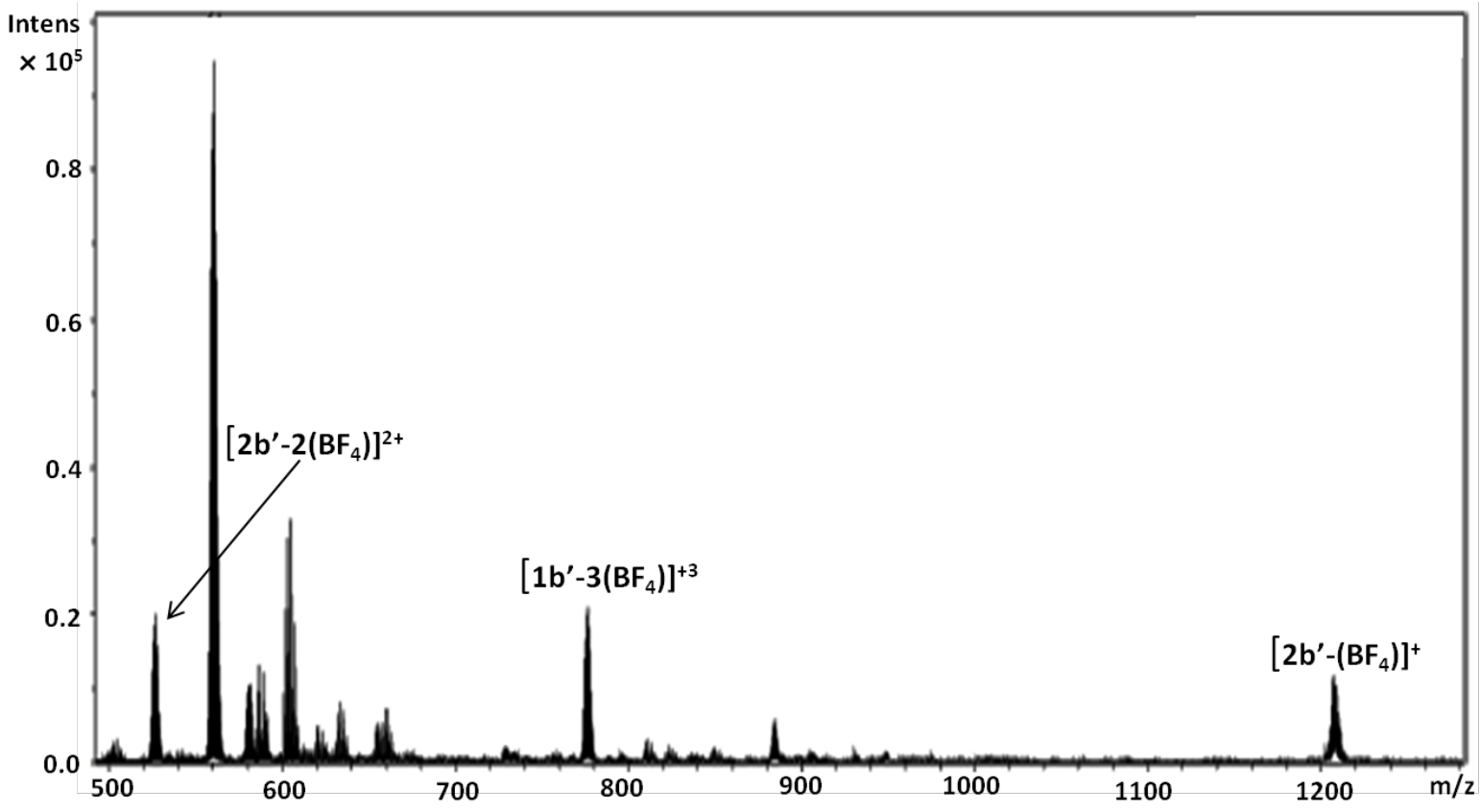

Figure S69. CSI-MS spectrum for $\mathbf{1 b}^{\prime} / \mathbf{2} \mathbf{b}^{\prime}$ recorded in $\mathrm{H}_{2} \mathrm{O}$.

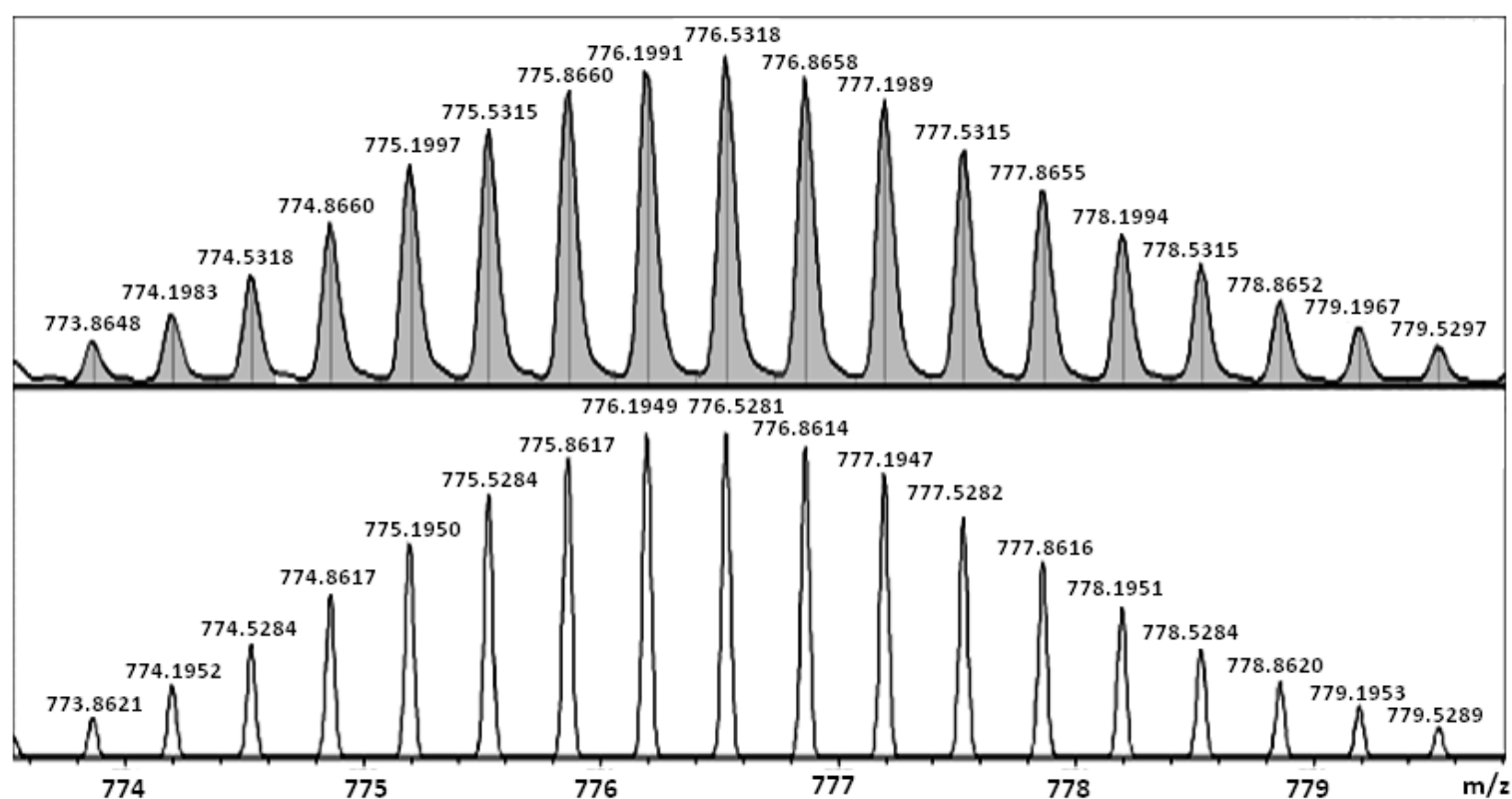

Figure S70. Isotopic pattern of $\left[\mathbf{1 b}^{\prime}-3 \mathrm{BF}_{4}\right]^{3+}$ recorded in $\mathrm{H}_{2} \mathrm{O}$ (top) and simulated pattern (bottom). 


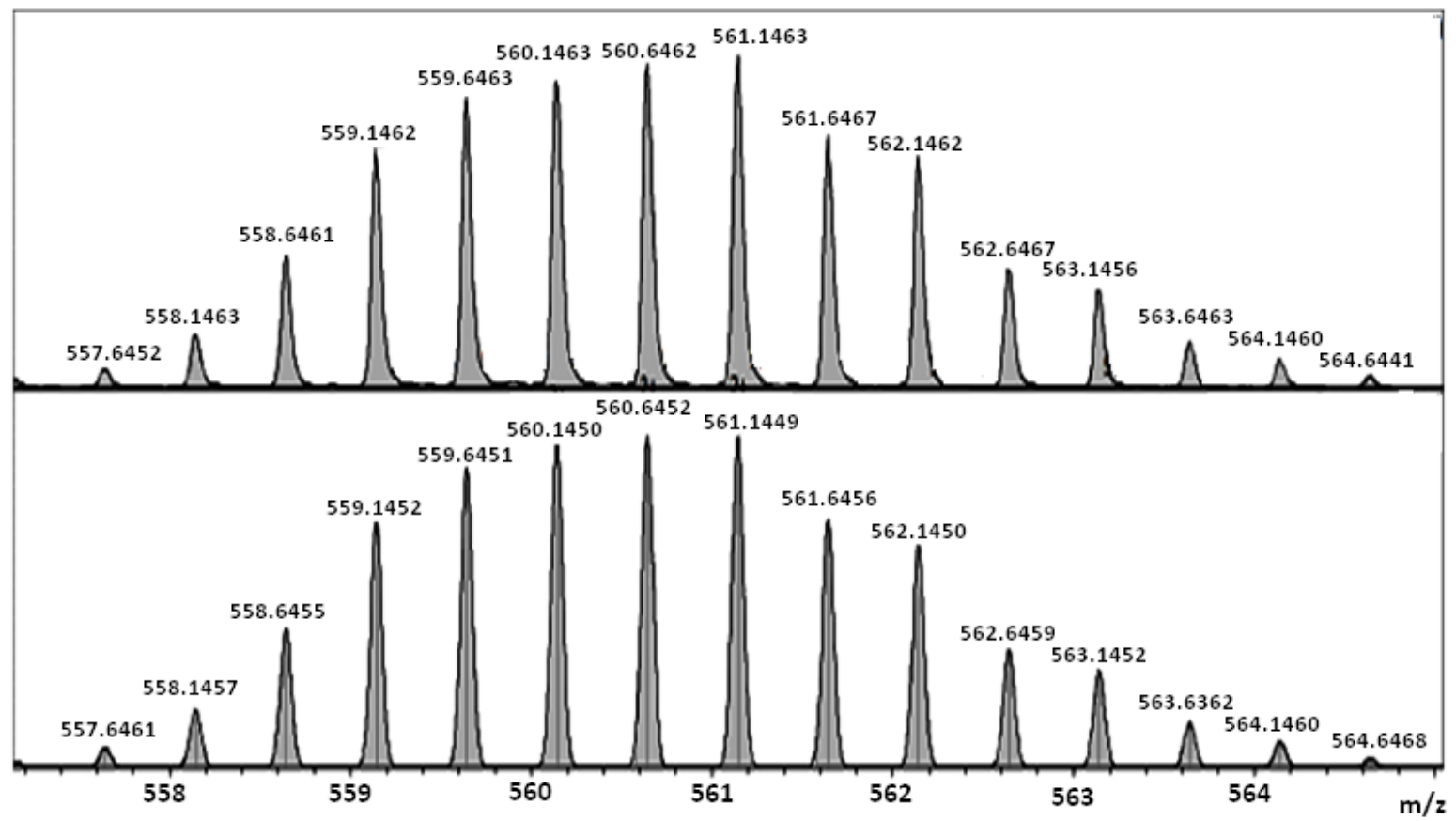

Figure S71. Isotopic pattern of $\left[\mathbf{2} \mathbf{b}^{\prime}-2 \mathrm{BF}_{4}\right]^{2+}$ recorded in $\mathrm{H}_{2} \mathrm{O}$ (top) and simulated pattern (bottom).

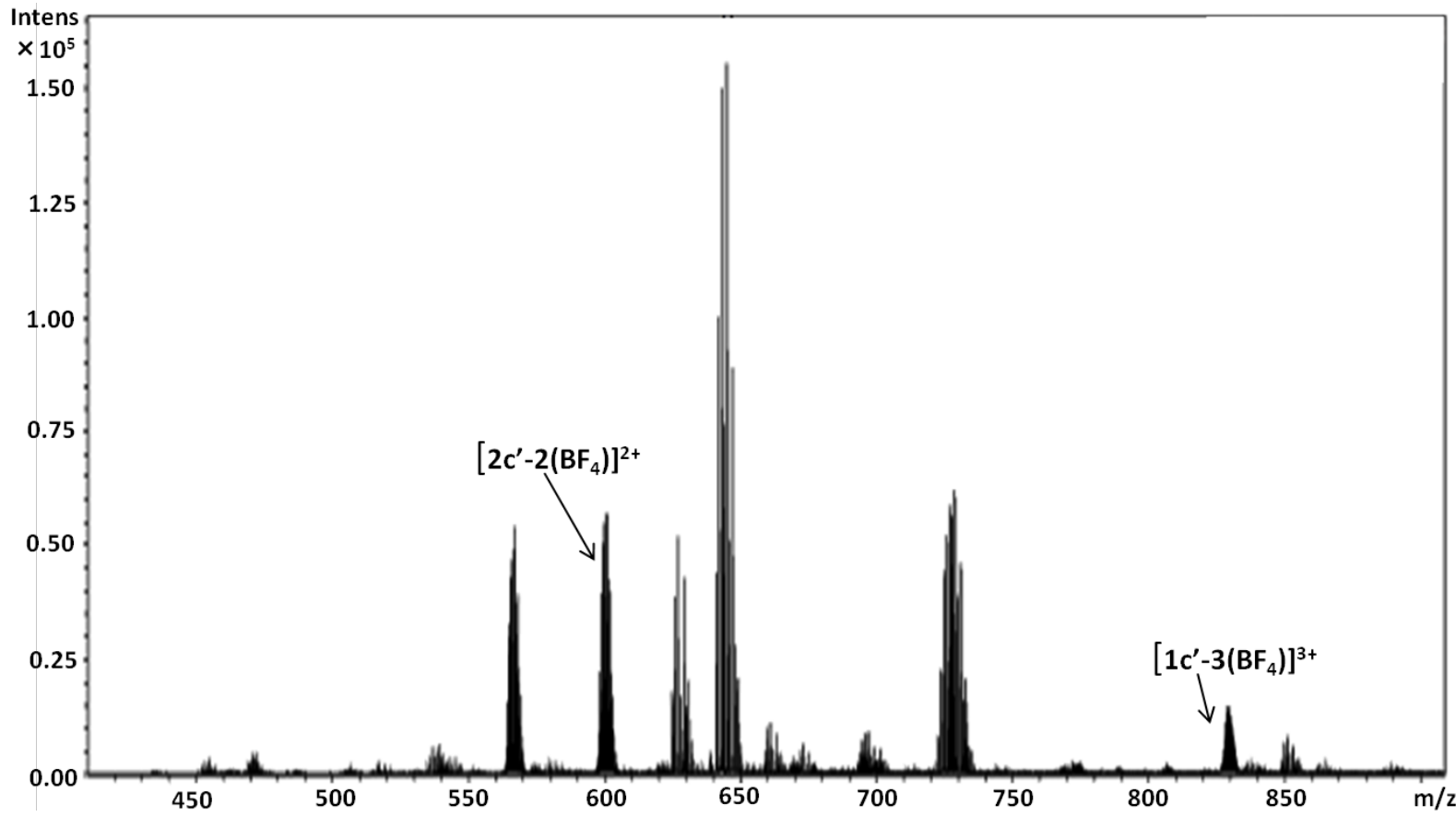

Figure S72. CSI-MS spectrum for $\mathbf{1} \mathbf{c}^{\prime} / \mathbf{2} \mathbf{c}^{\prime}$ recorded in $\mathrm{H}_{2} \mathrm{O}$. 


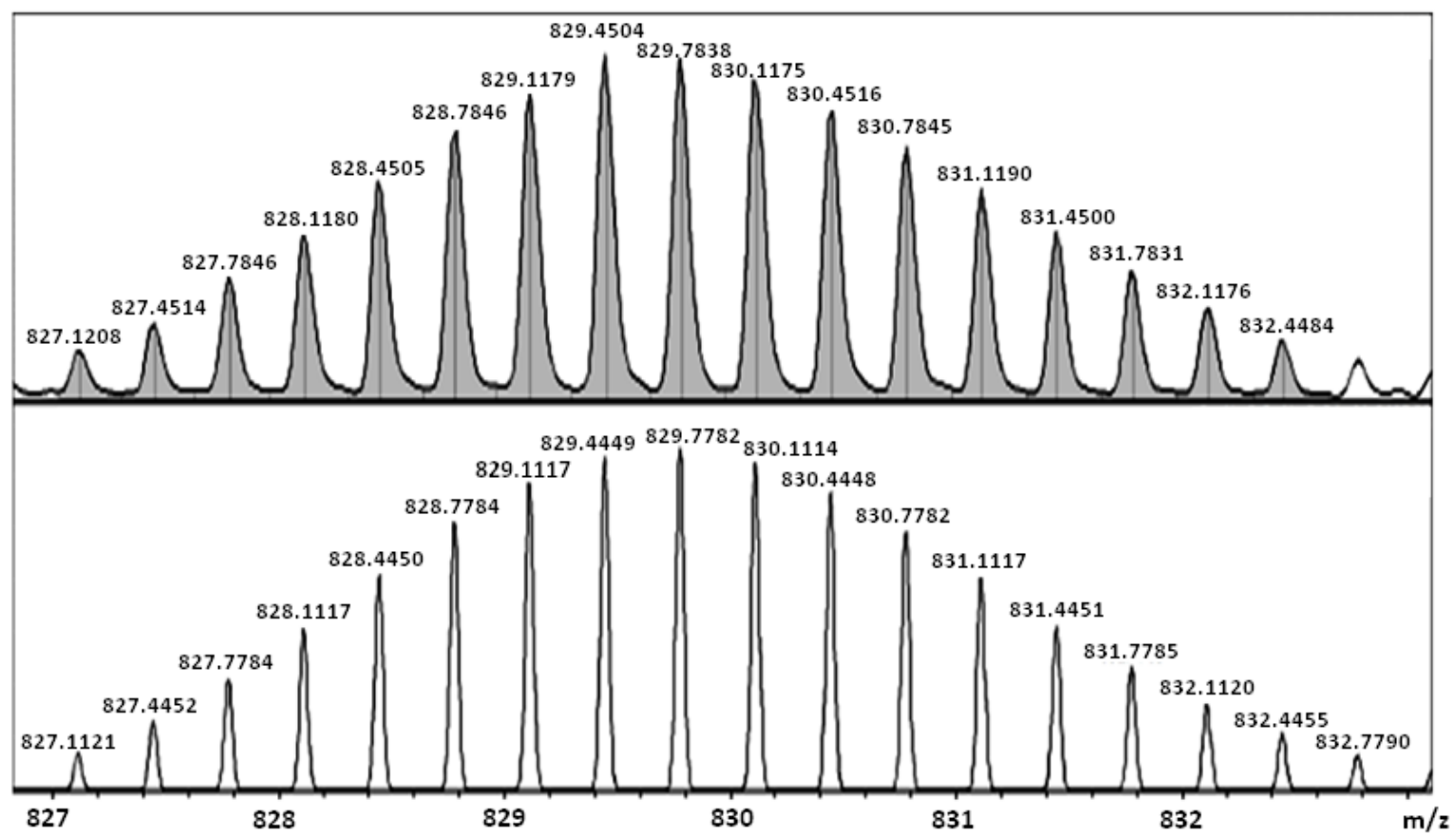

Figure S73. Isotopic pattern of $\left[\mathbf{1 c}^{\prime}-3 \mathrm{BF}_{4}\right]^{3+}$ recorded in $\mathrm{H}_{2} \mathrm{O}$ (top) and simulated pattern (bottom).

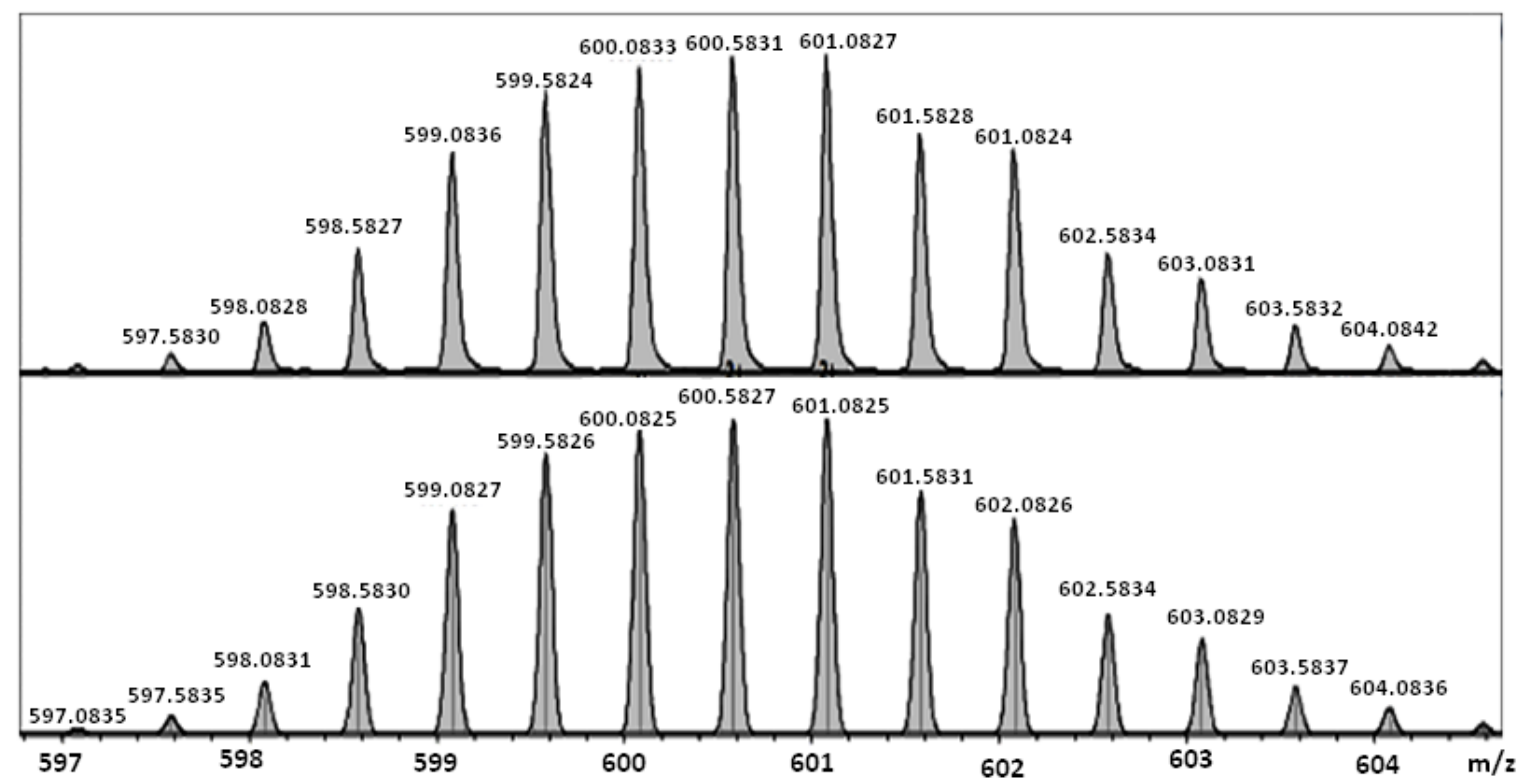

Figure S74. Isotopic pattern of $\left[2 \mathbf{c}^{\prime}-2 \mathrm{BF}_{4}\right]^{2+}$ recorded in $\mathrm{H}_{2} \mathrm{O}$ (top) and simulated pattern (bottom). 


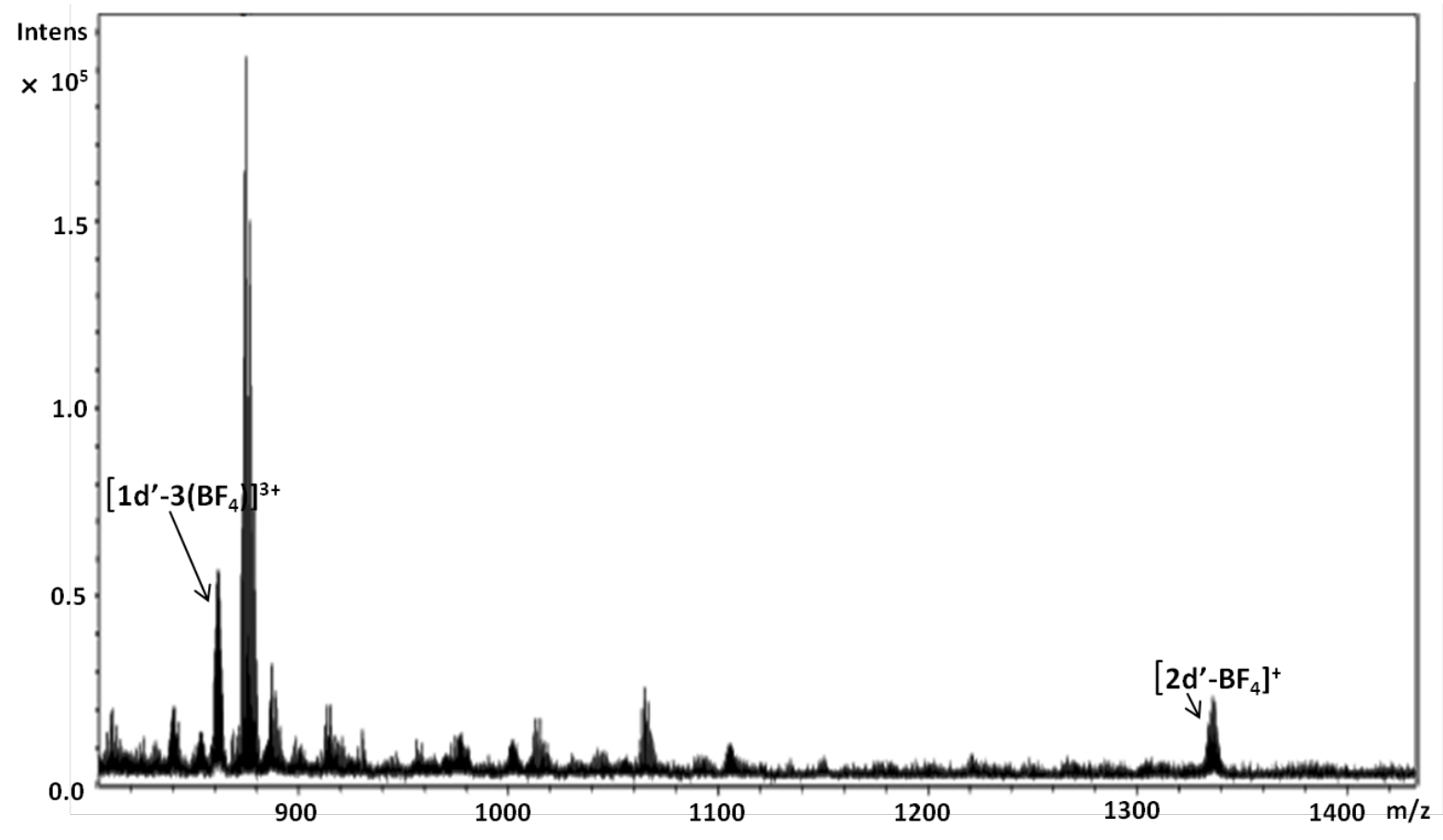

Figure S75. CSI-MS spectrum for $\mathbf{1} \mathbf{d}^{\prime} / \mathbf{2} \mathbf{d}^{\prime}$ recorded in $\mathrm{H}_{2} \mathrm{O}$.

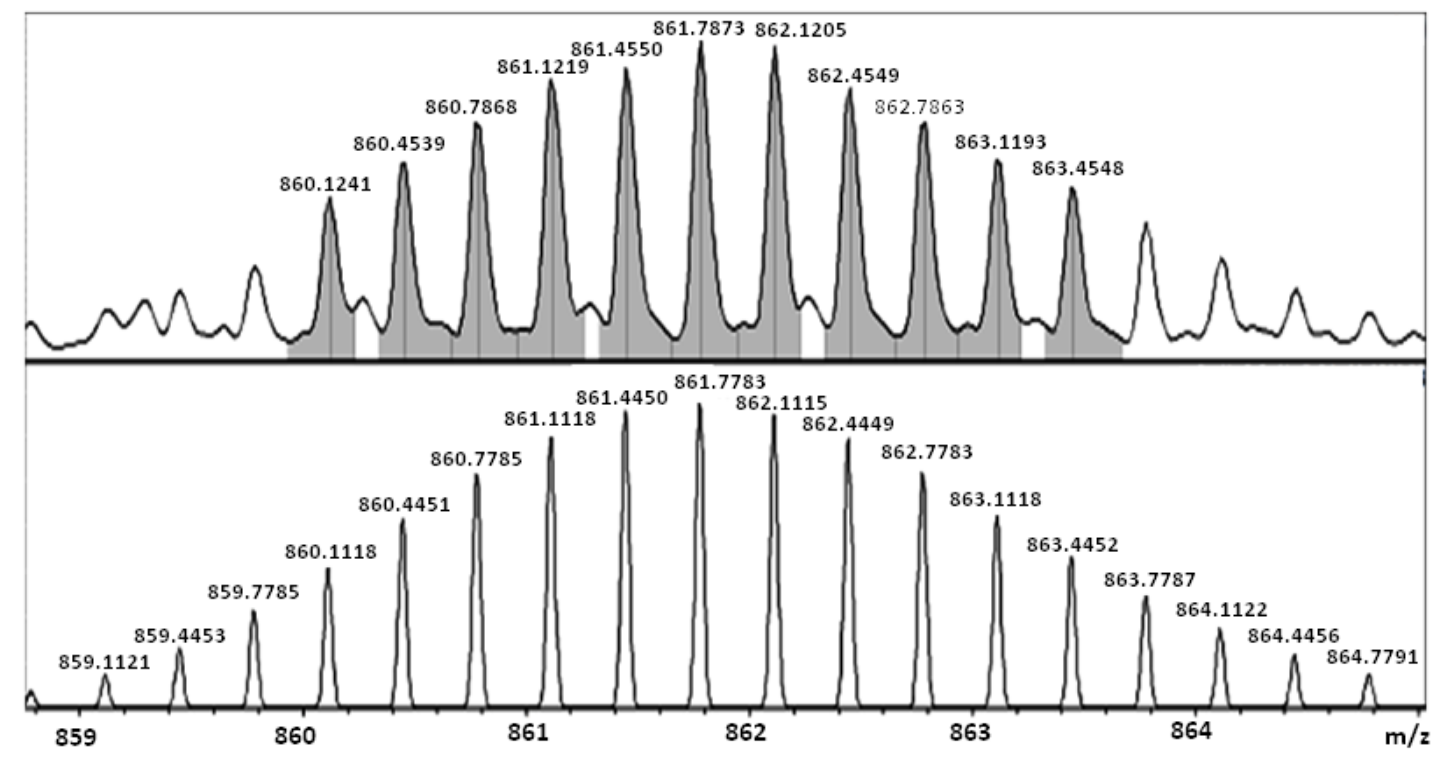

Figure S76. Isotopic pattern of $\left[\mathbf{1 d}^{\prime}-3 \mathrm{BF}_{4}\right]^{3+}$ recorded in $\mathrm{H}_{2} \mathrm{O}$ (top) and simulated pattern (bottom). 


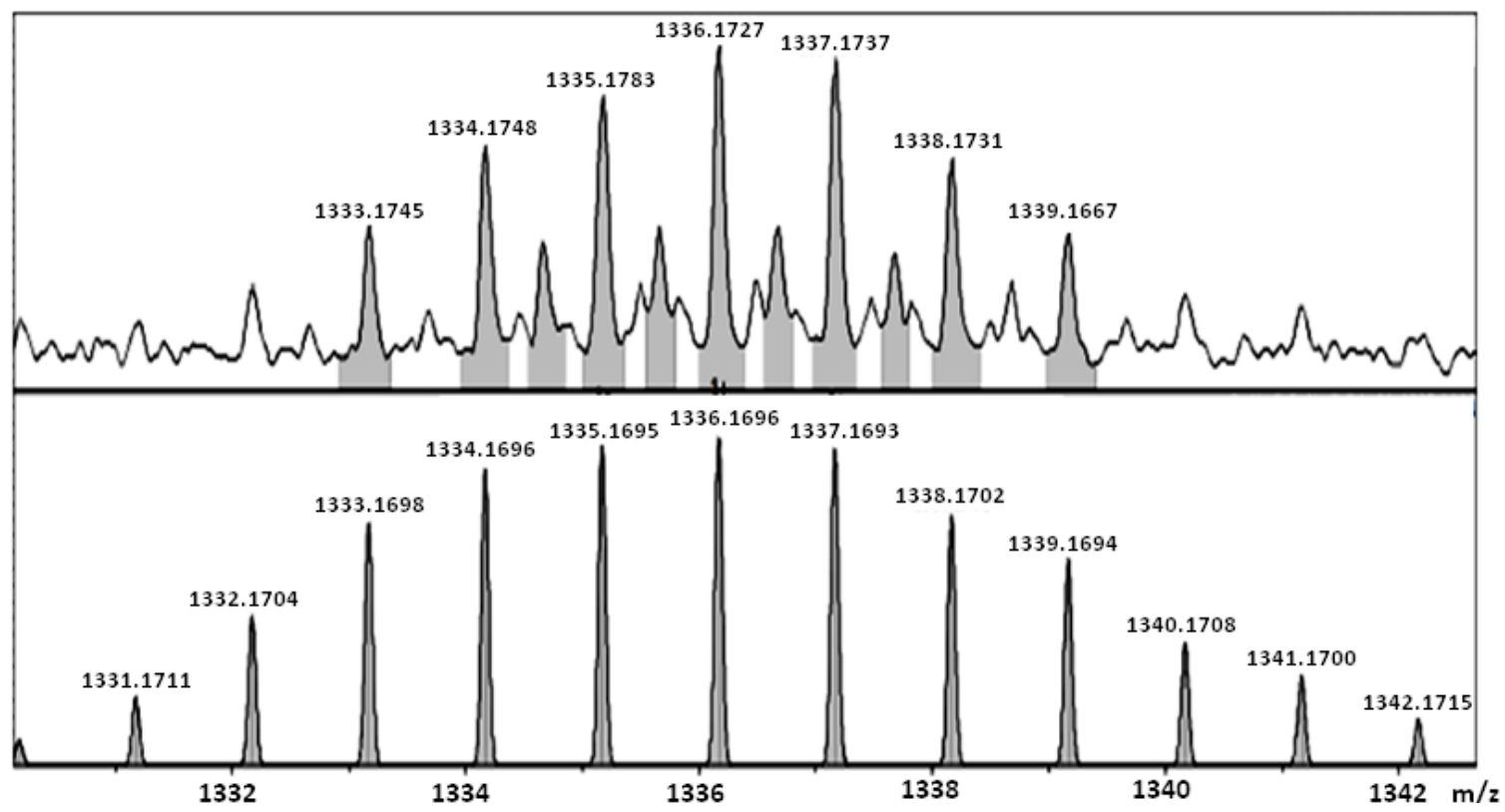

Figure S77. Isotopic pattern of $\left[2 \mathbf{d}^{\prime}-\mathrm{BF}_{4}\right]^{+}$recorded in $\mathrm{H}_{2} \mathrm{O}$ (top) and simulated pattern (bottom). 


\section{X-ray crystallography}

Table S3. Summary of crystallographic data for crystals of $\mathbf{2 c}$ and $\mathbf{2 d}$.

\begin{tabular}{|c|c|c|c|}
\hline & $2 \mathrm{cI}$ & 2dI & 2dII \\
\hline Chemical formula & $\mathrm{C}_{50} \mathrm{H}_{42} \mathrm{~N}_{10} \mathrm{O}_{2} \mathrm{Pd}_{2}$ & $\mathrm{C}_{54} \mathrm{H}_{42} \mathrm{~N}_{10} \mathrm{O}_{2} \mathrm{Pd}_{2}$ & $\mathrm{C}_{108} \mathrm{H}_{146} \mathrm{~N}_{28} \mathrm{O}_{59} \mathrm{Pd}_{4}$ \\
\hline $\mathrm{M}_{\mathrm{r}}$ & 1027.73 & 1075.77 & 3206.12 \\
\hline Temp. (K) & $296(2)$ & $296(2)$ & 100 \\
\hline Crystal system & Monoclinic & Monoclinic & Monoclinic \\
\hline Space group & $C 2 / c$ & $C 2 / c$ & $P 2_{1} / n$ \\
\hline Morphology & Yellow block & Yellow block & Yellow prism \\
\hline Crystal size (mm) & $0.5 \times 0.35 \times 0.25$ & $0.4 \times 0.3 \times 0.3$ & $0.09 \times 0.16 \times 0.25$ \\
\hline$a(\AA)$ & $13.1208(5)$ & $13.419(5)$ & $12.6708(11)$ \\
\hline$b(\AA)$ & $28.8866(10)$ & $28.900(5)$ & $29.645(2)$ \\
\hline$c(\AA)$ & $37.6371(11)$ & $37.540(5)$ & $36.539(3)$ \\
\hline$\alpha\left(^{\circ}\right)$ & 90 & 90 & 90 \\
\hline$\beta\left(^{\circ}\right)$ & $94.437(2)$ & 96.995(5) & 99.532(2) \\
\hline$\gamma\left({ }^{\circ}\right)$ & 90 & 90 & 90 \\
\hline$V\left(\AA^{3}\right)$ & 14222.3(8) & $14450(6)$ & $13535.5(19)$ \\
\hline $\begin{array}{l}Z \\
D_{\text {calc }}\left(\mathrm{g} \mathrm{cm}^{-3}\right)\end{array}$ & $\begin{array}{l}8 \\
0.960 \\
\end{array}$ & $\begin{array}{l}8 \\
0.989\end{array}$ & $\begin{array}{l}4 \\
1.573 \\
\end{array}$ \\
\hline $\begin{array}{l}\mu\left(\mathrm{mm}^{-1}\right) \\
F(000)\end{array}$ & $\begin{array}{l}0.539 \\
4160\end{array}$ & $\begin{array}{l}0.533 \\
4352\end{array}$ & $\begin{array}{l}3.402 \\
6584 \\
\end{array}$ \\
\hline $\begin{array}{l}T_{\min } \\
T_{\max }\end{array}$ & $\begin{array}{l}0.564 \\
0.745\end{array}$ & $\begin{array}{l}0.545 \\
0.852\end{array}$ & $\begin{array}{l}0.522 \\
0.752\end{array}$ \\
\hline $\begin{array}{l}h, k, l \\
(\min , \max )\end{array}$ & $\begin{array}{l}(-9,14), \\
(-32,30) \\
(-41,41)\end{array}$ & $\begin{array}{l}(-12,12), \\
(-26,25), \\
(-34,34)\end{array}$ & $\begin{array}{l}(-15,16), \\
(-38,38), \\
(-30,47)\end{array}$ \\
\hline Reflns collected & 40798 & 46127 & 103374 \\
\hline Unique reflns & 10247 & 5746 & 30912 \\
\hline $\begin{array}{l}\text { Observed reflns } \\
\mathrm{R}_{\text {int }}\end{array}$ & $\begin{array}{l}4900 \\
0.0413\end{array}$ & $\begin{array}{l}3287 \\
0.0368\end{array}$ & $\begin{array}{l}24628 \\
0.050\end{array}$ \\
\hline No. of parameters & 565 & 601 & 2062 \\
\hline GoF & 1.052 & 1.108 & 1.026 \\
\hline $\mathrm{R}_{1}[I>2 \sigma(I)]$ & 0.0970 & 0.0960 & 0.0683 \\
\hline $\mathrm{WR}_{2}[I>2 \sigma(I)]$ & 0.2972 & 0.2653 & 0.1858 \\
\hline $\mathrm{R}_{1} \_$all data & 0.1575 & 0.1435 & 0.0851 \\
\hline $\mathrm{Wr}_{2} \_$all data & 0.3509 & 0.3480 & 0.2048 \\
\hline$\Delta \rho_{\max }, \Delta \rho_{\min }\left(\mathrm{e} \AA^{-3}\right)$ & $0.66,-0.37$ & $0.44,-0.33$ & $1.66,-1.43$ \\
\hline CCDC No. & 1988795 & 1988797 & 1988796 \\
\hline
\end{tabular}




\section{Details of crystal structure solution}

2cI: The asymmetric unit consists of a single D-shaped molecule. Even though attempts were made to locate the anions and solvent water molecules through difference Fourier map, it was observed that the located positions did not show good convergence during refinement. The thermal disorder was too high to model the solvent and anions as chemically meaningful moieties. Therefore, it was decided to squeeze the data to remove scattering contribution from anions and solvent molecules. A total of scattering material equivalent to 268 electrons are removed from asymmetric unit. This may roughly correspond to 4 nitrate anions and 14 water molecules. FLAT, SADI and DFIX commands were used to maintain geometry and bond lengths of the aromatic rings. RIGU and SIMU restraints were used to keep the ADPs of the bonded atoms reasonable. Hydrogen atoms were placed in geometrically idealized positions $(\mathrm{C}-\mathrm{H}=0.93 \AA$ for aromatic $\mathrm{H}$ atoms; $\mathrm{C}-\mathrm{H}=0.97 \AA$ for methylene $\mathrm{H}$ atoms $)$ and refined isotropically.

2dI: The asymmetric unit consists of a single D-shaped molecule. The crystal was poorly diffracting at higher Bragg angles. There were practically no observed reflections for Bragg angle above 19 deg. The thermal motion parameters were also found to be quite large. Even though serious attempts were made to locate the anions and solvent water molecules through difference Fourier map, it was found that the located positions did not show good convergence during refinement. The thermal disorder was too high to model the solvent and anions to chemically meaningful moieties. Therefore, it was decided to squeeze the data to remove scattering contribution from anions and solvent molecules. A total of scattering material equivalent to 237 electrons are removed from asymmetric unit. This may roughly correspond to 4 nitrate anions and 11 water molecules. DFIX commands were used to maintain geometry and bond lengths of the aromatic rings. RIGU and SIMU restraints were used to keep the ADPs of the bonded atoms reasonable. Hydrogen atoms were placed in geometrically idealized positions ( $\mathrm{C}-\mathrm{H}=0.93 \AA$ for aromatic $\mathrm{H}$ atoms; $\mathrm{C}-\mathrm{H}=0.97 \AA$ for methylene $\mathrm{H}$ atoms) and refined isotropically.

2dII: The asymmetric unit consists of a [2]catenane, eight nitrates and thirty-seven water molecules. All non-H atoms were refined by full-matrix least-squares with anisotropic displacement parameters. The $\mathrm{H}$ atoms on $\mathrm{C}$ and $\mathrm{N}$ atoms were generated geometrically $(\mathrm{C}-\mathrm{H}$ 0.95 to $0.99 \AA, \mathrm{N}-\mathrm{H} 0.88 \AA$ ) and were included in the refinement in the riding model 
approximation; their temperature factors were set to 1.5 times those of the equivalent isotropic temperature factors of the parent site (methyl and $\mathrm{OH}$ ) and 1.2 times for others. The water $\mathrm{H}$ atoms were generated using Olex2, creating an idealized $\mathrm{HOH}$ molecule with fixed $\mathrm{O}-\mathrm{H}$ distance of $0.87 \AA$ and $\mathrm{HH}$ distances of $1.42 \AA$. Their initial positions were left to refine using AFIX 6 riding model on the parent $\mathrm{O}$ atom. Three water molecule $\mathrm{H}$ positions were sufficiently stable and properly orientated to keep them on a AFIX 6 riding model, the other water molecules were aligned manually to point $\mathrm{O}-\mathrm{H}$ bonds towards donors and kept in place with an AFIX 3. Most water molecules have $\mathrm{O}$ or $\mathrm{N}$ acceptors in the proper range, except $\mathrm{O} 14 \mathrm{w}$ and $\mathrm{O} 25 \mathrm{w}$, where one hydrogen points towards an aromatic ring from the cation. All nitrate anions were restrained using SIMU, RIGU and SAME commands. Three nitrate anions also have positional disorder, their occupancy was refined and fixed to the nearest whole fraction. One of the main cation molecules also showed positional disorder on a phenanthroline group. A RIGU restraint was applied to the involved atoms and occupancy was left to refine and fixed to its nearest whole fraction. 


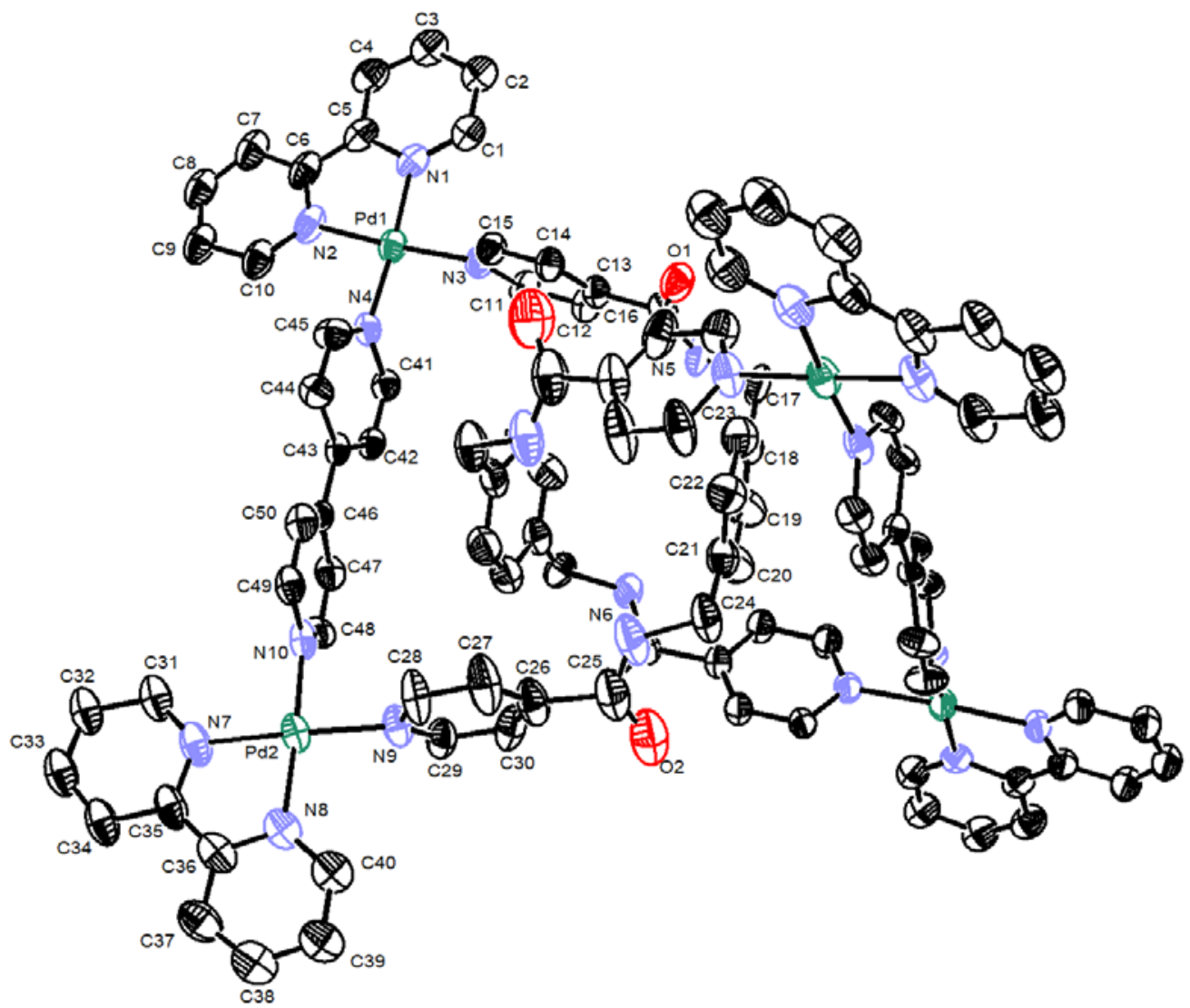

Figure S78. ORTEP of the molecule(s) in the crystals of 2cI. The asymmetric unit consists of one macrocycle. Thermal ellipsoids are drawn at 15\% probability and hydrogen atoms are omitted for clarity. 


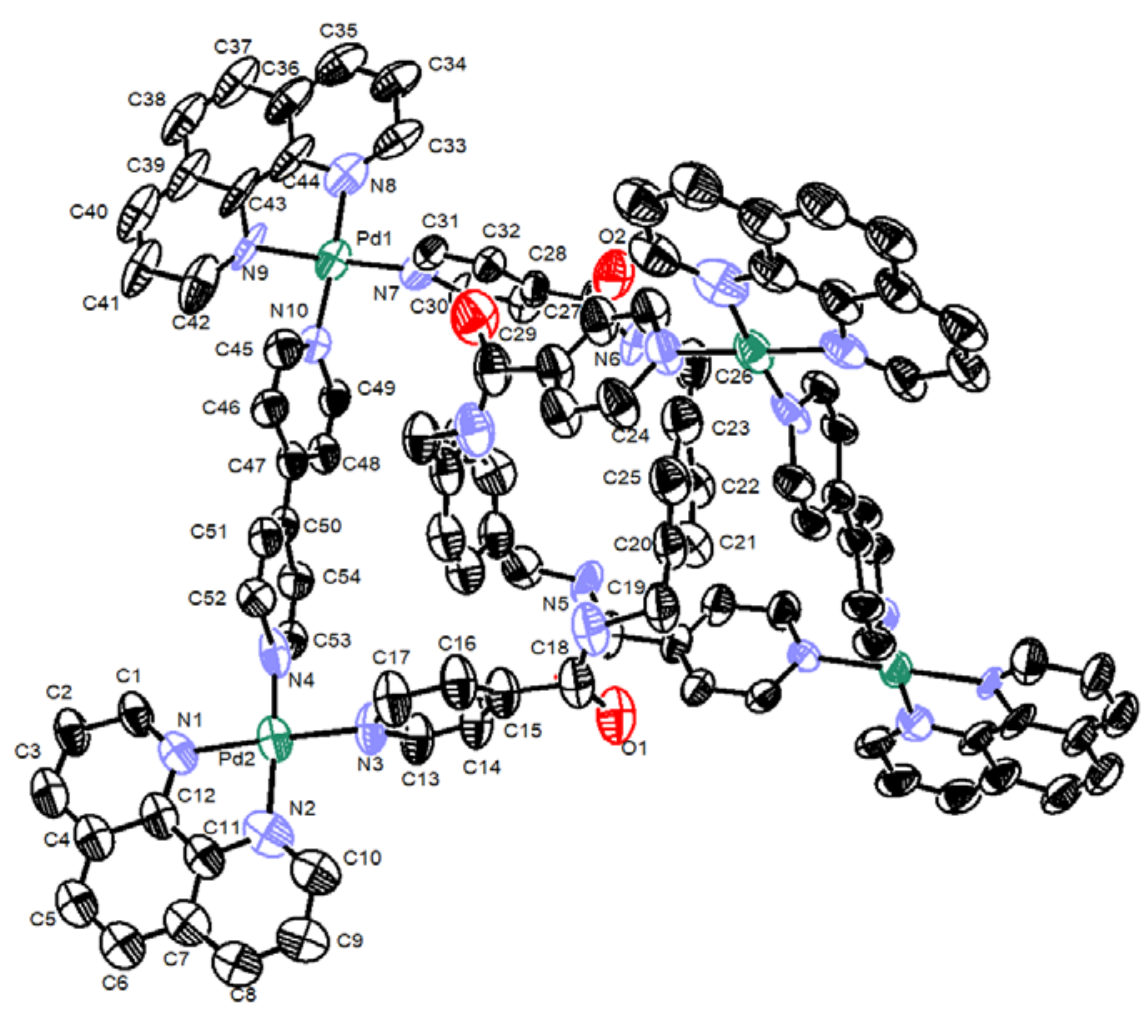

Figure S79. ORTEP of the molecule(s) in the crystals of 2dI. The asymmetric unit consists of one macrocycle. Thermal ellipsoids are drawn at 15\% probability and hydrogen atoms are omitted for clarity. 


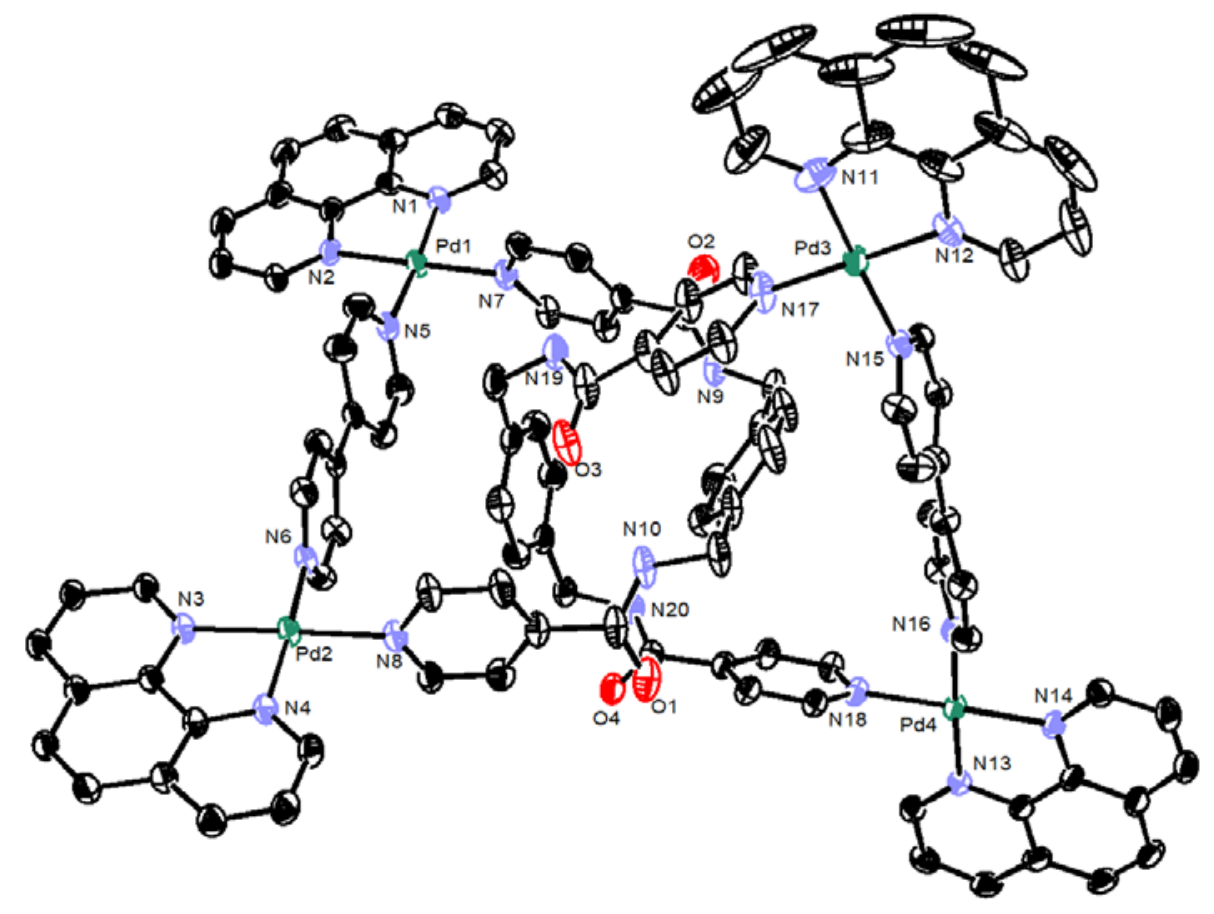

Figure S80. ORTEP of the molecules in the crystals of 2dII. The asymmetric unit consists of two interlocked macrocycles. Thermal ellipsoids are drawn at 35\% probability and hydrogen atoms are omitted for clarity. Anions and solvent molecules are not shown. 


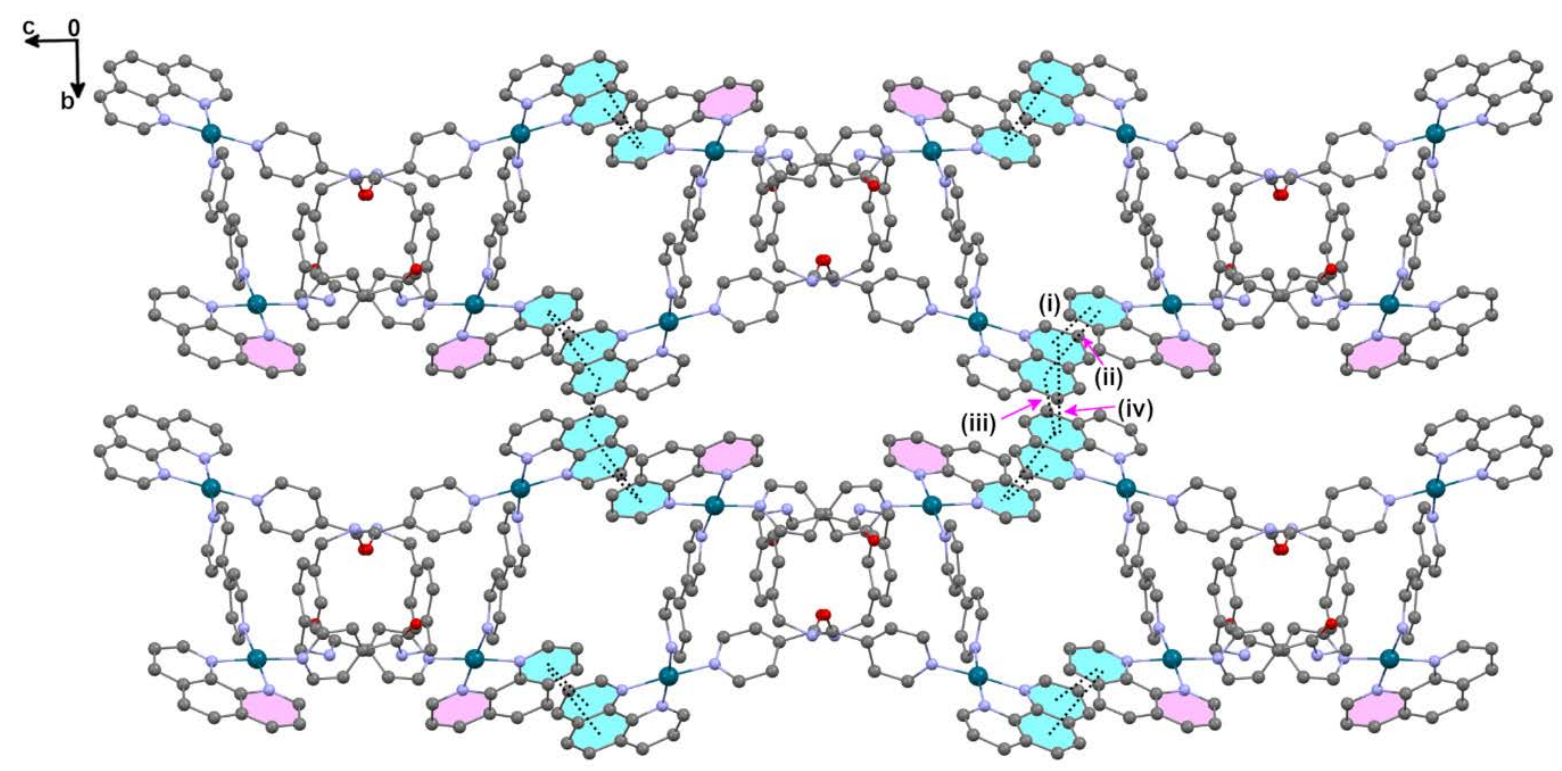

(a)

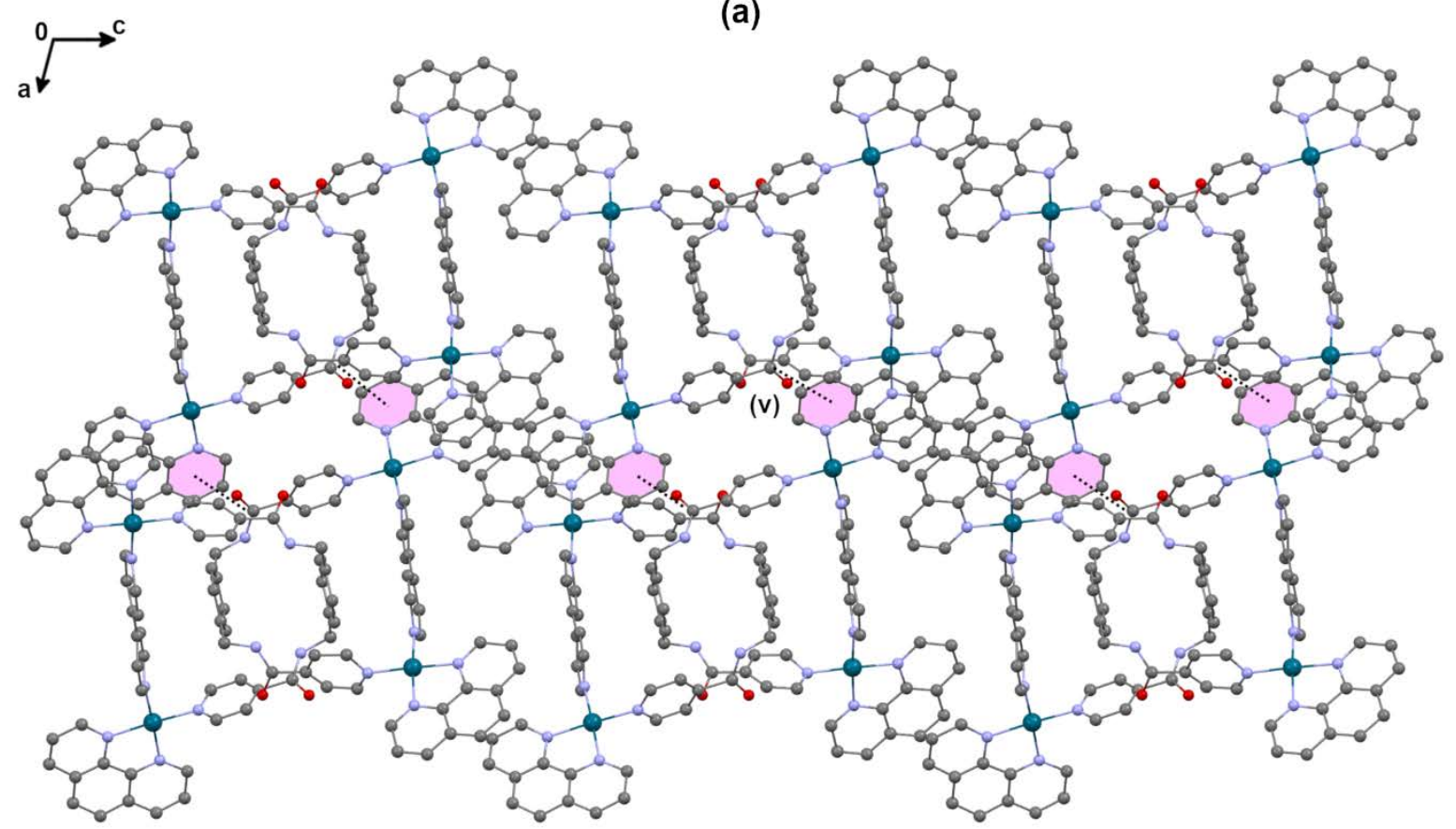

(b)

Figure S81. Views of the packing in crystals of 2dI show (a) chain of [2]catenanes along the $c$ axis linked via $\pi \ldots \pi$ interactions between phen units [see Table S4 for details] and (b) $\mathrm{C}=\mathrm{O} \ldots \pi$ interactions [(ii) $\mathrm{C} 27=\mathrm{O} 8 \cdots \mathrm{Cg} 8$, Table $\mathrm{S} 4]$ between the chains along the $a$-axis. Hydrogen atoms are omitted for clarity. 


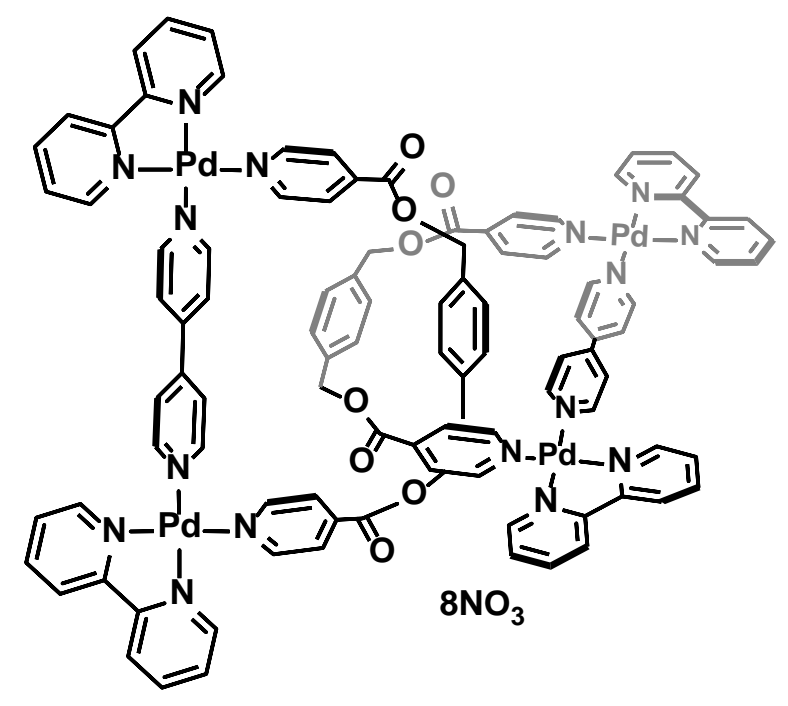

Scheme S1. Chemical structure of the [2]catenane 3. (See supplementary Reference 1)

Crystals of 3 suitable for single-crystal X-ray diffraction analysis were obtained by slow evaporation of a $1: 1 \mathrm{CH}_{3} \mathrm{CN} / \mathrm{H}_{2} \mathrm{O}$ solution of the equilibrium mixture of the macrocycle and corresponding [2]catenane. The [2]catenane crystallized in the monoclinic space group Pc as a pair of interlocked symmetry-independent molecules. The crystals contained several water molecules, the slow loss of which resulted in a decrease in crystallinity over time. A total of seven out of eight nitrate anions were located. Detailed description can be found in the supplementary reference 1 . 


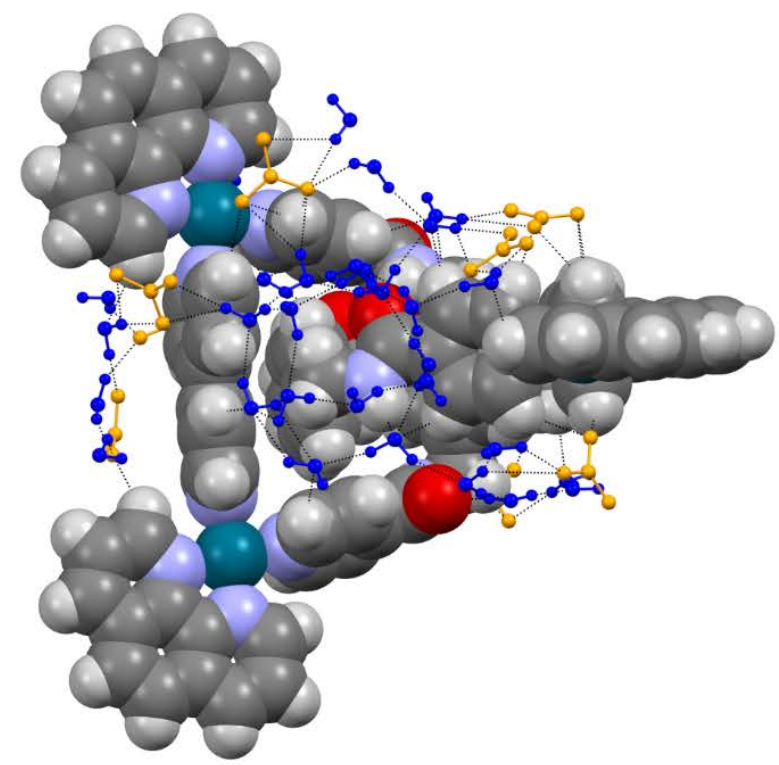

(a)

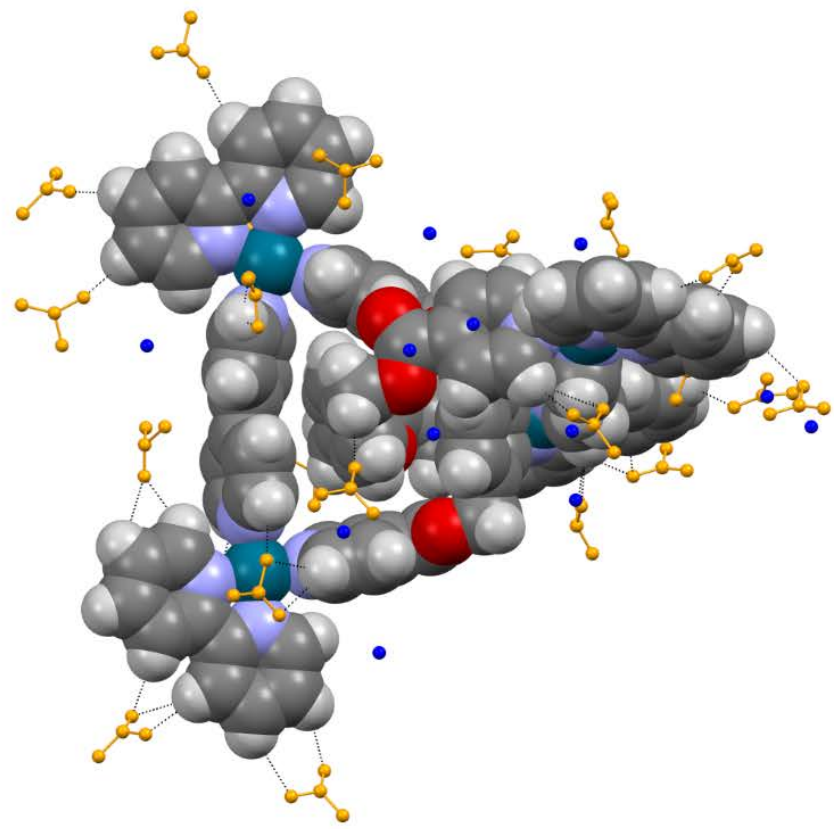

(b)

Figure S82. Hydrogen bonding interactions of the nitrate anions (orange) and water molecules (blue) with each other and with the [2]catenane molecules in the crystals of (a) 2dII and (b) 3. 
Table S4. Intermolecular interactions in the crystals of 3, 2cI, 2dI and $\mathbf{2 d I I . ~}$

\begin{tabular}{|c|c|c|c|c|c|c|c|}
\hline Crystal & $\begin{array}{l}\text { S. } \\
\text { No. }\end{array}$ & $\mathrm{D}-\mathrm{H} \cdots \mathrm{A}$ & $\begin{array}{l}\text { D-H } \\
(\AA)\end{array}$ & $\begin{array}{l}\mathrm{H} \cdots \mathrm{A} \\
(\AA)\end{array}$ & $\begin{array}{l}D \cdots A \\
(\AA)\end{array}$ & $\begin{array}{l}\mathrm{D}-\mathrm{H} \cdots \mathrm{A} / \alpha \\
\left(^{\circ}\right)\end{array}$ & $\begin{array}{l}\text { Symmetry } \\
\text { Code }\end{array}$ \\
\hline \multirow[t]{10}{*}{3} & 1 & $\mathrm{C} 4-\mathrm{H} 4 \cdots \mathrm{O} 8$ & 0.93 & 2.50 & $3.34(2)$ & 151 & $x, y, z$ \\
\hline & 2 & 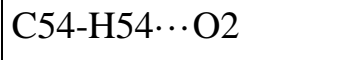 & 0.93 & 2.57 & 3.42(3) & 152 & $x, y, z$ \\
\hline & 3 & Cg5 …Cg22 & & & $4.745(9)$ & 36.4(7) & $x, y, z$ \\
\hline & 4 & Cg9 …Cg22 & & & $4.648(8)$ & 20.0(7) & $x, y, z$ \\
\hline & 5 & Cg22‥Cg11 & & & $4.684(9)$ & $35.8(8)$ & $x, y, z$ \\
\hline & 6 & Cg17‥Cg11 & & & $4.794(9)$ & $40.5(7)$ & $x, y, z$ \\
\hline & 7 & Cg11‥Cg20 & & & $4.815(8)$ & 19.8(7) & $x, y, z$ \\
\hline & 8 & Cg4… Cg7 (i) & & & $4.685(8)$ & 13.3(7) & $x+1, y+1, z$ \\
\hline & 9 & Cg8*.Cg19 (ii) & & & 4.798(8) & 11.5(7) & $x,-y+1, z-1 / 2$ \\
\hline & 10 & Cg7’..Cg18 (iii) & & & $4.698(8)$ & 12.3(7) & $x,-y, z-1 / 2$ \\
\hline \multirow[t]{6}{*}{$2 \mathrm{cI}$} & 1 & 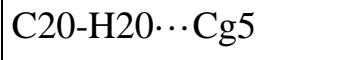 & 0.93 & 2.85 & $3.64(12)$ & 144 & $-x+1, y,-z+1 / 2$ \\
\hline & 2 & Cg6…Cg11 & & & $4.321(6)$ & 11.1(5) & $-x+1, y,-z+1 / 2$ \\
\hline & 3 & 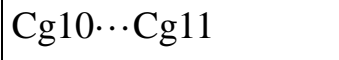 & & & $4.406(6)$ & 13.9(5) & $-x+1, y,-z+1 / 2$ \\
\hline & 4 & Cg11‥Cg11 & & & $4.691(5)$ & 13.1(4) & $-x+1, y,-z+1 / 2$ \\
\hline & 5 & Cg4 $\cdots$ Cg7 & & & 4.613(9) & $5.4(7)$ & $-x+1,-y+1,-z$ \\
\hline & 6 & Cg5 $\cdots$ Cg5 & & & $4.744(7)$ & $61.3(6)$ & $-x+2, y,-z+1 / 2$ \\
\hline \multirow[t]{9}{*}{$2 d I$} & 1 & 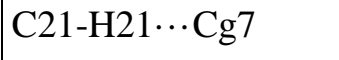 & 0.93 & 2.84 & $3.65(2)$ & 146 & $-x+1, y,-z+1 / 2$ \\
\hline & 2 & Cg6…Cg12 & & & $4.409(12)$ & 13 & $-x+1, y,-z+1 / 2$ \\
\hline & 3 & 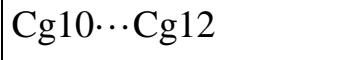 & & & $4.274(13)$ & 8 & $-x+1, y,-z+1 / 2$ \\
\hline & 4 & 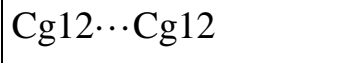 & & & $4.644(11)$ & 11 & $-x+1, y,-z+1 / 2$ \\
\hline & 5 & Cg3…Cg9 (i) & & & $4.088(13)$ & 4 & $-x+1,-y+2,-z$ \\
\hline & 6 & Cg11‥Cg11 (iii) & & & $4.100(13)$ & 0 & $-x+1 / 2,-y+5 / 2,-z$ \\
\hline & 7 & Cg3…Cg11 (iv) & & & 3.778(13) & 1 & $-x+1 / 2,-y+5 / 2,-z$ \\
\hline & 8 & Cg9 …Cg11 (ii) & & & $3.704(13)$ & 4 & $-x+1,-y+2,-z$ \\
\hline & 9 & 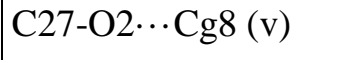 & $1.19(4)$ & $3.96(2)$ & $4.00(3)$ & 83.2(18) & $-x+2, y,-z+1 / 2$ \\
\hline \multirow[t]{6}{*}{ 2dII } & 1 & N11-H11 $\cdots \mathrm{O} 2 \mathrm{~A}$ & 0.88 & 2.02 & $2.8286(2)$ & 153 & $x, y, z$ \\
\hline & 2 & C38A-H38А $\cdots$ O2 & 0.95 & 2.49 & $3.397(8)$ & 159 & $x, y, z$ \\
\hline & 3 & C51-H51A $\cdots$ Cg26 & 0.95 & 2.83 & 3.701(7) & 153 & $x, y, z$ \\
\hline & 4 & C53A-H53А $\cdots$ Cg27 & 0.95 & 2.94 & $3.734(7)$ & 142 & $x, y, z$ \\
\hline & 5 & 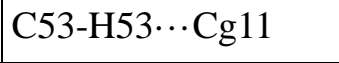 & 0.95 & 2.73 & $3.505(6)$ & 139 & $x, y, z$ \\
\hline & 6 & Cg17‥Cg24 & & & $4.322(3)$ & $9.1(3)$ & $x, y, z$ \\
\hline
\end{tabular}




\begin{tabular}{|c|c|c|c|c|}
\hline 7 & Cg17…Cg25 & $4.412(3)$ & $10.8(3)$ & $x, y, z$ \\
\hline 8 & Cg17‥Cg30 & 4.634(3) & $45.2(3)$ & $x, y, z$ \\
\hline 9 & 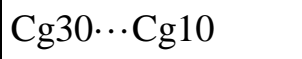 & $4.632(4)$ & $46.5(3)$ & $x, y, z$ \\
\hline 10 & Cg11‥Cg30 & 4.725(3) & $50.9(3)$ & $x, y, z$ \\
\hline 11 & Cg13‥Cg30 & 4.392(4) & $18.5(3)$ & $x, y, z$ \\
\hline 12 & Cg21...Cg6 (i) & $3.554(8)$ & $3.7(6)$ & $x-1 / 2,-y+1 / 2, z-1 / 2$ \\
\hline 13 & Cg21...Cg15(ii) & $4.506(7)$ & $2.0(5)$ & $x-1 / 2,-y+1 / 2, z-1 / 2$ \\
\hline 14 & Cg5...Cg22(iii) & $3.767(3)$ & $3.9(2)$ & $x+1 / 2,-y+1 / 2, z+1 / 2$ \\
\hline 15 & Cg5...Cg29(iv) & $3.510(3)$ & $3.6(2)$ & $x+1 / 2,-y+1 / 2, z+1 / 2$ \\
\hline 16 & Cg14...Cg29(v) & 3.729(3) & $4.4(2)$ & $x+1 / 2,-y+1 / 2, z+1 / 2$ \\
\hline 17 & Cg6...Cg15(vi) & 3.773(10) & $2.3(8)$ & $-x+1,-y+1,-z+1$ \\
\hline 18 & Cg29...Cg29(vii) & 3.884(3) & $0.0(2)$ & $-x+1,-y+1,-z$ \\
\hline 19 & Cg12...Cg26(viii) & 4.355(3) & $46.7(3)$ & $x+1, y, z$ \\
\hline
\end{tabular}

3:

$\mathrm{Cg} 4 \mathrm{~N} 2 \rightarrow \mathrm{C} 41 \rightarrow \mathrm{C} 42 \rightarrow \mathrm{C} 43 \rightarrow \mathrm{C} 44 \rightarrow \mathrm{C} 45 \rightarrow$

$\mathrm{Cg} 5 \mathrm{~N} 3 \rightarrow \mathrm{C} 38 \rightarrow \mathrm{C} 37 \rightarrow \mathrm{C} 36 \rightarrow \mathrm{C} 40 \rightarrow \mathrm{C} 39 \rightarrow$

$\mathrm{Cg} 7 \mathrm{~N} 5 \rightarrow \mathrm{C} 21 \rightarrow \mathrm{C} 22 \rightarrow \mathrm{C} 23 \rightarrow \mathrm{C} 24 \rightarrow \mathrm{C} 25 \rightarrow$

$\mathrm{Cg} 8 \mathrm{~N} 6 \rightarrow \mathrm{C} 26 \rightarrow \mathrm{C} 27 \rightarrow \mathrm{C} 28 \rightarrow \mathrm{C} 29 \rightarrow \mathrm{C} 30 \rightarrow$

$\mathrm{Cg} 9 \mathrm{~N} 7 \rightarrow \mathrm{C} 31 \rightarrow \mathrm{C} 32 \rightarrow \mathrm{C} 33 \rightarrow \mathrm{C} 34 \rightarrow \mathrm{C} 35 \rightarrow$

$\mathrm{Cg} 11 \mathrm{C} 8 \rightarrow \mathrm{C} 9 \rightarrow \mathrm{C} 10 \rightarrow \mathrm{C} 11 \rightarrow \mathrm{C} 12 \rightarrow \mathrm{C} 13 \rightarrow$

$\mathrm{Cg} 17 \mathrm{~N} 12 \rightarrow \mathrm{C} 88 \rightarrow \mathrm{C} 87 \rightarrow \mathrm{C} 86 \rightarrow \mathrm{C} 90 \rightarrow \mathrm{C} 89 \rightarrow$

$\mathrm{Cg} 18 \mathrm{~N} 13 \rightarrow \mathrm{C} 76 \rightarrow \mathrm{C} 77 \rightarrow \mathrm{C} 78 \rightarrow \mathrm{C} 79 \rightarrow \mathrm{C} 80 \rightarrow$

$\mathrm{Cg} 19 \mathrm{~N} 14 \rightarrow \mathrm{C} 71 \rightarrow \mathrm{C} 72 \rightarrow \mathrm{C} 73 \rightarrow \mathrm{C} 74 \rightarrow \mathrm{C} 75 \rightarrow$

$\mathrm{Cg} 20 \mathrm{~N} 15 \rightarrow \mathrm{C} 81 \rightarrow \mathrm{C} 82 \rightarrow \mathrm{C} 83 \rightarrow \mathrm{C} 84 \rightarrow \mathrm{C} 85 \rightarrow$

$\mathrm{Cg} 22 \mathrm{C} 58 \rightarrow \mathrm{C} 59 \rightarrow \mathrm{C} 60 \rightarrow \mathrm{C} 61 \rightarrow \mathrm{C} 62 \rightarrow \mathrm{C} 63 \rightarrow$ 
2cI:

$\mathrm{Cg} 4 \mathrm{~N} 2 \rightarrow \mathrm{C} 6 \rightarrow \mathrm{C} 7 \rightarrow \mathrm{C} 8 \rightarrow \mathrm{C} 9 \rightarrow \mathrm{C} 10 \rightarrow$

$\mathrm{Cg} 5 \mathrm{~N} 3 \rightarrow \mathrm{C} 11 \rightarrow \mathrm{C} 12 \rightarrow \mathrm{C} 13 \rightarrow \mathrm{C} 14 \rightarrow \mathrm{C} 15 \rightarrow$

$\mathrm{Cg} 6 \mathrm{~N} 4 \rightarrow \mathrm{C} 41 \rightarrow \mathrm{C} 42 \rightarrow \mathrm{C} 43 \rightarrow \mathrm{C} 44 \rightarrow \mathrm{C} 45 \rightarrow$

$\mathrm{Cg} 7 \mathrm{~N} 7 \rightarrow \mathrm{C} 31 \rightarrow \mathrm{C} 32 \rightarrow \mathrm{C} 33 \rightarrow \mathrm{C} 34 \rightarrow \mathrm{C} 35 \rightarrow$

$\mathrm{Cg} 10 \mathrm{~N} 10 \rightarrow \mathrm{C} 48 \rightarrow \mathrm{C} 47 \rightarrow \mathrm{C} 46 \rightarrow \mathrm{C} 50 \rightarrow \mathrm{C} 49 \rightarrow$

$\mathrm{Cg} 11 \mathrm{C} 18 \rightarrow \mathrm{C} 19 \rightarrow \mathrm{C} 20 \rightarrow \mathrm{C} 21 \rightarrow \mathrm{C} 22 \rightarrow \mathrm{C} 23 \rightarrow$

2dI:

$\mathrm{Cg} 3 \mathrm{~N} 1 \rightarrow \mathrm{C} 1 \rightarrow \mathrm{C} 2 \rightarrow \mathrm{C} 3 \rightarrow \mathrm{C} 4 \rightarrow \mathrm{C} 12 \rightarrow$

$\mathrm{Cg} 6 \mathrm{~N} 4 \rightarrow \mathrm{C} 52 \rightarrow \mathrm{C} 51 \rightarrow \mathrm{C} 50 \rightarrow \mathrm{C} 54 \rightarrow \mathrm{C} 53 \rightarrow$

$\mathrm{Cg} 7 \mathrm{~N} 7 \rightarrow \mathrm{C} 30 \rightarrow \mathrm{C} 29 \rightarrow \mathrm{C} 28 \rightarrow \mathrm{C} 32 \rightarrow \mathrm{C} 31 \rightarrow$

$\mathrm{Cg} 8 \mathrm{~N} 8 \rightarrow \mathrm{C} 33 \rightarrow \mathrm{C} 34 \rightarrow \mathrm{C} 35 \rightarrow \mathrm{C} 36 \rightarrow \mathrm{C} 44 \rightarrow$

Cg9 N9 $\rightarrow$ C42 $\rightarrow$ C41 $\rightarrow$ C40 $\rightarrow$ C39 $\rightarrow$ C43 $\rightarrow$

$\mathrm{Cg} 10 \mathrm{~N} 10 \rightarrow \mathrm{C} 45 \rightarrow \mathrm{C} 46 \rightarrow \mathrm{C} 47 \rightarrow \mathrm{C} 48 \rightarrow \mathrm{C} 49 \rightarrow$

$\mathrm{Cg} 11 \mathrm{C} 4 \rightarrow \mathrm{C} 5 \rightarrow \mathrm{C} 6 \rightarrow \mathrm{C} 7 \rightarrow \mathrm{C} 11 \rightarrow \mathrm{C} 12 \rightarrow$

$\mathrm{Cg} 12 \mathrm{C} 20 \rightarrow \mathrm{C} 21 \rightarrow \mathrm{C} 22 \rightarrow \mathrm{C} 23 \rightarrow \mathrm{C} 24 \rightarrow \mathrm{C} 25 \rightarrow$

2dII:

$\mathrm{Cg} 5 \mathrm{N3A} \rightarrow \mathrm{C} 6 \mathrm{~A} \rightarrow \mathrm{C} 7 \mathrm{~A} \rightarrow \mathrm{C} 8 \mathrm{~A} \rightarrow \mathrm{C} 9 \mathrm{~A} \rightarrow \mathrm{C} 10 \mathrm{~A} \rightarrow$

Cg6 N4A $\rightarrow$ C13A $\rightarrow$ C14A $\rightarrow$ C15A $\rightarrow$ C16A $\rightarrow$ C17A $\rightarrow$

$\mathrm{Cg} 10 \mathrm{~N} 6 \mathrm{~A} \rightarrow \mathrm{C} 25 \mathrm{~A} \rightarrow \mathrm{C} 26 \mathrm{~A} \rightarrow \mathrm{C} 27 \mathrm{~A} \rightarrow \mathrm{C} 28 \mathrm{~A} \rightarrow \mathrm{C} 29 \mathrm{~A} \rightarrow$

$\mathrm{Cg} 11 \mathrm{~N} 7 \mathrm{~A} \rightarrow \mathrm{C} 30 \mathrm{~A} \rightarrow \mathrm{C} 31 \mathrm{~A} \rightarrow \mathrm{C} 32 \mathrm{~A} \rightarrow \mathrm{C} 33 \mathrm{~A} \rightarrow \mathrm{C} 34 \mathrm{~A} \rightarrow$

$\mathrm{Cg} 12 \mathrm{~N} 8 \mathrm{~A} \rightarrow \mathrm{C} 35 \mathrm{~A} \rightarrow \mathrm{C} 36 \mathrm{~A} \rightarrow \mathrm{C} 37 \mathrm{~A} \rightarrow \mathrm{C} 38 \mathrm{~A} \rightarrow \mathrm{C} 39 \mathrm{~A} \rightarrow$

$\mathrm{Cg} 13 \mathrm{N9A} \rightarrow \mathrm{C} 41 \mathrm{~A} \rightarrow \mathrm{C} 42 \mathrm{~A} \rightarrow \mathrm{C} 43 \mathrm{~A} \rightarrow \mathrm{C} 44 \mathrm{~A} \rightarrow \mathrm{C} 45 \mathrm{~A} \rightarrow$

$\mathrm{Cg} 14 \mathrm{C} 4 \mathrm{~A} \rightarrow \mathrm{C} 5 \mathrm{~A} \rightarrow \mathrm{C} 10 \mathrm{~A} \rightarrow \mathrm{C} 9 \mathrm{~A} \rightarrow \mathrm{C} 11 \mathrm{~A} \rightarrow \mathrm{C} 12 \mathrm{~A} \rightarrow$

$\mathrm{Cg} 15 \mathrm{C} 16 \mathrm{~A} \rightarrow \mathrm{C} 17 \mathrm{~A} \rightarrow \mathrm{C} 22 \mathrm{~A} \rightarrow \mathrm{C} 21 \mathrm{~A} \rightarrow \mathrm{C} 23 \mathrm{~A} \rightarrow \mathrm{C} 24 \mathrm{~A} \rightarrow$

$\mathrm{Cg} 17 \mathrm{C} 49 \mathrm{~A} \rightarrow \mathrm{C} 50 \mathrm{~A} \rightarrow \mathrm{C} 51 \mathrm{~A} \rightarrow \mathrm{C} 52 \mathrm{~A} \rightarrow \mathrm{C} 53 \mathrm{~A} \rightarrow \mathrm{C} 54 \mathrm{~A} \rightarrow$

$\mathrm{Cg} 21 \mathrm{~N} 3 \rightarrow \mathrm{C} 6 \rightarrow \mathrm{C} 7 \rightarrow \mathrm{C} 8 \rightarrow \mathrm{C} 9 \rightarrow \mathrm{C} 10 \rightarrow$ 


$$
\begin{aligned}
& \mathrm{Cg} 22 \mathrm{~N} 4 \rightarrow \mathrm{C} 13 \rightarrow \mathrm{C} 14 \rightarrow \mathrm{C} 15 \rightarrow \mathrm{C} 16 \rightarrow \mathrm{C} 17 \rightarrow \\
& \mathrm{Cg} 24 \mathrm{~N} 6 \rightarrow \mathrm{C} 25 \rightarrow \mathrm{C} 26 \rightarrow \mathrm{C} 27 \rightarrow \mathrm{C} 28 \rightarrow \mathrm{C} 29 \rightarrow \\
& \mathrm{Cg} 25 \mathrm{~N} 7 \rightarrow \mathrm{C} 30 \rightarrow \mathrm{C} 31 \rightarrow \mathrm{C} 32 \rightarrow \mathrm{C} 33 \rightarrow \mathrm{C} 34 \rightarrow \\
& \mathrm{Cg} 26 \mathrm{~N} 8 \rightarrow \mathrm{C} 35 \rightarrow \mathrm{C} 36 \rightarrow \mathrm{C} 37 \rightarrow \mathrm{C} 38 \rightarrow \mathrm{C} 39 \rightarrow \\
& \mathrm{Cg} 27 \mathrm{~N} 9 \rightarrow \mathrm{C} 41 \rightarrow \mathrm{C} 42 \rightarrow \mathrm{C} 43 \rightarrow \mathrm{C} 44 \rightarrow \mathrm{C} 45 \rightarrow \\
& \mathrm{Cg} 29 \mathrm{C} 16 \rightarrow \mathrm{C} 17 \rightarrow \mathrm{C} 22 \rightarrow \mathrm{C} 21 \rightarrow \mathrm{C} 23 \rightarrow \mathrm{C} 24 \rightarrow \\
& \mathrm{Cg} 30 \mathrm{C} 49 \rightarrow \mathrm{C} 50 \rightarrow \mathrm{C} 51 \rightarrow \mathrm{C} 52 \rightarrow \mathrm{C} 53 \rightarrow \mathrm{C} 54 \rightarrow
\end{aligned}
$$

\section{Supplementary Reference:}

1. Prusty, S.; Krishnaswamy, S.; Bandi, S.; Chandrika, B.; Luo, J.; McIndoe, J. S.; Hanan, G. S.; Chand, D. K. Reversible Mechanical Interlocking of D-Shaped Molecular Karabiners bearing Coordination-Bond Loaded Gates: Route to Self-Assembled [2]Catenanes. Chem. - Eur. J. 2015, 21, 15174-15187. 